\title{
Reduction of erosion in elbows due to flow modifications: Final report, Phase 1
}

Johnson, E.K.; Means, K.H.; Eyler, R.L.; Holtzworth, J.D.

Nov 1987

West Virginia Univ., Morgantown (USA). Dept. of Mechanical and Aerospace Engineering

Reproduced and Distributed by:

U.S. DEPARTMENT OF ENERGY

Office of Scientific and Technical Information

P.O. Box 62

Oak Ridge, TN 37831 


\section{DISCLAIMER}

This report was prepared as an account of work sponsored by an agency of the United States Government. Neither the United States Government nor any agency Thereof, nor any of their employees, makes any warranty, express or implied, or assumes any legal liability or responsibility for the accuracy, completeness, or usefulness of any information, apparatus, product, or process disclosed, or represents that its use would not infringe privately owned rights. Reference herein to any specific commercial product, process, or service by trade name, trademark, manufacturer, or otherwise does not necessarily constitute or imply its endorsement, recommendation, or favoring by the United States Government or any agency thereof. The views and opinions of authors expressed herein do not necessarily state or reflect those of the United States Government or any agency thereof. 


\section{DISCLAIMER}

Portions of this document may be illegible in electronic image products. Images are produced from the best available original document. 


\section{DISCLAIMER}

This report was prepared as an account of work sponsored by an agency of the United States Government. Neither the United States Government nor any agency thereof, nor any of their employees, makes any warranty, express or implied, or assumes any legal liability or responsibility for the accuracy, completeness, or usefulness of any information, apparatus, product, or process disclosed, or represents that its use would not infringe privately owned rights. Reference herein to any specific commercial product, process, or service by trade name, trademark, manufacturer, or otherwise does not necessarily constitute or imply its endorsement, recommendation, or favoring by the United States Government or any agency thereof. The views and opinions of authors expressed herein do not necessarily state or reflect those of the United States Government or any agency thereof.

This report has been reproduced directly from the best available copy.

Available from the National Technical Information Service, U. S. Department of Commerce, Springfield, Virginia 22161.

Price: Printed Copy A05

Microfiche A01

Codes are used for pricing all publications. The code is determined by the number of pages in the publication. Information pertaining to the pricing codes can be found in the current issues of the following publications, which are generally available in most libraries: Energy Research Abstracts (ERA): Government Reports Announcements and Index (GRA and 1); Scientific and Technical Abstract Reports (ST AR): and publication NTIS-PR-360 available from NTIS at the above address. 


\title{
Reduction of Erosion in Elbows Due to Flow Modifications
}

\author{
Final Report \\ Phase I
}

\author{
E.K. Johnson \\ K.H. Means \\ R.L. Eyler \\ J.D. Holtzworth
}

Work Performed Under Contract No.: DE-AC21-84MC21349

\author{
For \\ U.S. Department of Energy \\ Office of Fossil Energy \\ Morgantown Energy Technology Center \\ P.O. Box 880 \\ Morgantown, West Virginia 26507-0880 \\ By \\ West Virginia University \\ Department of Mechanical and Aerospace Engineering \\ P.O. Box 6101 \\ Morgantown, West Virginia 26506-6101
}

November 1987 


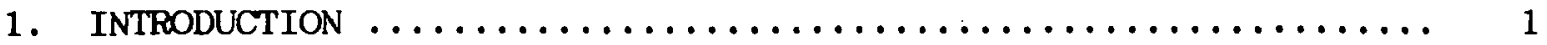

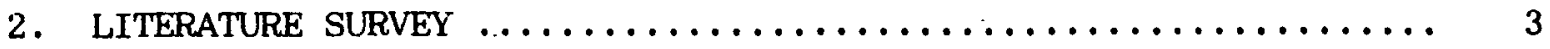

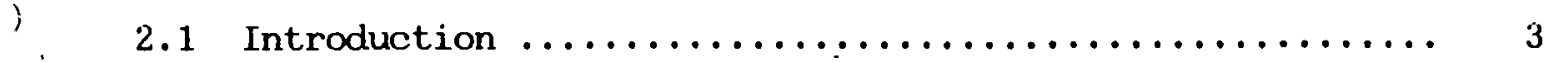

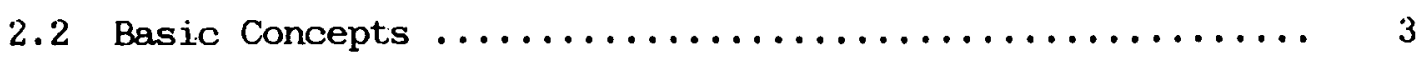

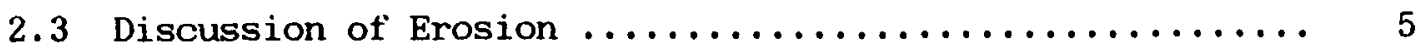

2.4 Flow of Particles $\ldots \ldots \ldots \ldots \ldots \ldots \ldots \ldots \ldots \ldots \ldots \ldots \ldots$

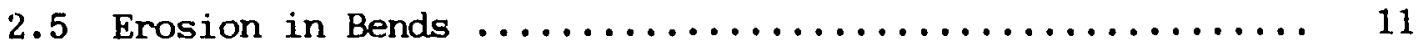

3. EXPERIMENTAL SYSTEM $\ldots \ldots \ldots \ldots \ldots \ldots \ldots \ldots \ldots \ldots \ldots \ldots \ldots \ldots \ldots \ldots \ldots$

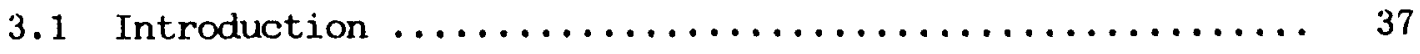

3.2 Test-Loop Design Philosophy $\ldots \ldots \ldots \ldots \ldots \ldots \ldots \ldots \ldots \ldots . \ldots \ldots \ldots$

3.3 Test-Loop Design $\ldots \ldots \ldots \ldots \ldots \ldots \ldots \ldots \ldots \ldots \ldots \ldots \ldots \ldots$

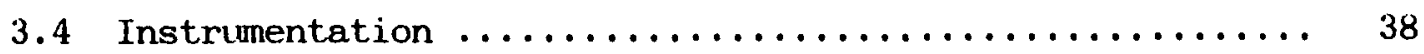

4. PROCEDURE AND DATA REDUCTION $\ldots \ldots \ldots \ldots \ldots \ldots \ldots \ldots \ldots \ldots \ldots \ldots$

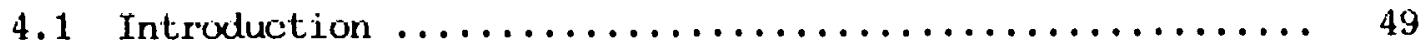

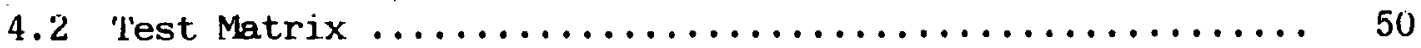

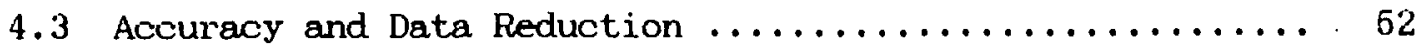

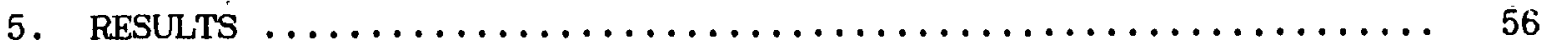

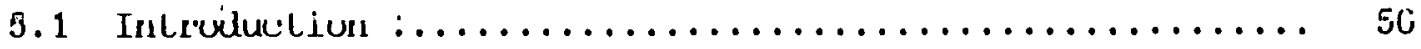

5.2 Discussion of Each Bend Design $\ldots \ldots \ldots \ldots \ldots \ldots \ldots \ldots . \ldots \ldots$

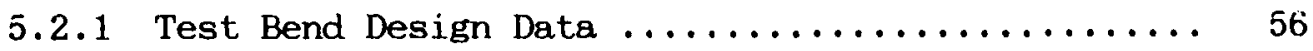

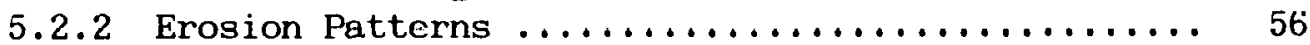

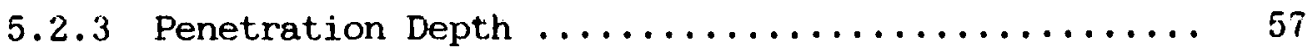

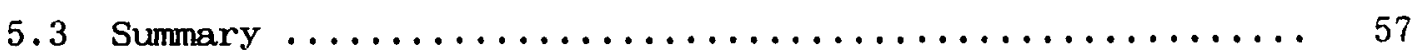

6. CONCLUSIONS AND RECOMMENDATIONS $\ldots \ldots \ldots \ldots \ldots \ldots \ldots \ldots \ldots \ldots \ldots$

6.1 Conolusions $\ldots \ldots \ldots \ldots \ldots \ldots \ldots \ldots \ldots \ldots \ldots \ldots \ldots \ldots \ldots$

6.2 Recommendations $\ldots \ldots \ldots \ldots \ldots \ldots \ldots \ldots \ldots \ldots \ldots \ldots \ldots \ldots$

7. LIST OF SYMBOLS $\ldots \ldots \ldots \ldots \ldots \ldots \ldots \ldots \ldots \ldots \ldots \ldots \ldots \ldots \ldots \ldots \ldots$

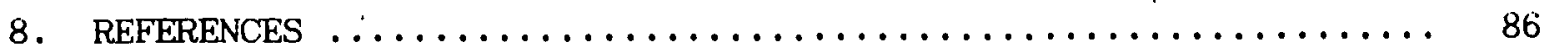




\section{LIS'T OF FIGURES}

Figure Number

Title

Page No.

2.1

2.2

2.3

2.4

2.5

2.6

2.7

2.8

2.9

2.11

2.12

2.13

2.14

2.15

2.16

2.17

2.18

2.19
Basic Erosion System and Terminology ......... 15

Erosion Characteristics of Materials ......... 16

Dependence of the Erosive Wear of $\mathrm{C} 60 \mathrm{H}$ Steel

on Hardness of the Abrasive ............... 16

Erosive Particle Cutting Model for Ductile

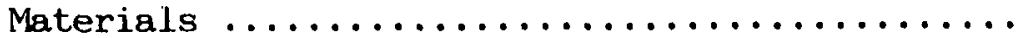

Predicted and Experimental Variation in Volume

Removed, from Ductile Materials, as a Function

of the Angle of Attack ..................

Penetration Depth as a Function of the Angle of Attack

The Three Penetration Depth Rate Periods and Their Relationship to Groove Configuration ...... 18

Effect of Particle Size on Erosion.......... 19

Size Distribution of Particles Before and After

Impact ........................ 20

Primary and Secondary Erosion ............. 20

Erosion Characteristics as a Function of

Particle Size ....................... 21

Erosion of Three Types of Rubber $\ldots \ldots \ldots \ldots \ldots \ldots, 21$

Pneumatic Transport System Performance

Curves . . ........................ 22

Minimum Conveying Air Velocily ............ 23

Flow Palterns in a pipe ................ 24

Pressure Variation Due to a Bend .......... 25

Jet Protection Principle .............. 26

Particle Trajectory in a Tube During

Pnelumatic Transportation ............... 27

Elbow Diagram lllustrating Report Symbols

and Terminology 
Rate of Penetration of Erosion Along the Back Arch of the Elbow as a Function of the Elbow

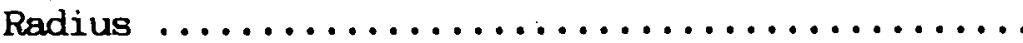

Rate of Penetration of Erosion Along the Back Arch as a Function of Air Velocity ...........

Rate of Penetration of Erosion Along the Back Arch as a Function of the Phase Density ........ 30

Wear Pattern on the Back Arch of the Elbow as

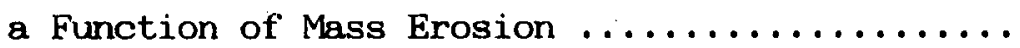
a Function of Phase Density, for Constant Mass

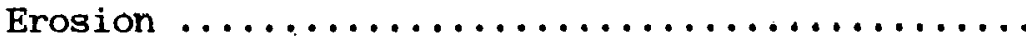

Wear Pattern on the Perimeter of $\beta=33^{\circ}$ as a Function of Phase Density, for Constant Mass Erosion ..........................

Ratio of Penetration to Mass Eroded as a Function

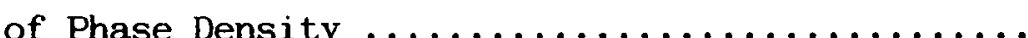

Penetration Rate as a Function of thase Density for Farticlcs at Tro Different Sizes ......... 35

Variation of Penetration of Wear as a Function of Elbow Geometry ................... 36

Test Loop $\ldots \ldots \ldots \ldots \ldots \ldots \ldots \ldots \ldots \ldots \ldots \ldots \ldots, 41$

Sight-Glass Installation $\ldots \ldots \ldots \ldots \ldots \ldots \ldots \ldots, 42$

Solids Feed System .................. 43

Solids Feed Port Assemhly .............. 44 
4.1

5.1

5.2

5.3

5.4

5.5

5.6

5.7

5.8

5.9

5.10

5.11

5.12

5.13

5.14

5.15

5.16

5.17

5.18

5.19

5.20

5.21
Basic Two-Jet Protection Bend

Flow Modification Elbow Design 1-T ......... 59

Flow Modification Elbow Design 1-T-R ........ 60

Flow Modification Elbow Design 2-T ......... 61

Flow Modification Elbow Design $2-T-R \ldots \ldots \ldots \ldots 62$

Flow Modification Elbow Design $3-T \ldots \ldots \ldots \ldots .63$

Flow Modification Elbow Design $4-T \ldots \ldots \ldots \ldots .64$

Flow Modification Elbow Design $5-\mathrm{T} \ldots \ldots \ldots \ldots \ldots 6$

Flow Modification Elbow Design $6-\mathrm{T} \ldots \ldots \ldots \ldots 66$

Flow Modification Elbow Design $6-T-R \ldots \ldots \ldots \ldots 67$

Flow Modification Elbow Design $7-\mathrm{T} \ldots \ldots \ldots \ldots \ldots$

Flow Modification Elbow Design $8-T \ldots \ldots \ldots \ldots . .69$

Flow Modification Elbow Design 9-T ......... 70

Erosion Pattern - Back Wall Thinning in

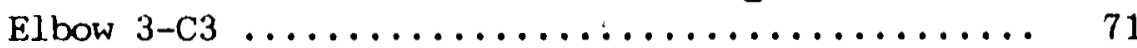

Erosion Pattern - Elbow 3-C3 ............ 72

Erosion Pattern - Complete Penetration in

Back Wall - Inside View ................ 73

Erosion Pattern - Complete Penetration in

Back Wall - Outsidc View ................

Nozzle Arrangement - Four-Part Injection

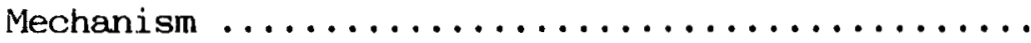

Erosion Pattern - Four-Nozzle Arrangement -

Inside View $\ldots \ldots \ldots \ldots \ldots \ldots \ldots \ldots \ldots \ldots \ldots$

Nozzle Arrangement - Four-Slot Injection

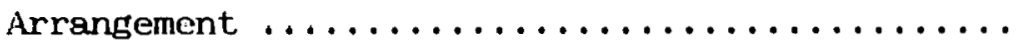

Erosion Pattern - Four-SLot Arrangement -

Inside View $\ldots \ldots \ldots \ldots \ldots \ldots \ldots \ldots \ldots \ldots \ldots \ldots \ldots$

Comparison of Depth of Wear for Run 1 and Run 2 for Elbow $9-\mathrm{T} \ldots \ldots \ldots \ldots \ldots \ldots \ldots \ldots \ldots \ldots \ldots$ 
Diagram Showing the Concentration of Particles from the Secondary Stream into the Primary Jet

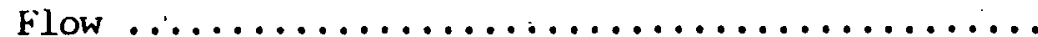




\section{ABSTRACT}

The objective of this project is to investigate the concept of flow-field modification as a method for reducing erosion in bends (elbows) used in pneumatic transport systems. Flow field modifications were primarily accomplished by injecting air at selected locations within the bends. Part I of this project shows the feasibility of the concept. Part II of this project will include further experiments and analysis, leading to a design methodology for incorporating this concept into piping systems. This report represents the final report for Part $I$ of this project.

This report contains a survey of the literature dealing with the erosion in bends (elbows) and the fundamental subjects of erosion and two-phase, gas-solids, flow. Based on this literature survey, a pneumatic transport test loop was constructed. Several bend designs were tested, using sand, under a variety of operating conditions.

The results of this exploratory effort indicate that modifying the flow field in a bend with jets may: 1) decrease erosion; 2) change the erosion pattern with the same amount of erosion; or 3) significantly increase the erosion process. Data indicates that the erosion rate may be reduced by low-velocity jets for high phase-density flow. Apparently the interaction of jets with dilute phase-density flow tends to accelerate the erosion process. It is recommended that the project be continued in order to more fully understand the process and its capabilities to solve the difficult technical problem of erosion in bends (elbows). 


\section{INTRODUCTION}

The objective of this project is to investigate the concept of flow-field modification as a method of reducing erosion in bends (elbows) used for the pneumatic transport of solids. Flow field modifications were initially accomplished by injecting gas at suitable locations in the bend. Part $I$ of this project investigated the feasibility of gas injection as a means of reducing erosion. If a potential for reducing erosion rates is demonstrated,the experimental results of this exploratory effort are to be employed in establishing a program for a more detailed evaluation. Thus Part II of this project is to include more comprehensive experiments and analysis, leading to a design methodology for incorporating the positive results of this project into future piping systems. This report represents the final report for Part I of this project.

Coal and other solids are commonly transported through pipes as a gas-solids mixture. The erosion of components in pneumatic transport systems represents a very serious and difficult design problem. The erosion rate in these components determines the useful life of the component. Consequently, it plays an important role in down-time of a plant. Pneumatic transport systems usually contain at least one bend (elbow) in the flow path, and the erosion that occurs in these bends represents one of the most difficult problems in both design and operation. State-of-the-technology solutions to this problem include: (1) the use of a blind tee, with which the bend surface is protected by an accumulation of the transported solid; (2) the selection of more wear-resistant materials for bends or inserts into bends; and (3) the reduction of air velocity or phase density by altering design conditions. To date, each of these solutions represents only a partial solution. Blinded tees accumulate and release material uncontrollably, which may upset plant operations, flow measurements, and inventories. Wear-resistant materials have not yet been developed to a satisfactory level. Altering the design conditions to avoid erosion frequently is not compatible with the operation of the process and leads to lower plant efficiencies.

In order to develop a research plan and to interpret the experimental results, a review of the basic concepts of the erosion process and the associated two-phase gas-solids flow phenomena were undertaken. The subjects of erosion and gas-solid flows are not well established; however, a useful body of knowledge does exist in these subjects, In addition, several studies on the erosion of bends have been published. Thus there exists a sufficient amount of information to plan, execute, and interpret an experimental project relating to erosion in bends. Chapler 2 represents a review of the literature directly related to this project.

Based on conclusions and data drawn from the literature review, a test loop was designed to provide the necessary data and resolve some of the apparent discrepancies in the reported experimental studies. Chapter 3 describes the test loop and the associated instrumentation. Chapter 4 discusses the test matrix, the operating procedure, and the error analysis for the system.

The results of this exploratory research indicate that the modification of the flow field within a bend may (1) decrease the erosion rate; (2) have no 
effect on the erosion rate, but create a new erosion pattern in the bend; or (3) increase the erosion rate. Chapter 5 describes the test results for each bend design and the corresponding test conditions. The results are summarized, and a tentative model for erosion rate reduction is presented in Chapter 6. 


\section{LITERATURE SURVEY}

\subsection{Introduction}

The erosion of components in pneumatic transport systems represents a very serious and difficult design problem. The erosion rate in these components determines the useful life of the component, and consequently it plays an important role in down-time of a plant. Although no detailed data is available, it appears that the rate of failure of bends is greater than that of any other component of a pneumatic transport system. A report by W. D. Lehrke and F. A. Noonen [2-1] indicates that the wear in bends can be up to fifty times greater than that in straight pipes. They also cite a case of steel bends having to be replaced every three to four months in systems conveying wood chips. These facts, coupled with the fact that the useful life (time to failure) for bends cannot be accurately predicted, demonstrate the importance of understanding and mitigating the erosion process in bends.

This literature survey is in support of an investigation of flow field modification in an elbow to reduce erosion. However, there does not appear to be any published studies directly related to the study of flow field modifications in bends. Thus, this literature survey consists of a review of the significant experimental studies in erosion (Section 2.3) and in two-phase gas-solid flow (Section 2.4). These sections will then be followed by a detailed review of studies relating to erosion in bends. The basis for reviewing the literature will be presented in Section 2.2, where the basic concepts and the terminology are described.

\section{$2: 2 \quad$ Basic Concepts}

The subject of erosion as a science is relatively new. Consequently, the concepts and terminology are not well established. Thus it appears appropriate to discuss erosion concepts, in general, and to establish the terminology to be used in this report. This will allow the following literature survey material to be considered in the proper context.

The basic particle-surface interaction resulting in erosion is shown in Figure 2.1. The angle of attack is defined as $\alpha$, and $v_{p}$ in the velocity of the particle (abrasive). The other variables playing a part in the particle-surface interaction are the properties of the particle and the properties of the surface material. The pruperties of the particle to be considered include size, shape, hardness, and modulus of elasticity. A particle with sharp corners (an angular particle) is more likely to abrade or cut on impact than a particle with rounded edges. The particles may, on impact, create erosion by cutting, surface fatigue, Hertzian stress interaction with surface flows, localized melting, adhesion, extrusion, and ductile fracture. Thus the process of particles impinging on a surface is a complex phenomenon, and the causes of erusion are not firmly established.

In this sludy, erosion is defined as the degradation (or wear) of a surface due to its interaction with particles (abrasives). Wear is the degradation of a surface, in generul, and erosion is one process leading to wear. 
The results of erosion studies are usually presented in terms of:

1) volume of surface material removed per unit mass of particles -- $v_{R}$.

2) mass of surface material removed per unit mass of particles -- $m_{R}$.

3) volume of surface material removed per unit surface area $-v_{R}$.

These three erosion parameters are useful for comparison purposes. Each of the first two parameters may become rate parameters by multiplying it by the particle mass flow rate. Although these erosion parameters may apply to such operations as surface cleaning, they do not appear to be appropriate in describing erosion leading to failure in pneumatic and hydraulic transport systems. In these systems, it appears that the appropriate erosion parameter is the maximum penetration depth per unit time.: 'This parameter is more difficult to measure as the line rule of eliange of the ourfaoo profile is required. Obviously, when the deepest groove on the surface of a pipe (or elbow) equals the thickness of the wall, failure will occur.

The rate at which particles with a specified velocity and angle of attack interact with the surface is determined by the flow field. The flow field in gas-solid pipe flow is not only dictated by the Reynolds number and surface characteristics, but also the phase density, Froude number, acceleration length, and particle characteristics. The phase density, $\phi$, for two-phase, gas-solid, flow is defined as the ratio of mass flow rate of particles to the mass flow rate of gas. For low phase density ratios $(\Phi<1)$, the particles are more or less uniformly distributed in the flow field. However, as the phase density increases, an increasing number of particles move along the lower surface of a horizontal pipe. Thus the lower pipe surface will experience rubbing as the particles are dragged over the surface. Therefore, in order to predict erosion rates, a description of the flow field must first be established.

Tho Froude number playe an important role in the empirical formulas for calculating the pressure drops in pipes due to the particles. It has not yet been determined if this parameter is significant in describing the flow field in a bend.

A phenomenon which is important in two-phase gas-solid flow is the acceleration length. The acceleration length is that length required for particles, initially at a significantly different velocity than that of the gas, to accelerate to a final constant average velocity. After the bend in an elbow and in many solids feeders, the particles have very little momentum in the direction of flow, Thus an additional pressure drop in the flow is required to accelerate the particles and alter the gas flow pattern concurrently to achieve a fully established flow. Similarly, in a nozzle, the acceleration of the particles lags behind that of the gas. Consequently, the particles must first accelerate to achieve an established flow, but the gas flow in a jet downstream of the nozzle is decelerating. Thus no established flow will exist in this case until after the acceleration length has been reached.

The acceleration length problem enters this project by two routes. First, the solid particles entrained by the gas flow in the feeder must be 
accelerated to the established flow field. If the pipe length between the feeder and the first elbow is greater than the acceleration length, then the test results will be for a fully established flow field. However, if the distance between the feeder and the elbow is less than the acceleration length, then the test results will be a function of the distance and perhaps the characteristics of the feeder. The second route by which the acceleration length enters the problem is in determining the pressure drop across the elbow because of the acceleration length required downstream of the elbow will affect the pressure drop.

The acceleration of particles in a jet is an important problem in the early erosion studies. Jets of air, containing particles, were directed at surfaces of various materials. The results of these tests were described in terms of particle velocity. In some of the literature it is not apparent how or if the particle velocity was distinguished from the air velocity.

In conclusion, this section introduces the reader to some of the basic considerations in reviewing the literature on erosion. This literature survey essentially develops the review along historical lines. Thus the complex phenomena occurring in erosion, and especially the erosion of elbows, has been and is difficult to appreciate. Consequently, seemingly important results in the literature often really represent information for a very specific set of conditions.

\section{$\underline{2.3}$ Discussion of Erosion}

The erosion (or wear) of materials due to high velocity particles impinging on the material surface has long been of interest in technology. Until recently, the many studies of erosion and wear were directed towards specific situations. A survey of the literature on erosion up to 1946 may be found in the book by Wahl and Hartstein [2-2]. Studies of erosion from a basic mechanistic approach appear to have originated in Germany by Siebel and Brocksteam [2-3]. They eroded plates with a stream of quartz sand directed perpendicular to the surface and measured the mass removed. Their results were not in agreement with practical experience. In order to resolve this discrepancy, Wellinger and colleagues $[2-4,5,6,7,8]$ investigated the influence of the angle of attack of the sand-laden jet on the material surface. These suthors expressed the erosion as volume removed per unit aurfacc area. Their studies showed that the angle of attack for maximum erosion occurred at about $90^{\circ}$ for hard steel and about $30^{\circ}$ for the more ductile steel. The erosion of ductile material is illustrated in Figure $2.2 \mathrm{a}$, and the erosion of a brittle material is shown in figure $2.2 \mathrm{~b}$. A material is classified by its erosion curve and so materials cannot be classified as either ductile or brittle. These results appear to agree with Holtey's [2-9] concept of two distinct erosion processes denoted as "rub" and "shock" wear. Kashcheev [2-10] obtained similar results in eroding copper-aluminum alloys at different angels of attack. In addition to their contribution to understanding the influence of the angle of attack, Wellinger and Uetz [2-8] investigated the influence of the particle hardness and developed the informative curve shown in Figure 2.3.

In order to develop a more basic understanding of the erosion process I. Finnie [2-11] developed a pneumatic "sandblast" type tester in which the 
velocity, trajectory, and number of particles could be controlled. The individual motion of particles was observed by taking photographs with a high-speed double flashlight source. It was observed that during the erosion of ductile material, many particles bounce off the surface. while a large number of particles cut into the surface. The cutting particles remove material in a manner similar to the tooth of a milling cutter or grain on $a$ grinding wheel. These observations formed the basis for an erosion model which was formulated for a single particle striking a ductile material at a small angle of attack. Subsequently, in 1958, Finnie [2-12] introduced the theory of erosive cutting, which explained many aspects of erosion reported in the literature. The model is illustrated in Figure 2.4. The solution of the momentum equations for the particle describes the trajectory of this particle during thecutting action. Two possible erosion cutting mechanisms emerge from this analysis; (a) the particle cuts into the surface and then leaves the surface, and (b) the particle cuts into the surface until the particle stops moving. The angle of attack dictates which mechanism occurs. At small angles of attack mechanism (a) occurs, and for large angles of attack, mechanism (b) occurs. Employing the results of this analysis, the volume of surface removed per particle may be estimated. This expression is then differentiated with respect to $\alpha$ to determine the angle of attack for maximum material removal (erosion). As shown in Figure 2.5, the model developed in this study predicted the erosion as a function of angle of attack for ductile material at a small angle of attack. The busic relationship developed for ductile materials at relatively small angles of attack may then be written as

$$
\Delta m_{R}=\frac{M_{p} V_{p}^{2}}{2} \quad\left(\frac{1}{\sigma p}\right) f(\alpha)
$$

where $M_{p}$ represents the total mass of particles cutting into the surface, $v_{p} 2 / 2$ the kinetic energy of the particles, $\sigma p$ the plastic flow stress, and $f(\alpha)$ is the angle of attack function.

In reviewing the various aspects of the model, Finnie $[2-13\rfloor$ employed experimental data to verify the exponent on the particle velocity. Upon considering the influence of the shape, hardness, and strength of the particles on the results of his model, Finnie concluded the following: 1) the shape of the particle is important because the more rounded the particle, the less the erosion and the angle of attack is increased for maximum erosion; 2 ) when the particle hardness is greater than the surface hardness, the effect of particle hardness is minimal; however, if the particle hardness is less than the surface hardness, the erosion rate is significantly reduced (see Figure 2.3); and 3) the effect of particle strength appeared as the ability of the particles not to fracture on impact, and this uspecl is difficult to evaluate.

In evaluating the erosion of ductile material at high angles of attack, it is apparent that the data does not approach zero as the theory predicts. Finnie believed that the initial erosion of a surface created irregularities in that surface. Thus, later particles striking the damaged surface represented particles approaching a point on the surface with a wide range of angles of attack. No model or empirical formula was advanced for erosion at high angles of attack. 
After reviewing the experimental data for erosion of brittle material, it was apparent to Finnie that the erosive cutting model for ductile material was inappropriate. The simplest model for brittle material is to consider a particle striking a brittle material at an angle of attack of $\alpha=90^{\circ}$. The surface material was assumed to remain elastic until fracture occurred, thus the impinging particle creates Hertzian stresses, which reach a maximum just below the surface. If these Hertzian stresses interact with the surface flaws, then lumps of material will be emitted; and consequently, the surface damage is referred to as erosion. Unfortunately, this simple model does not lead to any. relationship involving velocity, angle of attack, etc.

'In two publications, Bitter $[2-14,15]$ proposed that two mechanisms are always present in erosion a cutting mechanism and a deformation mechanism. The model employs the concept of equating the particles's kinetic energy (normal to the surface) with to the elastic strain

$$
v_{e}\left(\frac{1}{2} m_{p} v_{p \cdot n}^{-2}\right)
$$

leaving elastic potential energy $U_{p e}$, and a energy dissipation term $U_{p}$. The results of Bitter's model are similar to those of Finnie's. Bitter's approach was significantly simplified by Neilson and Gilchrist [2-16]. Their effort is another theoretical model and yields no additional information to "be considered in the study of erosion in elbows.

The fundamental study of erosion changed direction in 1963 when Brauer and Kriegel [2-17] investigated the penetration depth resulting from erosion. They found that the maximum penetration depth did not occur at the same angle of attack as that for the maximum mass removal rate for either ductile or brittle materials. Typical results are shown in Figure 2.6. There have been three erosion periods established for the development of the penetration depth. The initial period represents rapid penetration into the material, followed by a transition period in which the penetration rate slows. The third period represents a slow steady rate of penetration. Figures $2.7 \mathrm{a}$ and $2.7 \mathrm{~b}$ show the relationship between the rate of penetration and the shape of the eroded groove.

G. P. Tilly presents a series of papers [2-18,19], starting in 1969, dealing with the particle effects in the erosion process. He found that very small quartz sand particles $\left(\left\langle d_{p}\right\rangle \approx 5 \mu \mathrm{m}\right)$ produced very little erosion and the erosion rate increased with mean particle diameter as shown in Figure 2.8. During these tests, no effect of temperature was noticed. Using high speed photography, Tilly and Sage [2-20] demonstrated the importance of particle fragmentation on erosion. The initial impact produced a crater and the shattered particle sent out fragments at an average velocity of $70 \%$ over the initial particle velocity. These fragments caused a considerable amount of additional (secondary) erosion. The potential to fragment is shownin Figure 2.9. It should be noted that these tests were conducted at rather high particle velocities that are somewhat higher than those normally encountered in a pneumatic transport system. Finally, Tilly [2-19] presents a graph illustrating the significance of the primary and secondary erosion for various angles of attack, Figure 2.10. 
In order to better understand the difference between a ductile and a brittle material, G. L. Sheldon and I. Finnie [2-21] eroded various materials with silicon carbide grit at various velocities, two particle sizes, and a large range of values for the angle of attack. Their experimental data indicated that if the particles were below a critical size and had a velocity greater than a minimum velocity, then the normally brittle surface would erode as a ductile material, as shown in Figure 2.11. Also, with smaller particles, it appeared that some brittle materials behave as neither brittle or ductile material. Thus it is the interaction between the particle and the surface material which dictates whether a material is ductile or brittle.

Arundel, et al., [2-22] tested three-surface materials: mild steel, nylon, and Linatex (a proprietary material containing 95\% pure gum rubber) in a shot blast type impact testing machine using alumina particles. The Linatex material exhibited a behavior close to that of mild steel. However, when investigating the effect of particle velocity on the erosion rate $\left(v_{R}\right)$, they found that the performance of Linatex was superior to that of mild steel for velocities normally encountered in pneumatic transport systems.

The erosion of rubber was investigated by G. M. Bartenev and N. S. Penkin [2-23]. They investigated three different rubber types exposed to a $40 \mathrm{~m} / \mathrm{sec}$ jet of $0.5-1.0 \mathrm{~mm}$ diameter particles at various angles of attack. In addition to the typical erosion curve for ductile material, the investigators obtained the data for erosion rate as a function of the thickness of the rubber, (see Figure 2.12). These authors present an interesting theory for the development of a quasi-brittle state of the rubber leading quickly to failure.

In this literature survey, it appears that most of the literature appearing in the last ten years has been concerned with the develupment of theories to explain the experimental results presented in this survey. A recenl arlicle, by P.V. Rao and D. H. Buckley [2-24], presents a brief review of the many. theories proposed for erosion. The proposed mechanisms of material removal during particle impingement include extrusion, ductile fracture, melting, low-cycle fatigue, delamination, localized shear, adhesive material transfer, etc. As this project deals with erosion in elbows, the experimental facts from the basic erosion studies constitute the primary information required to complete this study.

\section{$\underline{2.4 \quad \text { Flow of Particles }}$}

The flow of a gas-solid mixture in a pneumatic transport system is a verycomplex process. Unlike the flow of single-phase fluids, it is difficult to produce empirical formulas which are generally acceptable or consistent with data from other similar experiments. This implies that unknown (or neglected) phenomena are not included in the analysis of data.

The basic pneumatic transport system starts with a solids feeder. This feed system controls the phase density of the flow, which in turn establishes the flow patterns downstream of the feeder. The distance downstream of the feeder to the established flow is referred to as the acceleration length (referring to the acceleration of the particles). There are several equations for the same conditions. A condition to be considered for this project is the 
construction of the solids feeder and its potential for creating a non-uniform solids concentration profile or a secondary (swirl) flow pattern.

An overall diagram for describing the flow in a pneumatic transport system is shown in Figure 2.13 [2-25]. The variable gas (air) velocity throughout the system is avoided by using the mass flow rate. Also, the minimum gas transport velocity for the solids forms the left boundary limit for the pneumatic transport region. The minimum gas transport velocity depends on the type of powder and the phase density, as shown in Figure 2.14. The right-hand side of the region is essentially determined by erosion considerations. The specific details of Figure 2.13 depend on the geometry of the piping as well as the powder characteristics.

The details of the phenomena occurring in pneumatic transport systems cannot be so simply related in a diagram like Figure 2.13. Various flow patterns for the solids in pneumatic transport systems have been reported. In a recent text [2-26], two technically acceptable flow patterns are dilute phase flow and rope flow. These flow patterns are shown in Figure 2.15. Other flow patterns involve unsteady flow.

In a dilute phase flow, there is very little interaction between the particles in the flow. However, two-phase, solid-gas flow moves through a centrifugal flow field, the solids are thrown together at a surface. Under the appropriate flow conditions, the solids form a very porous body and flow through a horizontal pipe as a layer, rope, or strand. If the rope flows through a bend, there appears to be a high probability that the bend may be destroyed. Apparently, there is not an abundance of information on ropes. However, they do appear to play an important role in erosion in bends.

The flow of a solid-gas mixture through an elbow is a relatively unexplored topic. There is also an uncertainty in calculating the pressure drop across an elbow for a single phase fluid. The detailed study of the pressure drop caused by an elbow indicates that there is a pressure drop due to the change in velocity profile from that at the elbow exit to that in the fully developed pipe flow. The experimental results of Ito [2-27] are shown in Figure 2.16. Thus it is important to describe the method for reducing the pressiure drop data when reporting experimental data.

P. Schuchart [2-28] appears to be the first to investigate the pressure drop for solid-gas flow due to an elbow. His data was reduced to producing acorrection for the pressure drop predicted for the flow along an equivalent length of a straight pipe. This correlation was based on data for glass particles, $\left\langle d_{p}\right\rangle=1.5-3 \mathrm{~mm}$, at a phase density from $0-20$ and flowing in a 34 $\mathrm{mm}$ tube.

The pressure drop due to circular and elliptical elbows tranporting solid-air mixtures was presented by Y. Morikawa, Y. Tsuji, K. Matsui, and Y. Jittani [2-29]. The particles used were $1.1 \mathrm{~mm}$ spherical polyethylene pellets flowing through a $35 \mathrm{~mm}$ diameter tube at solids loading of from 0 to 8 . The air velocity ranged from 18 to $22 \mathrm{~m} / \mathrm{sec}$.

An interesting result from this study is shown in Figure 2,16. Not only does this figure illustrate an adjustment length downstream of the elbow, but 
the final flow has a greater pressure gradient than that upstream of the elbow. The similar type of data in Schuchart's paper indicates that the pressure gradient returns to its upstream value. Thus the flow conditions in Morikawa's paper may be such that the particles collect at the wall and form a different flow pattern downstream of the elbow. Upon emerging from the elbow, the air velocity may not have been sufficient to re-entrain the particles. Hence, the flow pattern downstream of the elbow may have retained the new flow pattern as its established flow.

F. Schmidt [2-30] invesstigated employing air jets to improve the flow of solids in a bend. One of his designs is shown in Figure 2.17. Apparently his goal was to reduce plugging in a pneumatic transport system; however, he also mentions that the wear is neglible. Reference [2-2] also indicates that the life of this bend is twelve times longer than the life on the standard bend that was replaced.

The forces acting on a particle in a flow field may be written as [2-31];

$$
\begin{aligned}
& m_{p} \frac{\bar{d} V_{p}}{d t}=\frac{C_{p} A_{p} \rho}{2}\left|\bar{V}-\bar{V}_{p}\right|\left(\bar{V}-\bar{V}_{p}\right)+K_{m} \rho\left(\frac{m_{p}}{\rho_{p}}\right)\left[\frac{d V}{d t}-\frac{\bar{d} V_{p}}{d t}\right] \\
& +\frac{m_{p}}{\rho_{p}}\left(-\frac{P}{x}\right)+\left[K_{B} d_{p}^{2} \frac{(\pi \rho \mu)^{3 / 2}}{4}\right] \int^{t} \frac{\left(\frac{d \bar{V}}{d t}-\frac{d \bar{V}_{p}}{d t}\right)}{\left(t-t^{\prime}\right)^{1 / 2}} \\
& +\frac{\pi}{g} \rho d_{p}^{3}\left(\bar{V}-\bar{V}_{p}\right) \times \bar{\omega}_{p}+1 / 61(\mu \rho)^{1 / 2}\left(\bar{V}-\bar{V}_{p}\right) \mid \frac{d \bar{V}^{3 / 2}}{d y}{ }^{3 / 2} \\
& +I_{p p}+I_{p w}+F_{e}
\end{aligned}
$$

The forces in this equation are:

I. The drag force

II. Force required to accelerate the apparent mass of the particle relative to the ambient gas

III. Buoyaricy forete

IV. Basset force due to the deviations from a steady state in the gas flow field

V. Magnus effect force caused by particle spin

VI. Säfman lift force caused by a velocity gradient 
VII. Particle-particle interaction

VIII. Particle-wall interaction

IX. Externally applied forces (gravity, electromagnetic, etc.)

To obtain a solution for the motion of a particle in a flow passage is extremely difficult, as are the problems in solving the fluid flow motion. Fortunately, there is some basic information on particle motion in dilute homogeneous gas-solid flow.

Employing high speed photography, O. Adam [2-32] obtained the data shown in Figure 2.18. He noted that particle collisions with the wall were either elastic or inelastic. The inelastic collisions deformed the particles and/or the wall surface (whence erosion). The elastic collisions frequently resulted in particles with a high spin $(38,000$ RPM estimated). This high rate of spin should make the Magnus force a significant parameter.

K. Goto and K. Iinoya [2-33] measured the air velocity and particle mass flux distribution in a horizontal pipe. Figure 2.15 illustrates that it appears the gas velocities are higher above the centerline, and that the particle concentration is greater below the centerline. It should be noted that in. many theoretical studies, not reviewed in this report, the concentration of particles is assumed uniform over the flow area, and the gas velocity is assumed symmetrical about the centerline of the duct.

\subsection{Erosion in Elbows}

Although erosion in elbows has been a significant problem for a long time, a systematic approach to the subject did not start until the 1960's. The illuminating fundamental work in erosive wear in the 1950's probably was the basis for re-evaluating the erosion of elbows from a more mechanistic point of view. After completing their basic erosion study [2-17], Brauer and Kriegel began to apply their results to elbows in pneumatic and hydraulic transport systems [2-34,35,36]. Their approach to erosion in elbows was to attempt to predict the maximum depth of penetration, which leads to elbow failure.

Bikbaev, Krasnow, Zhilinsleii, and colleagues published a series of studies in the early 1970's dealing with abrasive wear on elbows $[2-37,38]$. Their experimental system was a $5.2 \mathrm{~m}$ long, $50 \mathrm{~mm}$ diameter, vertical pipe leading into an elbow, and quartz sand was used as the transported solids. The first paper related the abrasive wear rate to the turning angle $\beta$ and the $\left(\mathrm{R}_{\mathrm{E}}+\right.$ $\mathrm{d} / 2$ ) elbow dimension (see Figure 2.19). The abrasive wear rate was defined as the penetration depth per unit time, $\Delta Z \equiv[\mathrm{mm} / \mathrm{hr}]$. An empirical formula was reported for the angle $\beta$ where the maximum abrasive wear occurs:

$$
\beta_{\max }=\frac{67.4}{\left(\frac{\mathrm{R}_{\mathrm{E}}}{\mathrm{D}}\right)}
$$

This formula was developed for grade 20 steel, aluminum alloy, and gray iron elbows. 
In a second paper, Bikbaev et al., [2-38] reported on experiments in which phase density, particle velocity, and elbow radius were the independent variables. Again the abrasive material was sand, and the elbow material was grade 20 steel (Russian designation). The test results showed that the phase density and gas velocity had no effect on $\beta_{\max }$. Their results are shown in Figures 2.20-22.

The third paper by Krasnov and Zhilinskii [2-38] describes an attempt to develop a methodology for estimating the reliability of material undergoing erosion. Applying probability theory, they arrive at the conclusion that the angle of attack for maximum abrasive wear is $\alpha=60^{\circ}$ (which corresponds to the angle for maximum penetration depth for steel).

In 1972, a series of papers began to appear on erosion in elbows, authored by J. S. Mason and colleagues, usually including D. Mills. In the first paper, J. Mason and B. V. Smith [2-40] described the wear patterns in 1 inch and 2 inch square-section 900 elbows. These perspex elbows were downstream of a 12 foot vertical tube, and the transported particles were alumina with a mean diameter between 50-60 $\mu \mathrm{m}$. The test conditions included a phase density from 0.5 to 3.8 and air velocities from 96 to $330 \mathrm{ft} / \mathrm{sec}$. The The results of this effort are summarized in terms of the mean wear rate $(\Delta \mathrm{Z})^{-1}$

$$
(\Delta Z)_{\max }^{-1}=\alpha(\phi)^{m}(V)^{n}
$$

for fixed materials and $\left(R_{E} / D\right)$ geometry. Note that $m$ and $n$ are considered to be time dependent, or average values to failure. Figure 2.23 illustrates the wear pattern observed in these tests. These authors also present an interesting discussion of the possibility of a minimum mean wear rate. Graphically, (Figure 2.24) they propose that the erosion rate increases (mean wear rate decreases) as the phase density increases. However, after the maximum erosion rate is achieved, the particles begin to interfere with each other in bombarding the surface. Consequently, as the phase density continues to increase, the mean wear rate increases.

In a series of papers J. S. Mason and D. Mills [2.41-4:3] investigated the effect of particle concentration on erosion. With a straight upstream section of pipe longer than the acceleration length, one may assume that particle concentration should have reached an equilibrium distribution. Thus, the phase density may replace the particle concentration as the variable under consideration. Seven elbows were simultaneously investigated in a horiznntal. loop transporting sand $\left(\left\langle\mathrm{d}_{\mathrm{p}}\right\rangle=70 \mu \mathrm{m}\right)$ at an initial air velocity of $25 \mathrm{~m} / \mathrm{sec}$ with the phase density varying from 0.5 to 8.0 . The results were presented as

$$
\dot{\mathrm{m}}_{\mathrm{R}}=\dot{\mathrm{V}}^{4.1} \Phi-0.37
$$

Unfortunately, the data for the seven test elbows showed some inconsistencies which could not be explained. The experimental system was 
batch operated, and the sand did not appear to degrade during the tests.

The work reported in [2-41] was extended to a more complete study, as described by Mason and Mills in [2-42]. They employed the same experimental system as in [2-40], but now employed two different size distributions: $\left\langle\mathrm{d}_{\mathrm{p}}\right\rangle$ of $70, \mu \mathrm{m}$ and $230 \mu \mathrm{m}$. The air velocity employed was again $25 \mathrm{~m} / \mathrm{sec}$, and the phase density was varied from 0.5 to 8.0. Although the mass erosion differed slightly with particle size, the penetration depth for $\left\langle d_{p}\right\rangle=70 \mu \mathrm{m}$ sand was over $40 \%$ greater than that for $\left\langle d_{p}\right\rangle=230 \mu \mathrm{m}$ sand. In evaluating the exponent on phase density for erosion,

$$
\dot{\mathrm{m}}_{\mathrm{R}}=\boldsymbol{\Phi} \mathbf{m}
$$

these investigators found $m=-0.16$ for new "fresh" sand whereas $m=-0.38$ for worn and degraded sand. An important revelation in these studies is the wear profiles in the elbow. Figure 2.25 illustrates the wear pattern on the back arch of the elbow, for $\phi=3.0$, as a function of mass removed. Figure 2.26 shows the effect of phase density on wear pattern for a fixed amount of mass removed $(20 \mathrm{gr})$. This figure definitely establishes the fact that the mass removed by erosion is not proportional to the penetration depth. Finally Figure 2.27 shows that the maximum penetration depth does not necessarily occur at the mid-plane of a horizontal elbow. It was pointed out that some of the elbows that failed had surface markings which indicated that there may have been a swirling component to the flow through the elbow.

Continuing their investigation of penetration depth, Mason, Mills, and long investigated the effects of phase density, particle size,and elbow geometry in [2-43]. Their test conditions included using sand at $\left\langle\mathrm{d}_{\mathrm{p}}\right\rangle=70 \mu \mathrm{m}$ and an air velocity of $25 \mathrm{~m} / \mathrm{sec}$. Combining their recent data with previously reported data, it appears that the penetration depth increases with phase density until a critical phase density is achieved, after which any further increase leads to significantly reduced penetration depth per unit mass eroded $\left(\Delta \mathrm{Z} / \mathrm{m}_{\mathrm{R}}\right)$. This result is illustrated in Figure 2.28. The mean particle size was found to have a significant effect on penetration depth if sufficiently small, as shown in Figure 2.29 . Finally, the $\left(2 \mathrm{~K}_{\mathrm{E}} / \mathrm{D}\right)$ ratio effect on penetration depth is shown in Figure 2.30 for three geometries.

In order to obtain information on the effects of particle and elbow material effects on erosive failure, Agrawal, Mills, and Mason [2-44] studied the erosive wear of alumina, coke, and sand on mild steel and rubber elbows. Preliminary tests for rubber and mild steel abraided by alumina indicated that for velocities encountered in pneumatic transport systems, the rubber would be significantly more resistive to erosion. However, when these elbow materials were employed in an experiment loop, the rubber elbow was only effective in resisting erosion by sand, whereas mild steel was more resistive to erosion by coke and alumina than was rubber.

In a recent study, Mason, Mills, and Agrawal [2-45] investigated the effect of acceleration length on bend erosion. Although no effect of acceleration length could be established, it was interesting to note that every other bend, in the loop, had a very large erosion rate compared to the intervening bends. 
If the flow pattern was similar into each bend, then the erosion rate would have increased with the increasing velocity of the air as it moved through the loop. 


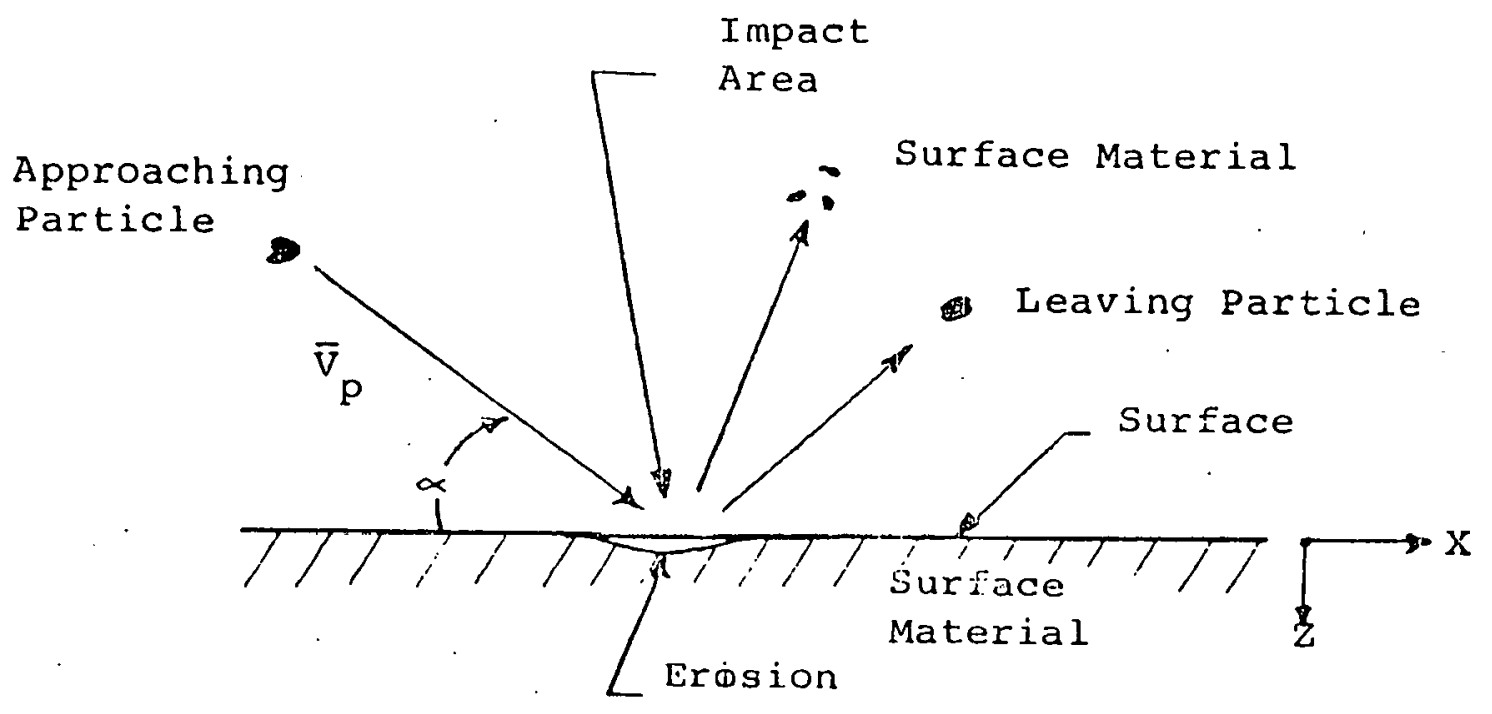

Figure 2.1. Basic Erosion System and Terminology 

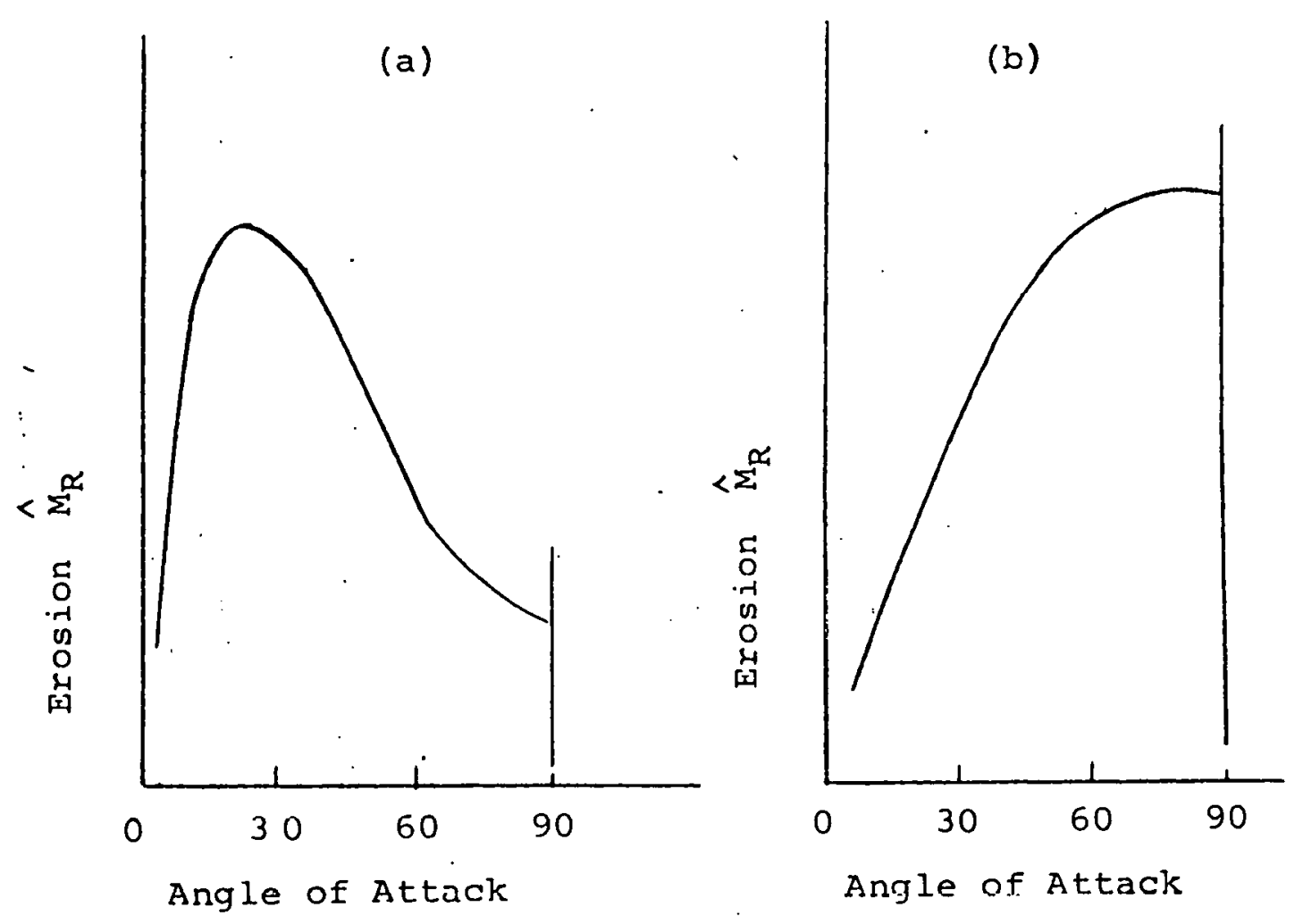

Figure 2.2. Erosion Characteristics

(a) Erosion Characteristics of a Ductile Material

(b) Erosion Characteristics of a Brittle Material

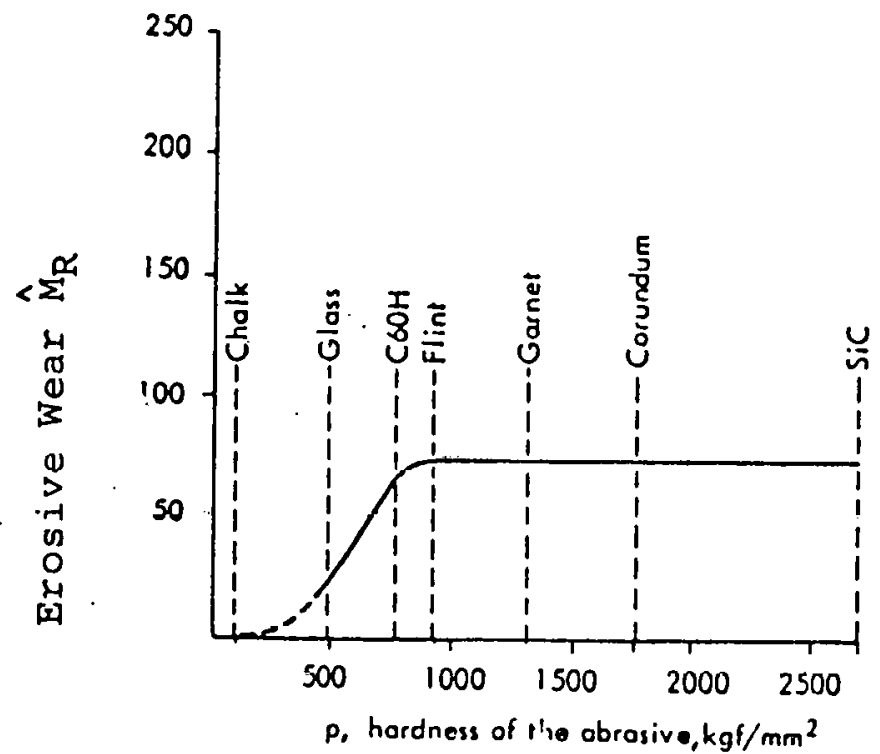

Figure 2.3. Dependence of the Erosive Wear of $\mathrm{C} 60 \mathrm{H}$ Steel $\left(p=750 \mathrm{kgf} / \mathrm{mm}^{2}\right)$ on the Hardness of the Abrasives. Normal Impact, $\alpha=90^{\circ}$. 


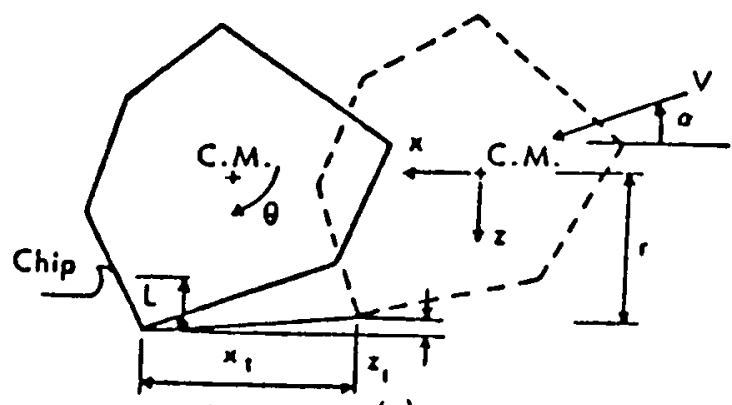

(o)

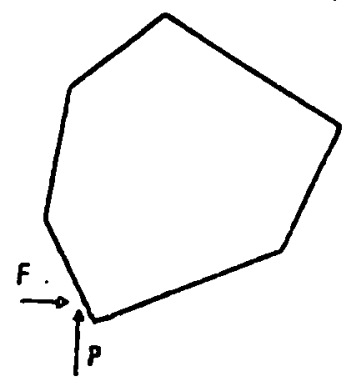

(b)

Figure 2.4. Incident two-dimensional erosive particle cutting into a ductile surface at an angle of attack $\alpha$. (a) Cutting geometry; (b) Contact forces acting on the particle during cutting.

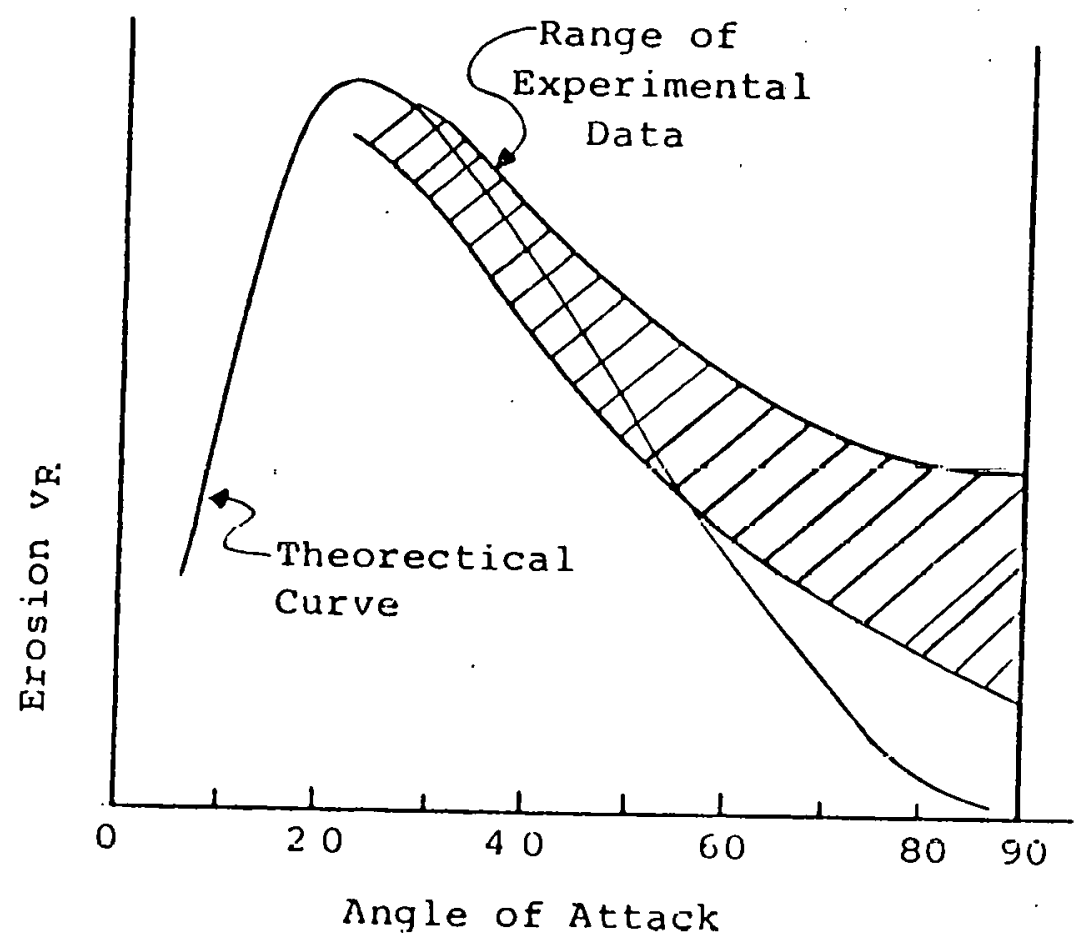

Figure 2.5. Predicted variation of volume removal with angle for a single abrasive grain. Experimental points for erosion by many grains ( $\triangle$ copper, $\square$ SAE 1020 steel, 0 aluminum) are plotted so that the maximum erosion is the same in al1 cases. 


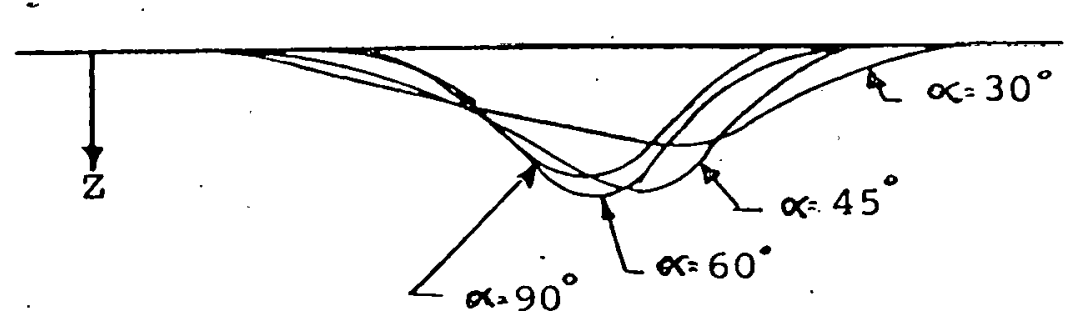

Figure 2.6. Penetration Depth as a Function of the Angle of Attack. -
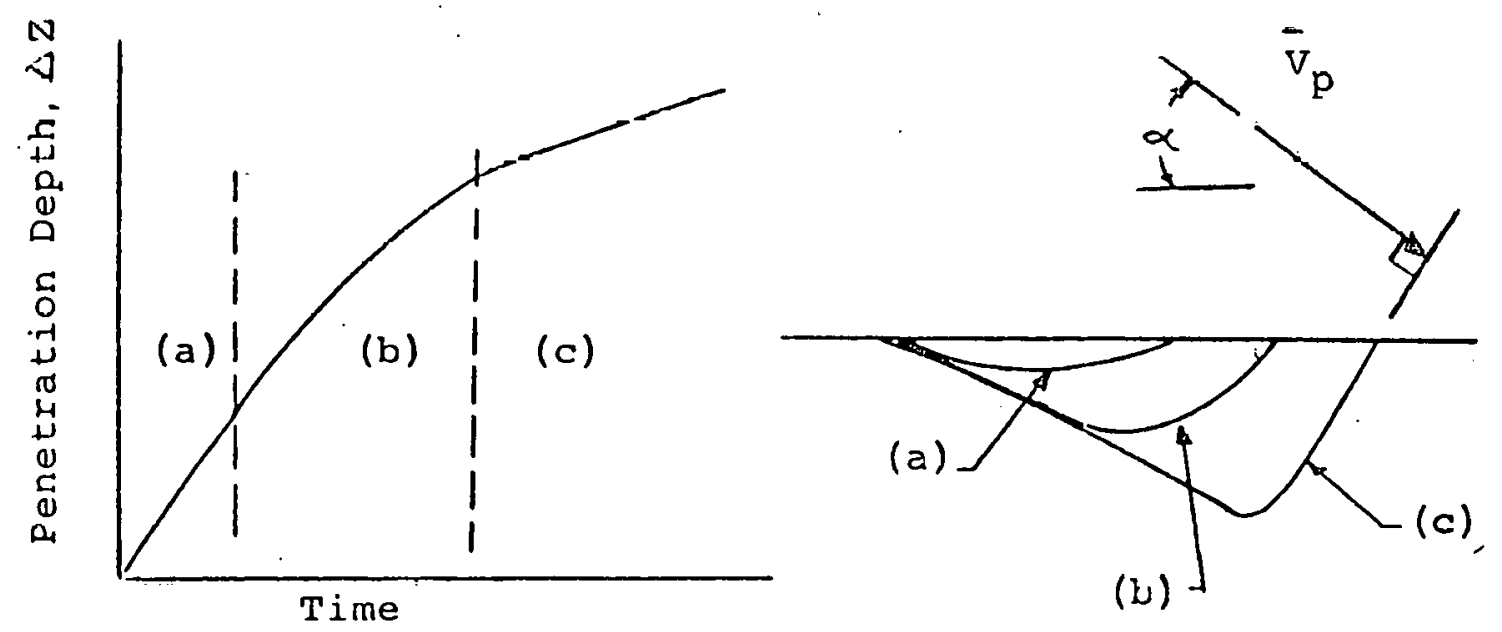

Figure 2.7. The Three Penetration Depth Rate Periods and Their Relationship to Groove Configuration. 
(a)

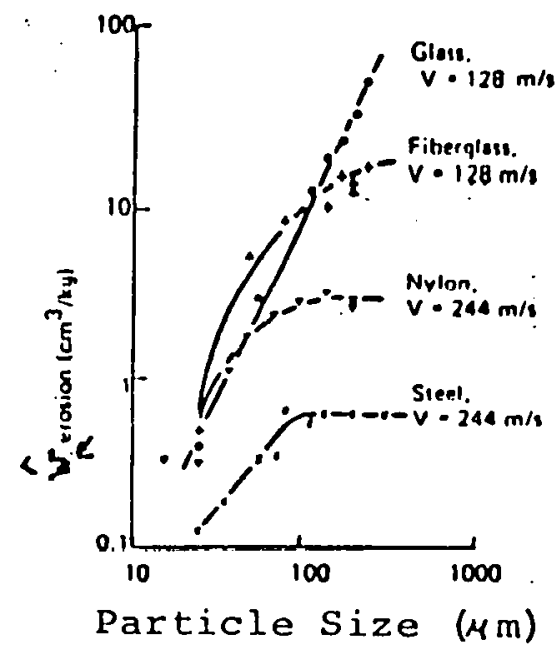

(b)

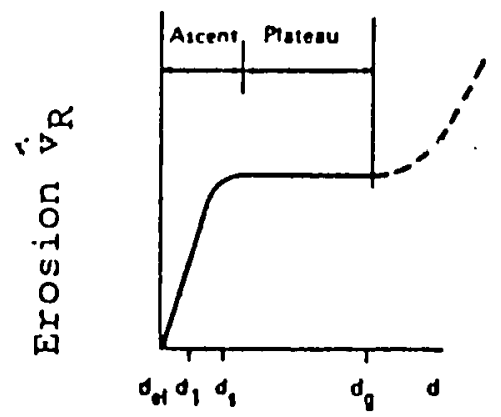

Particle Diameter

Figure 2.8. Effect of Particle Size on Erosion. 


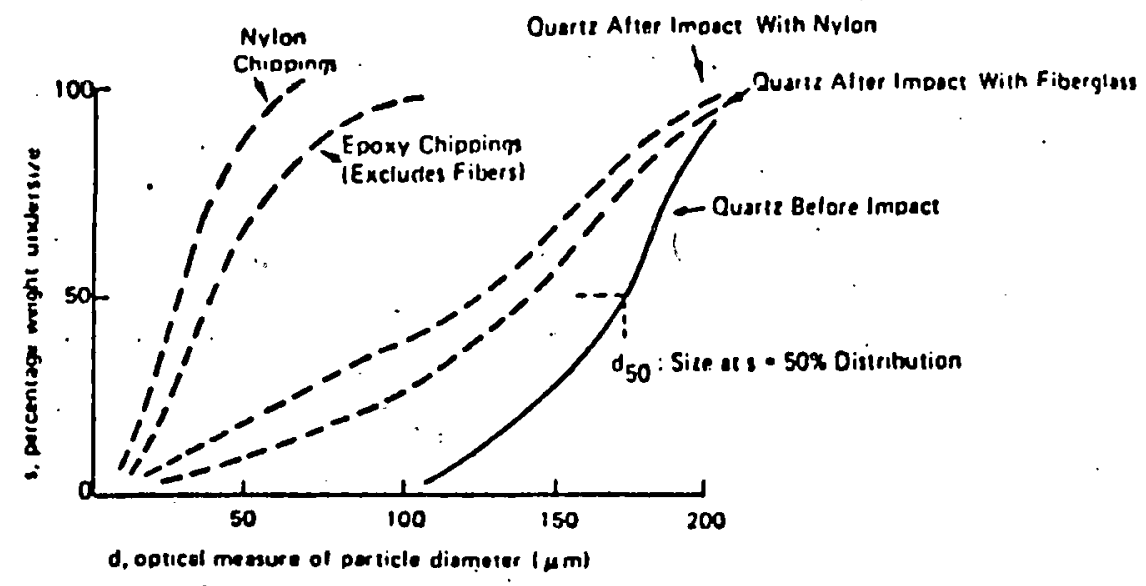

Figure 2.9. Size Distribution of Particles Before and After Impact.

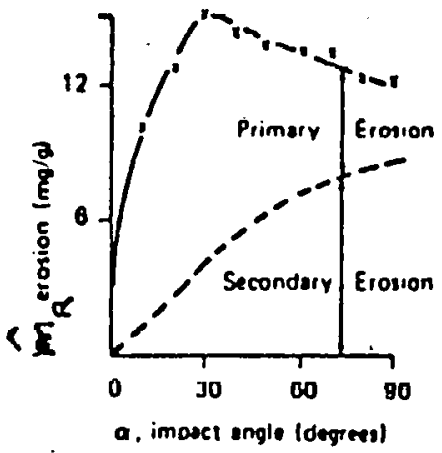

Figure 2.10. Primary and Secondary Erosion. 


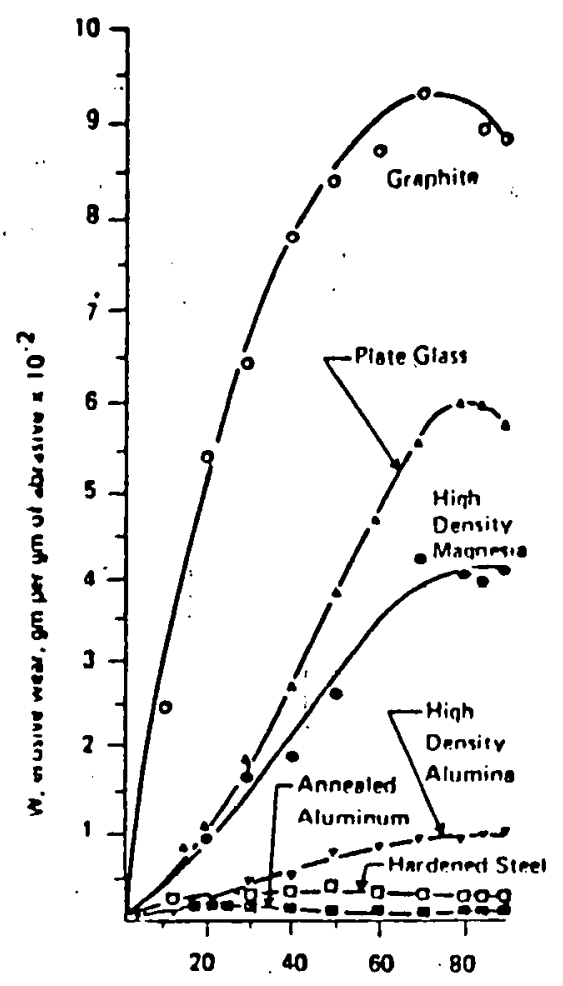

|al

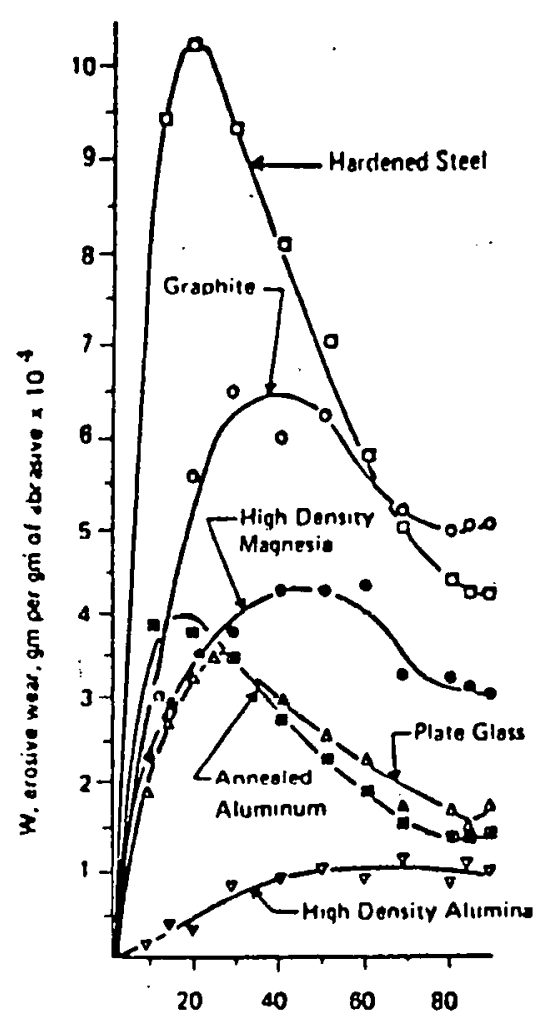

b

Figure 2.11. Ercsion Characteristics as a Function of Particle Size.

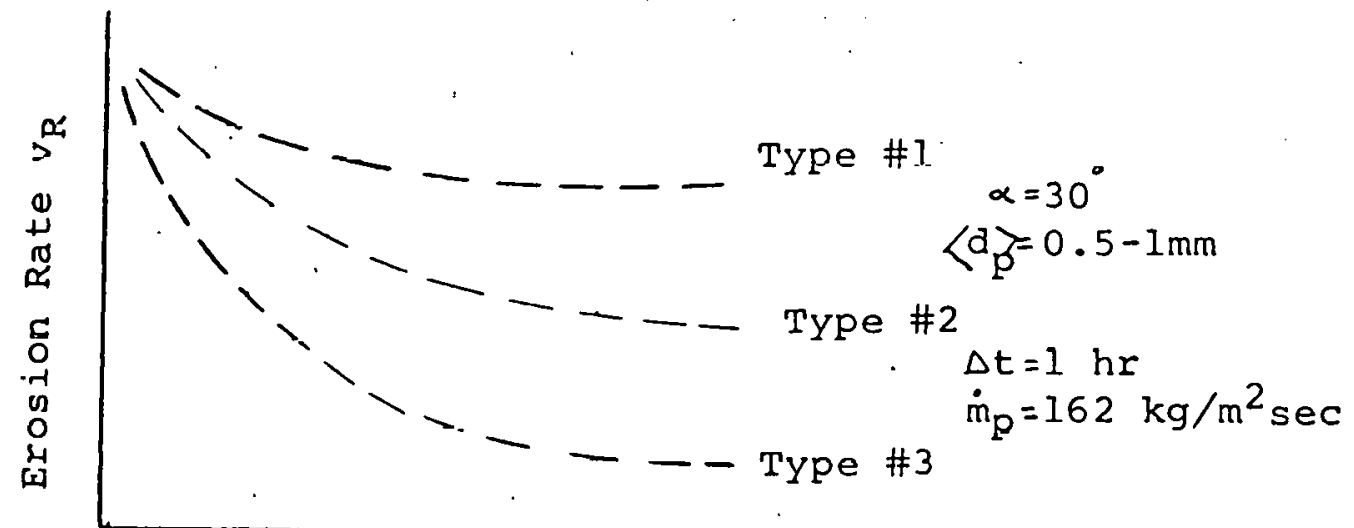

Thickness of Rubber Specimen

Figure 2.12. Erosion of Three Types of Rubber. Test Rubber Mounted on a Steel Support Plate. 


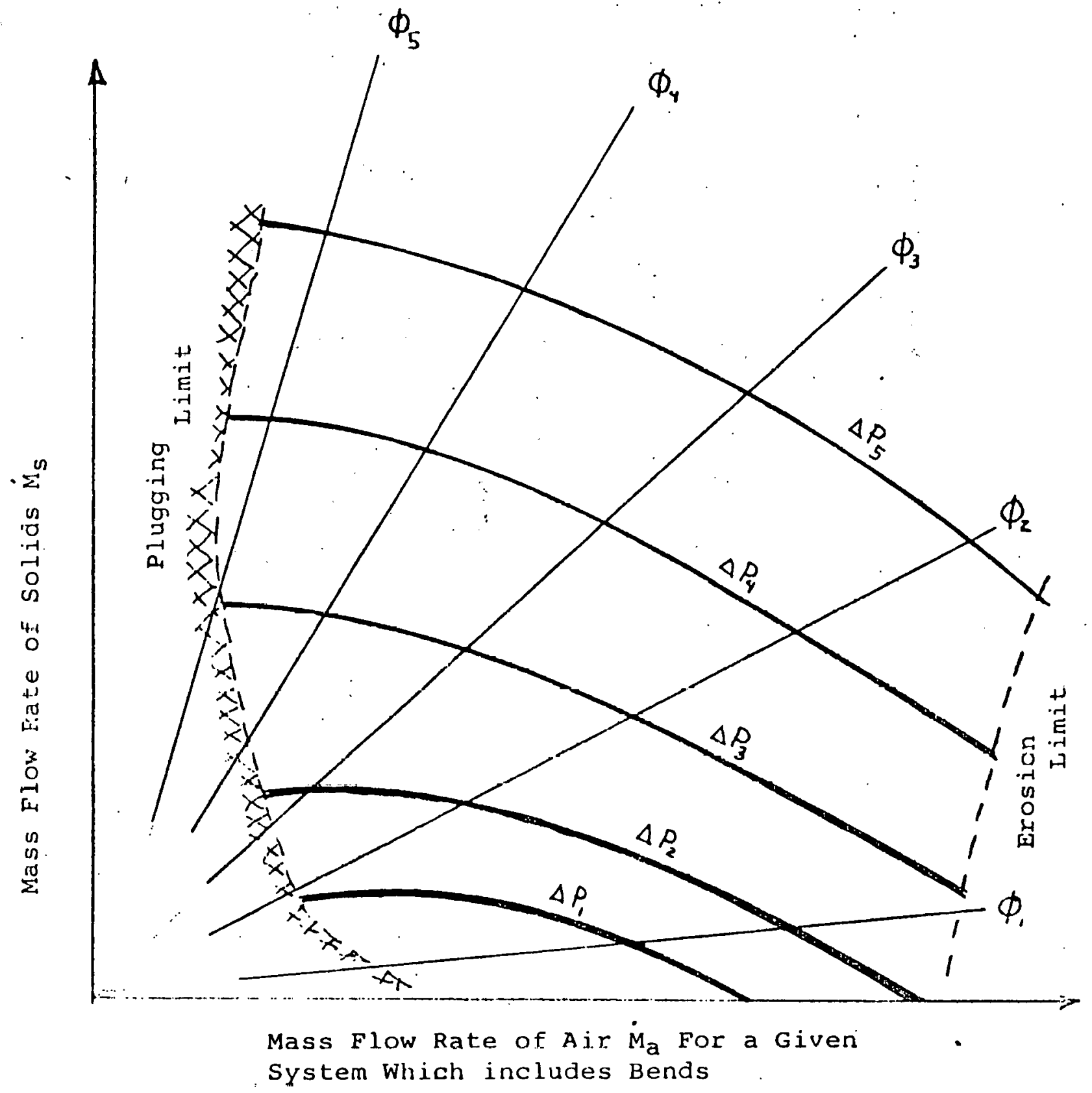

Figure 2.13. Pneumatic Transport System. Performance Curves. 


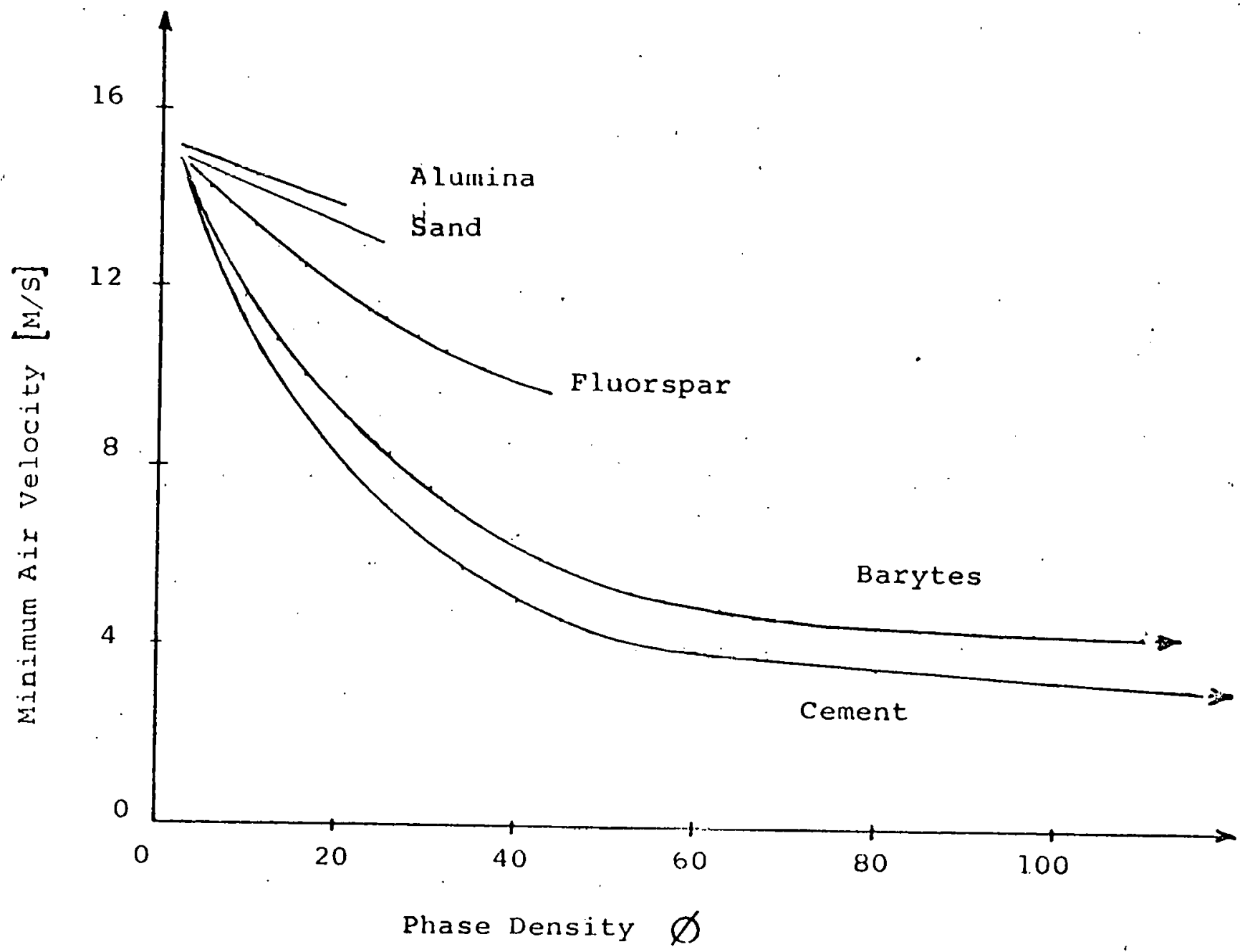

Figure 2.14. Minimum Conveying Air Velocity. 


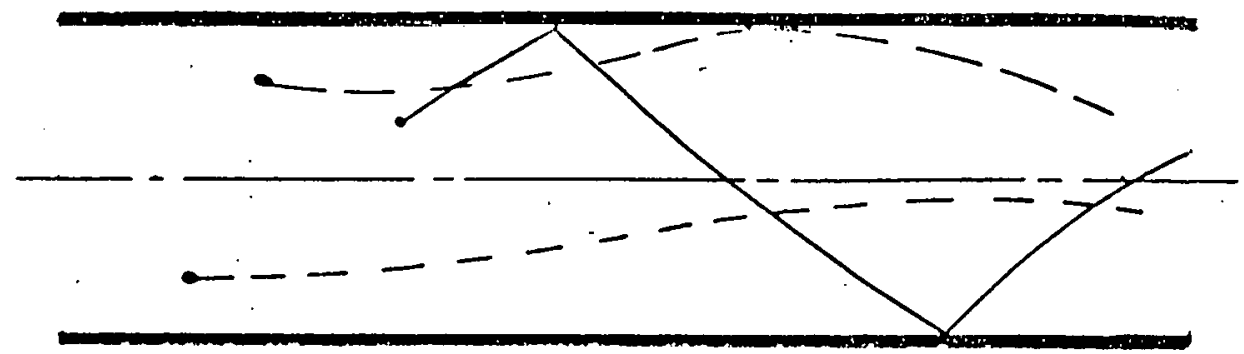

(A)
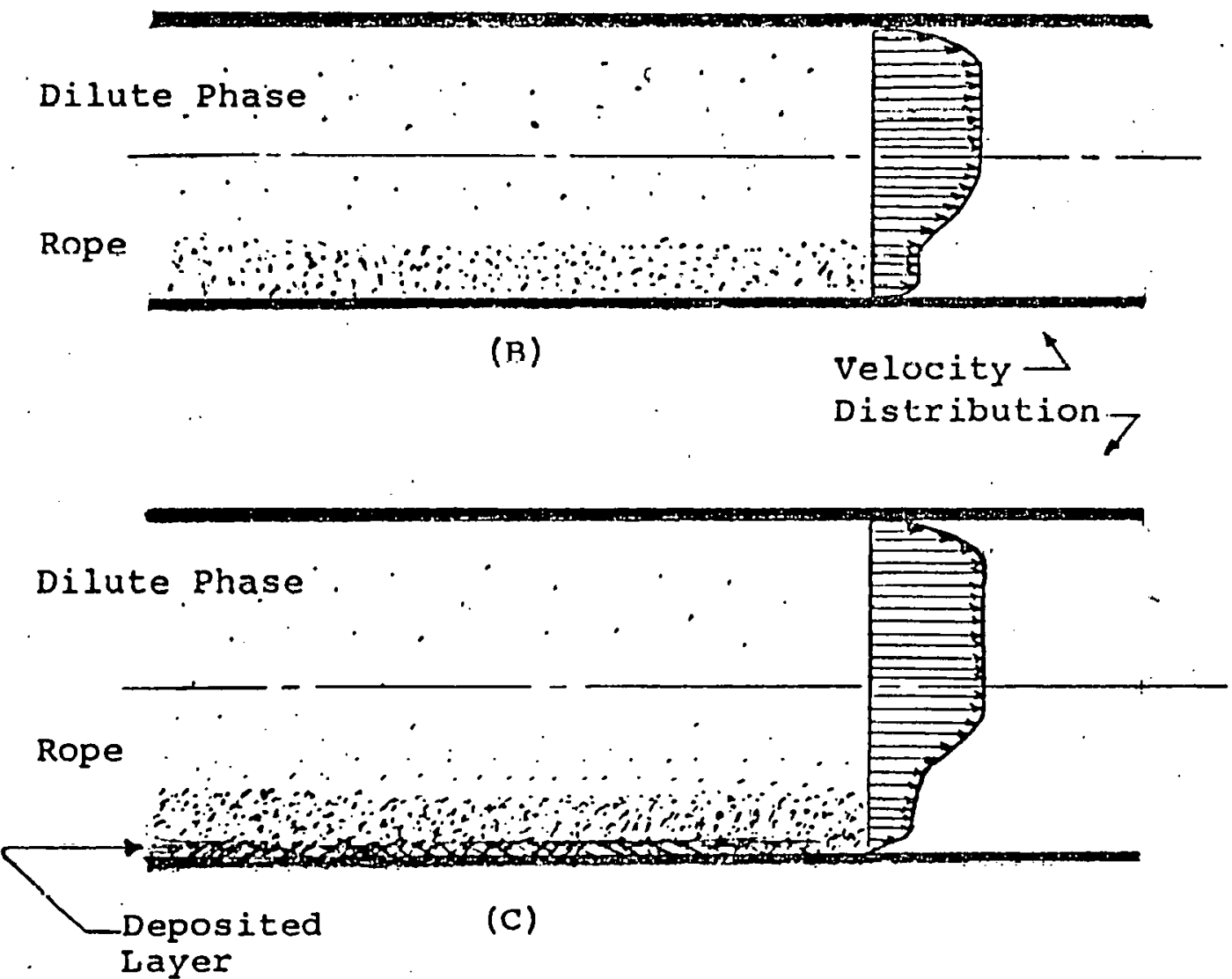

Figure 2.15. Flow Patterns in a Pipe. 


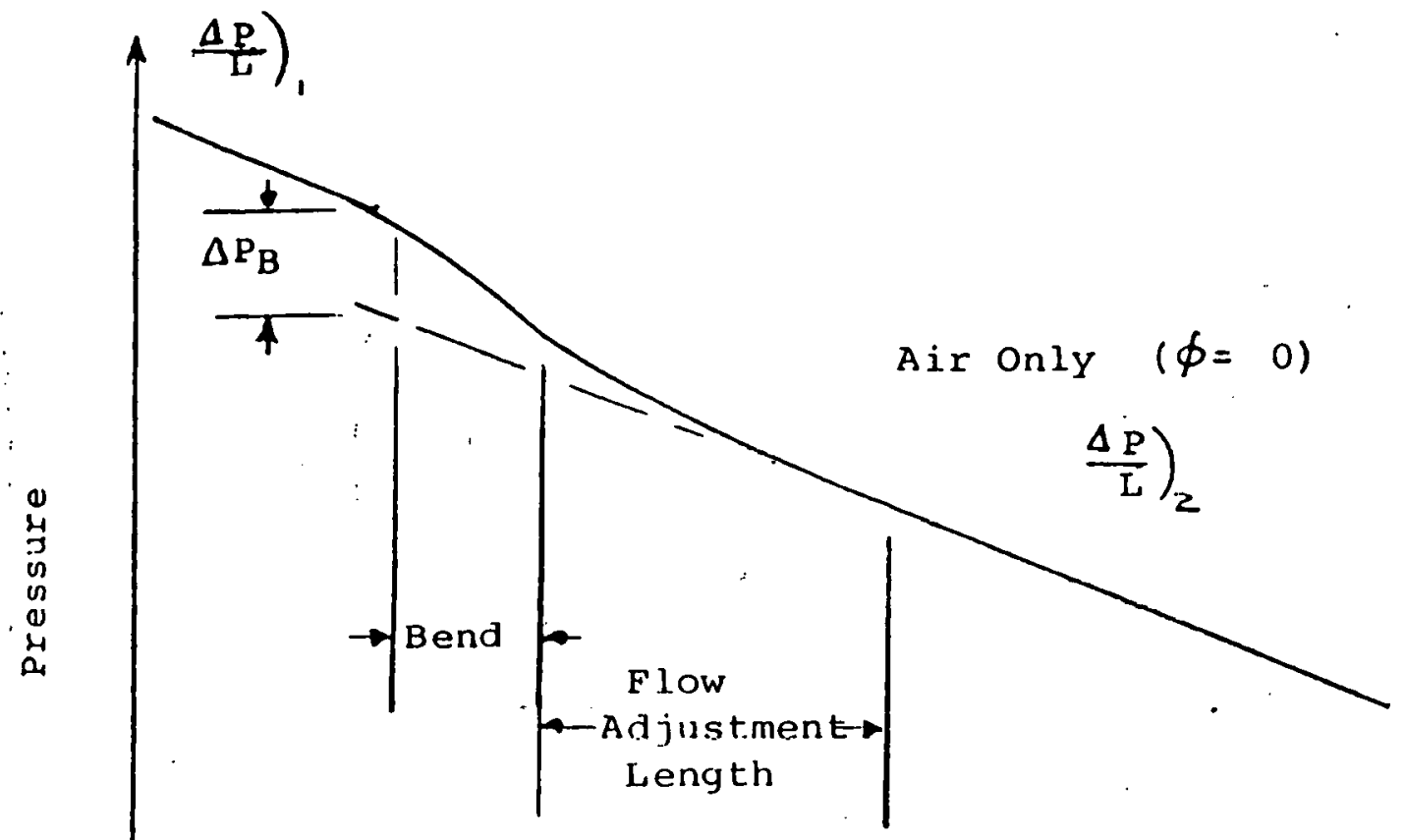

Distance

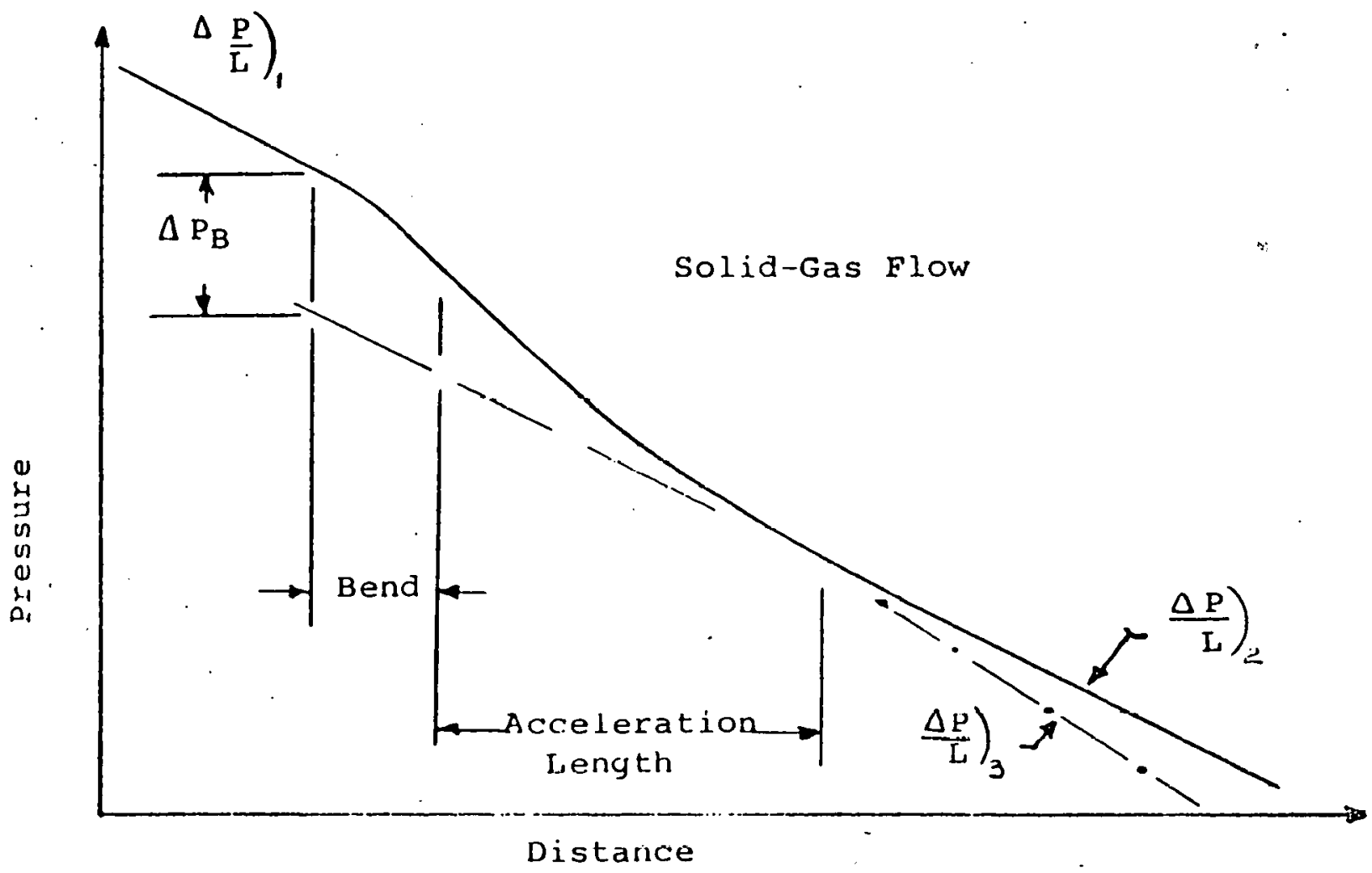

Figure 2.16. Pressure Variation Due to a Bend. 


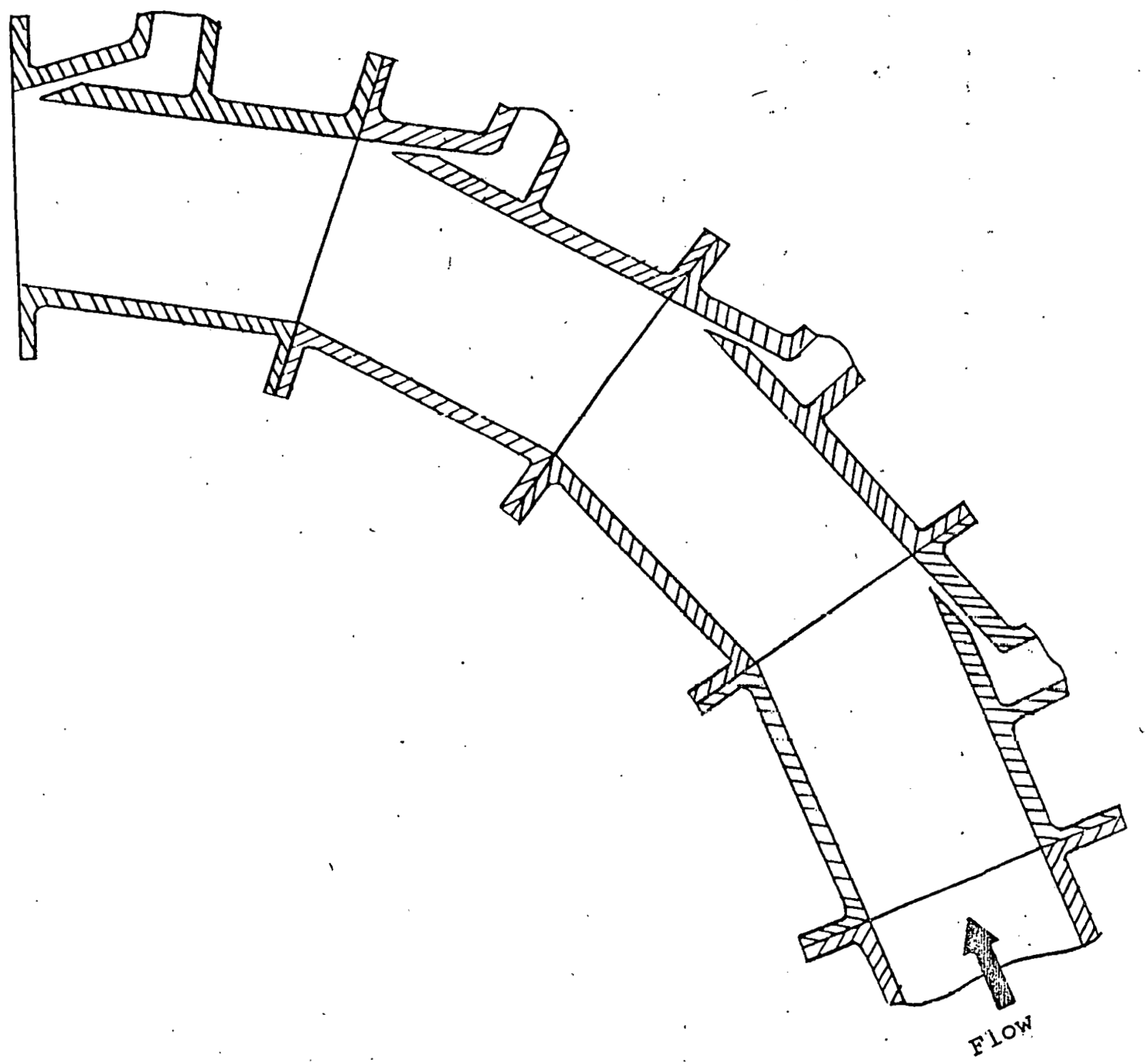

Figure 2.17. Jet Protection Principle, F. Schmidt 1935-1940. 

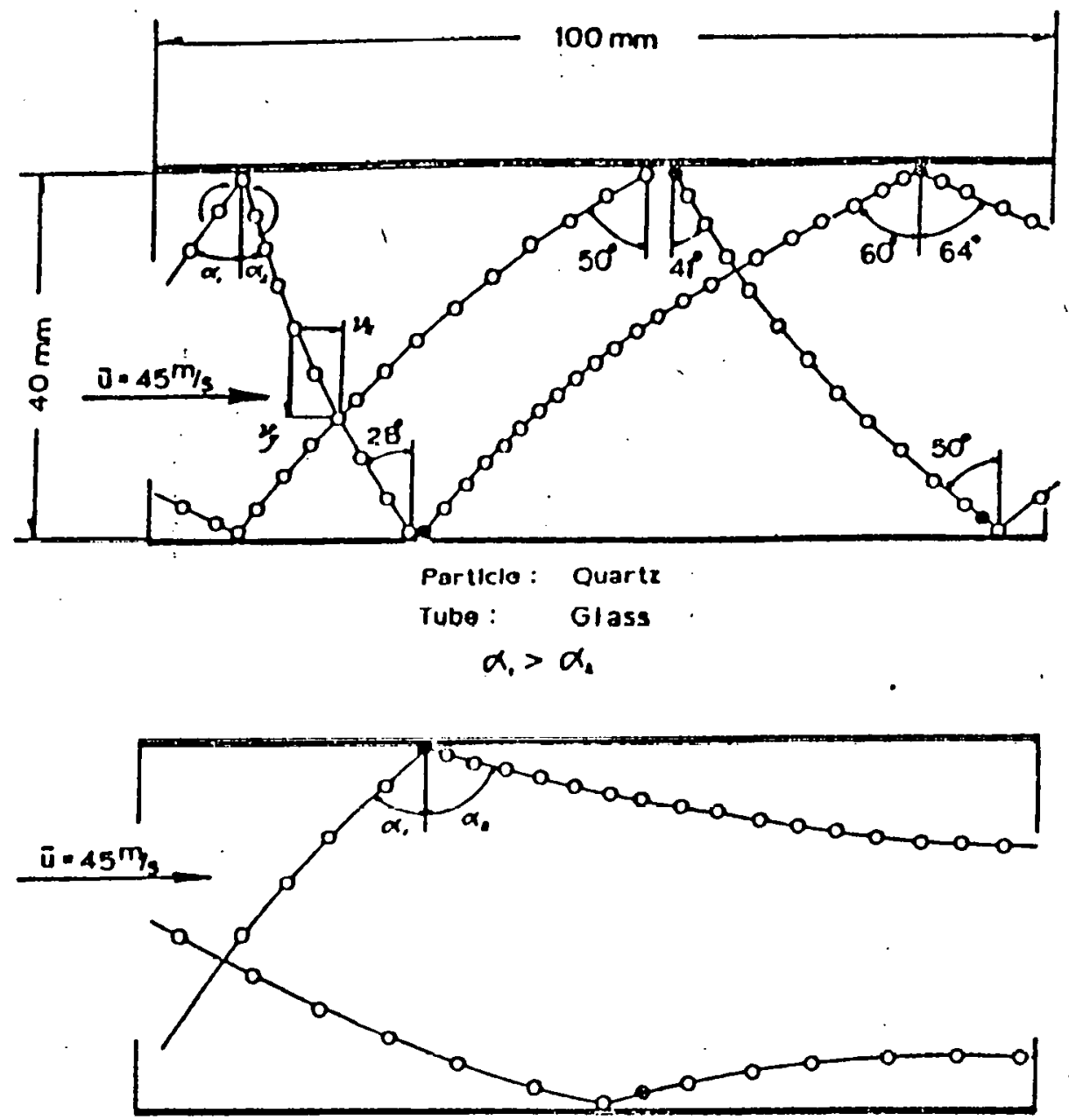

Particle: Limestone

Tubo: Glass

$\alpha_{1}<\alpha_{2}$

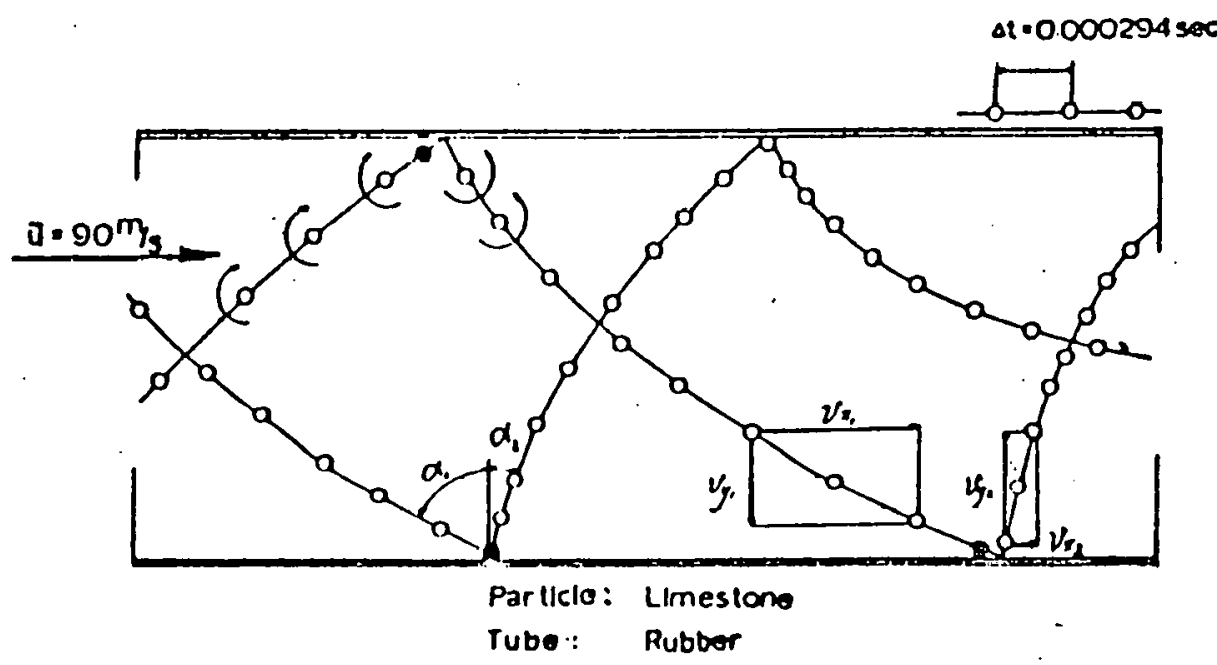

Figure 2.18. Particle Trajectory in a Tube During Pneumatic Transportation ( 3 Meters from Entrance). 


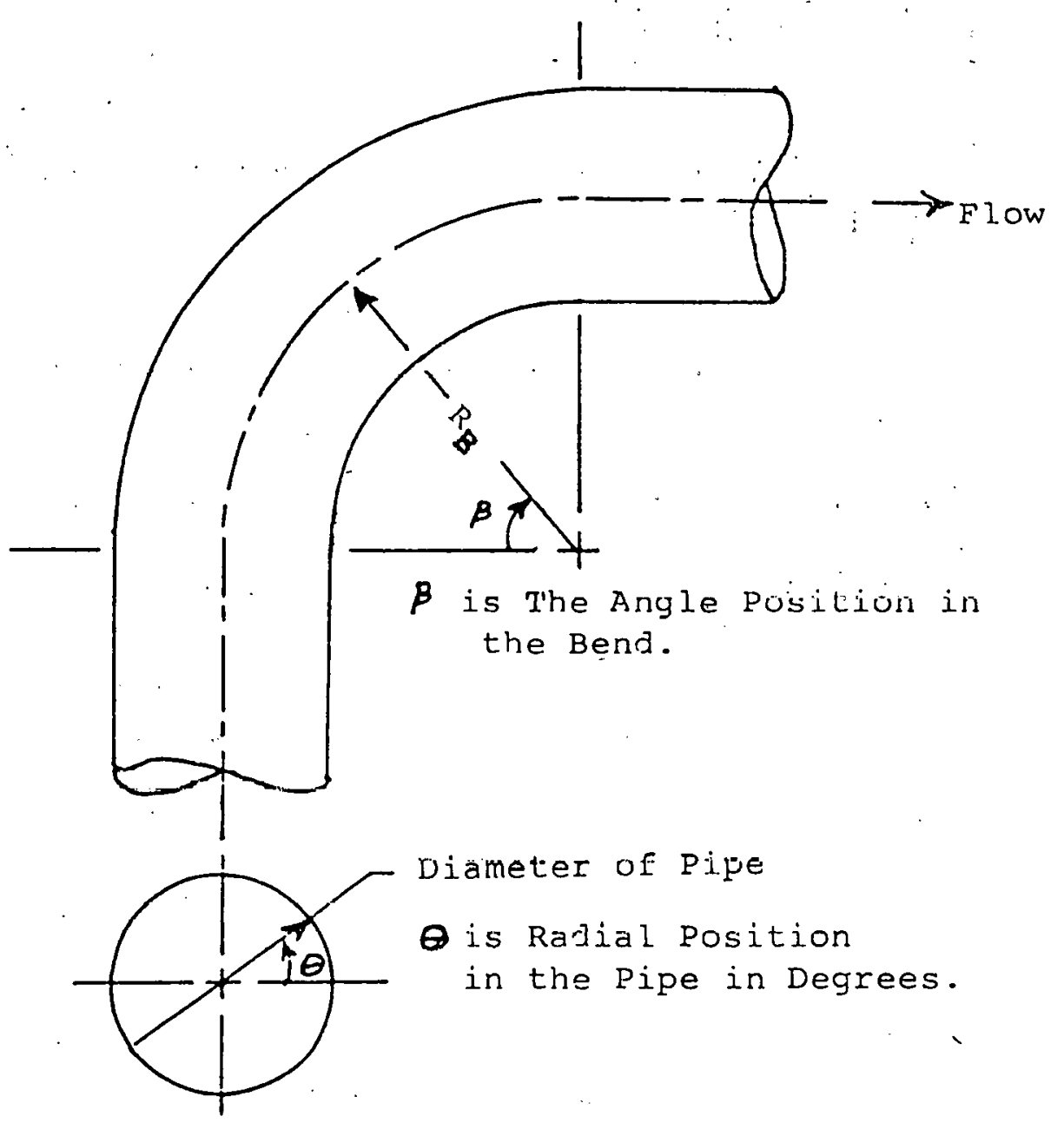

Figure 2.19. Elbow Diagram Illustrating Report Symbols and Terminology. 


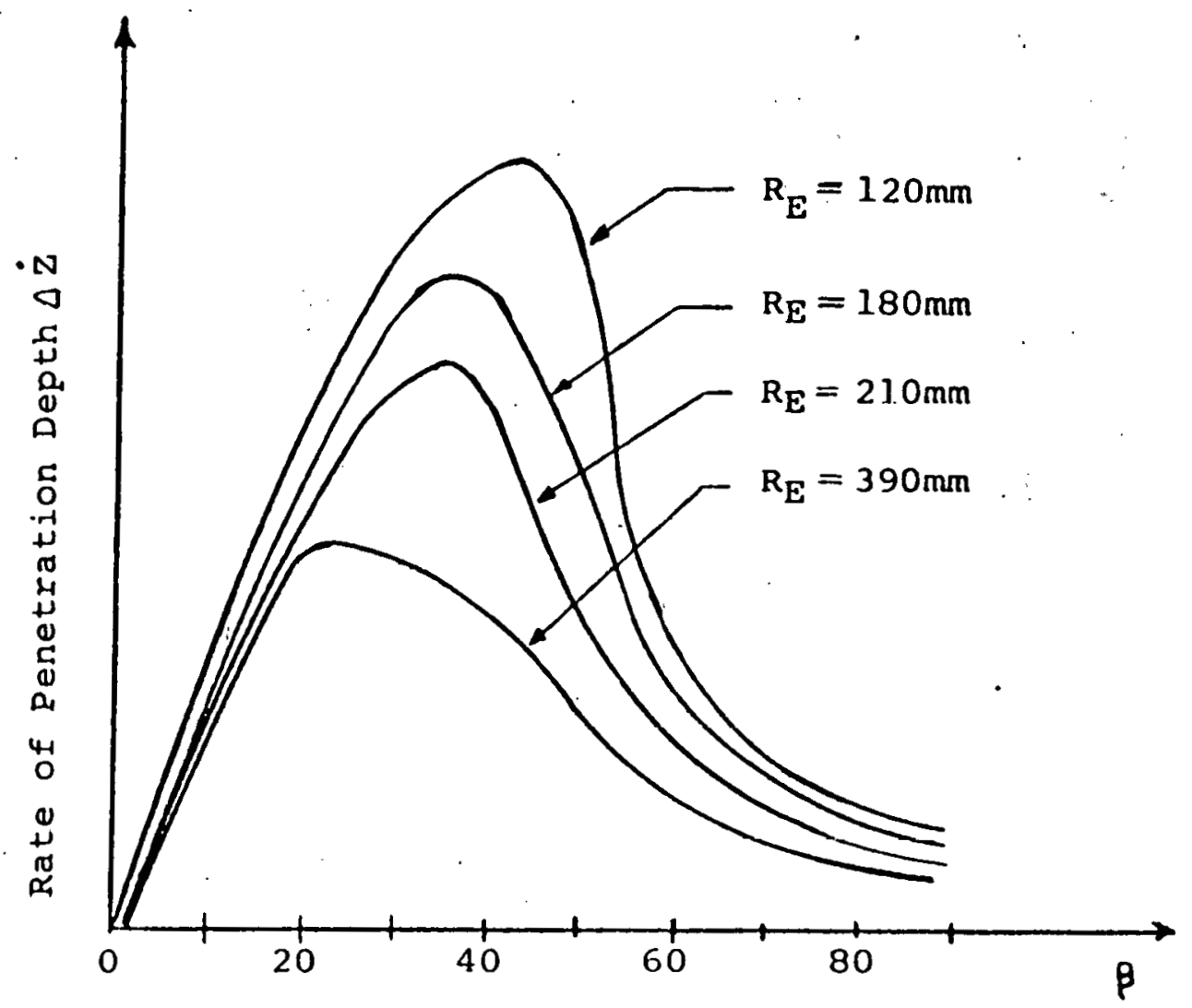

Figure 2.20. Rate of Penetration of Erosion Along the Back Arch of the Elbow as a Function of the Elbow Radius.

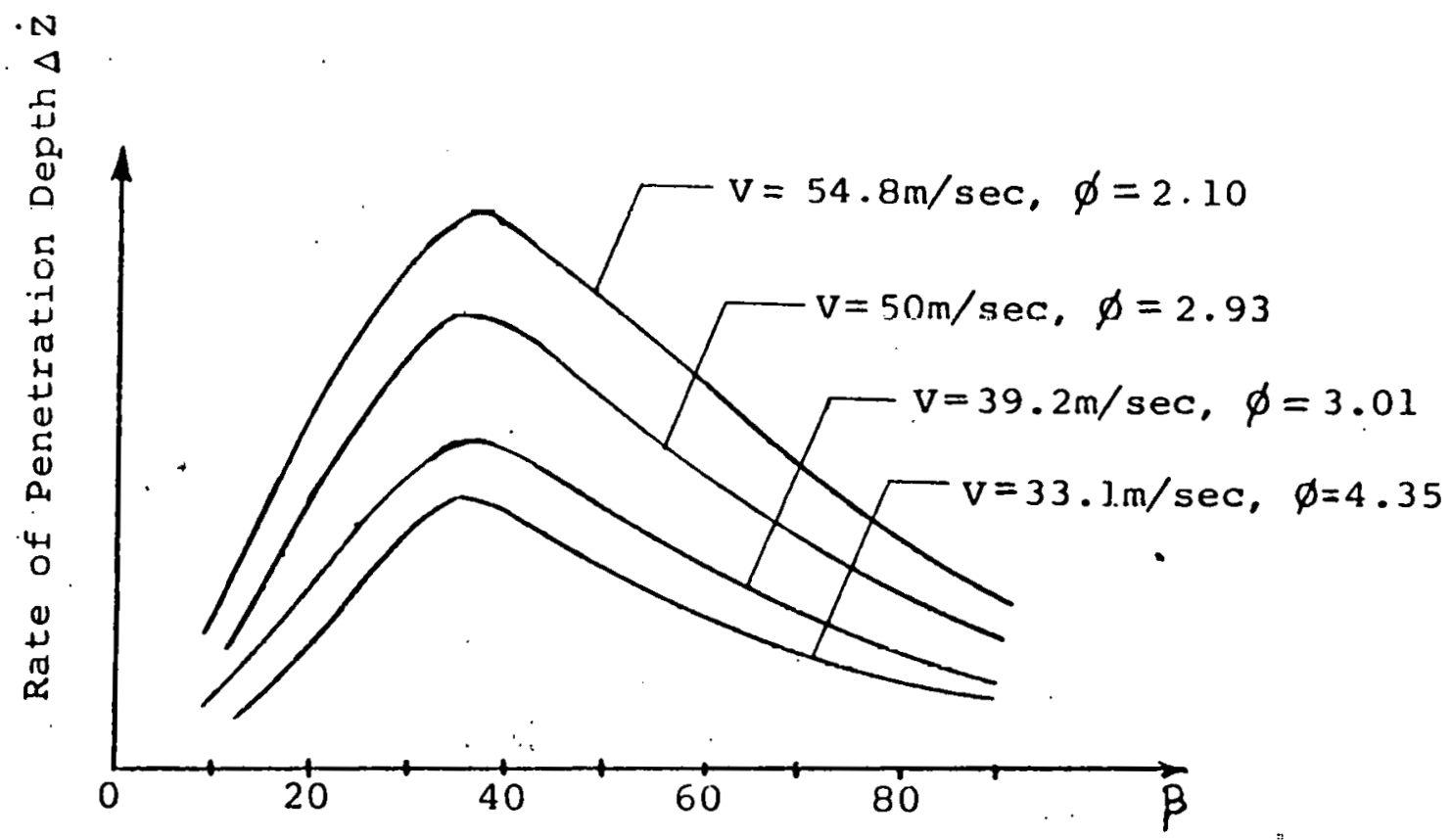

Figure 2.21. Rate of Penetration of Erosion Along the Back Arch $\left(R_{E}=128 \mathrm{~mm}, D=50 \mathrm{~mm}\right)$ Elbow as a Function of Air Velocity. 


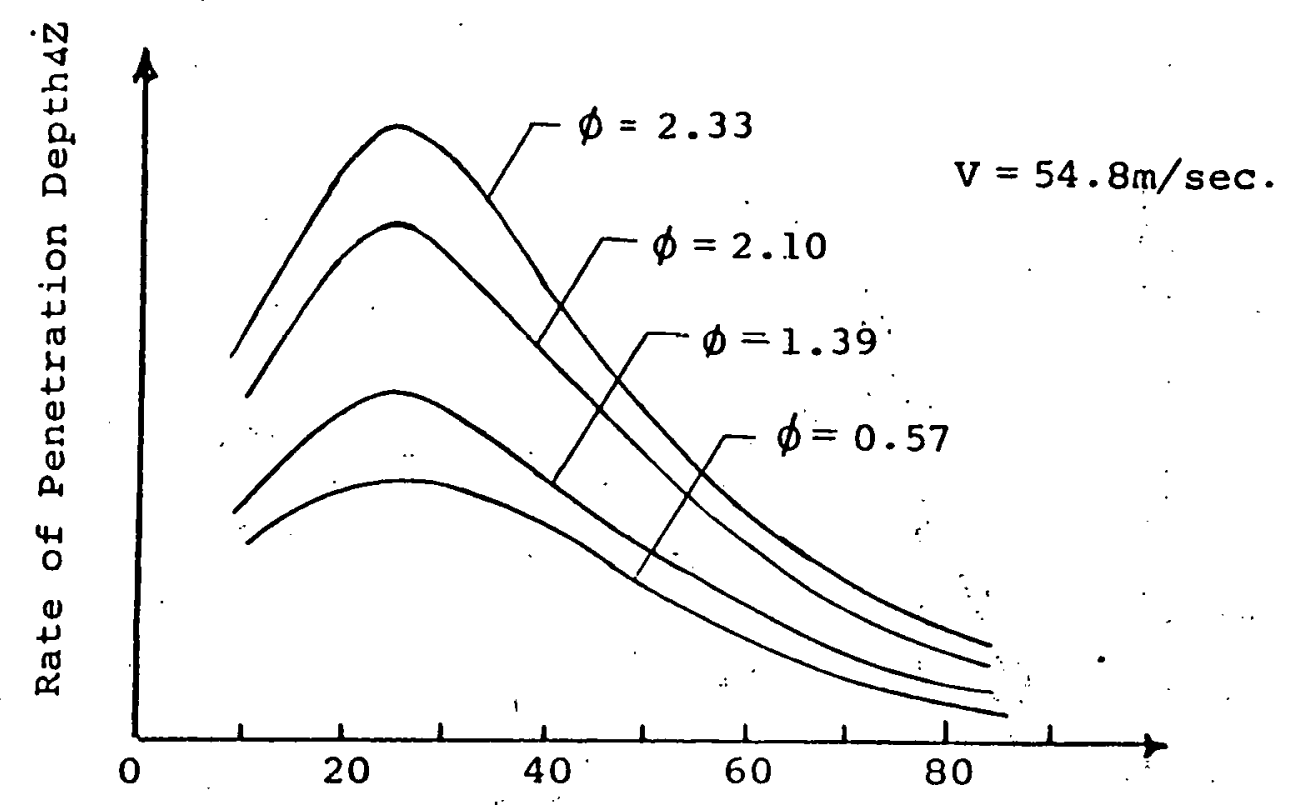

Figure 2.22. Rate of Penetration of Erosion Along the Back Arch of $\mathrm{R}_{\mathrm{E}}=380 \mathrm{~mm}, \mathrm{D}=50 \mathrm{~mm}$ Elbow as a Function of Phase Dêns1ty.

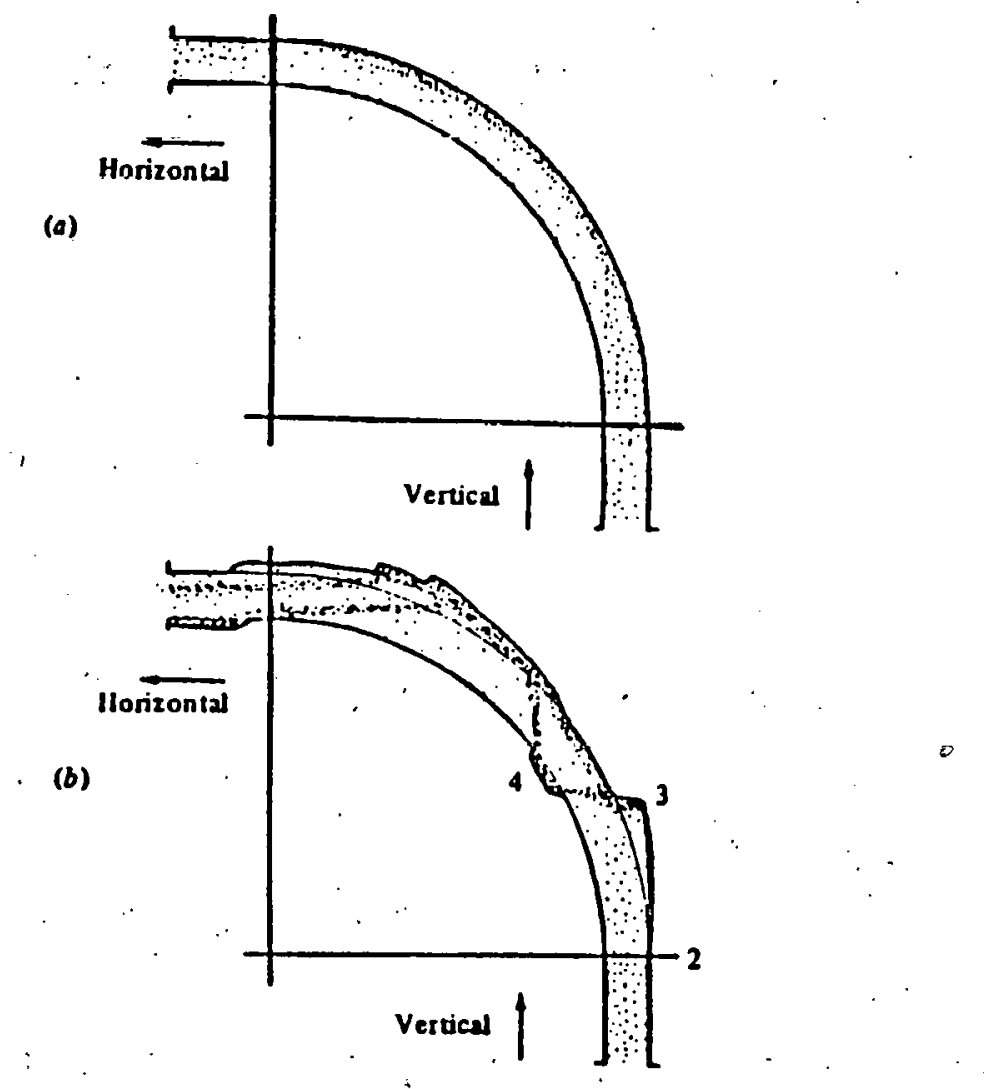

Figure 2.23, Erosion Patterns in a Rectangular Duct. 


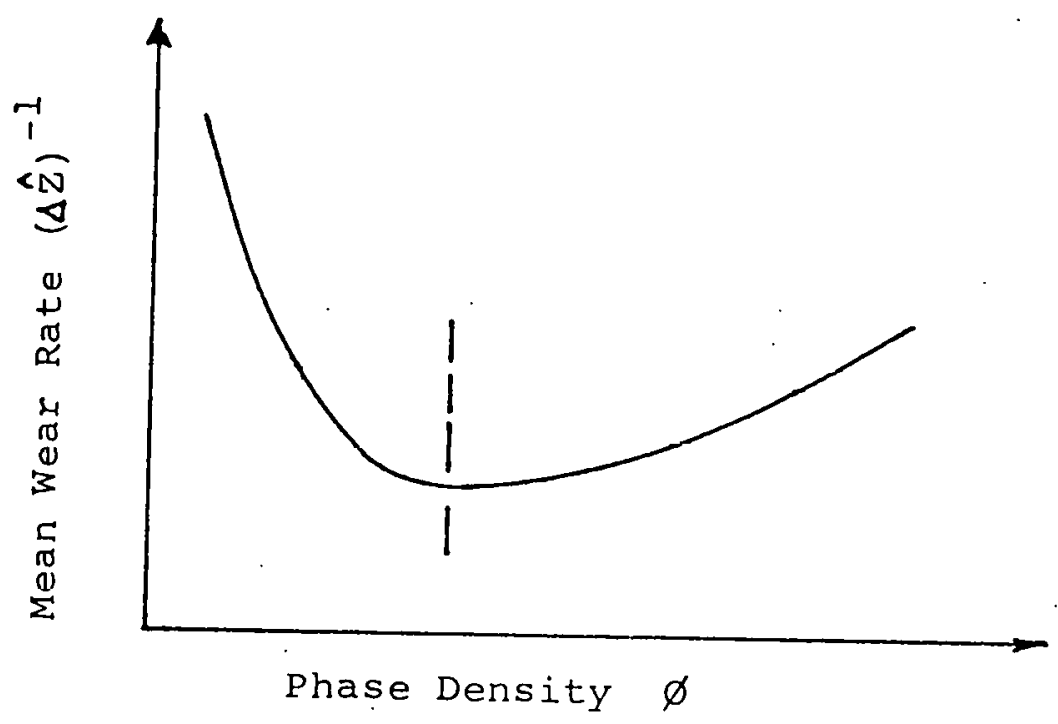

Figure 2.24. Proposed Minimum Mean Wear Rate as a Function of Phase Density. 


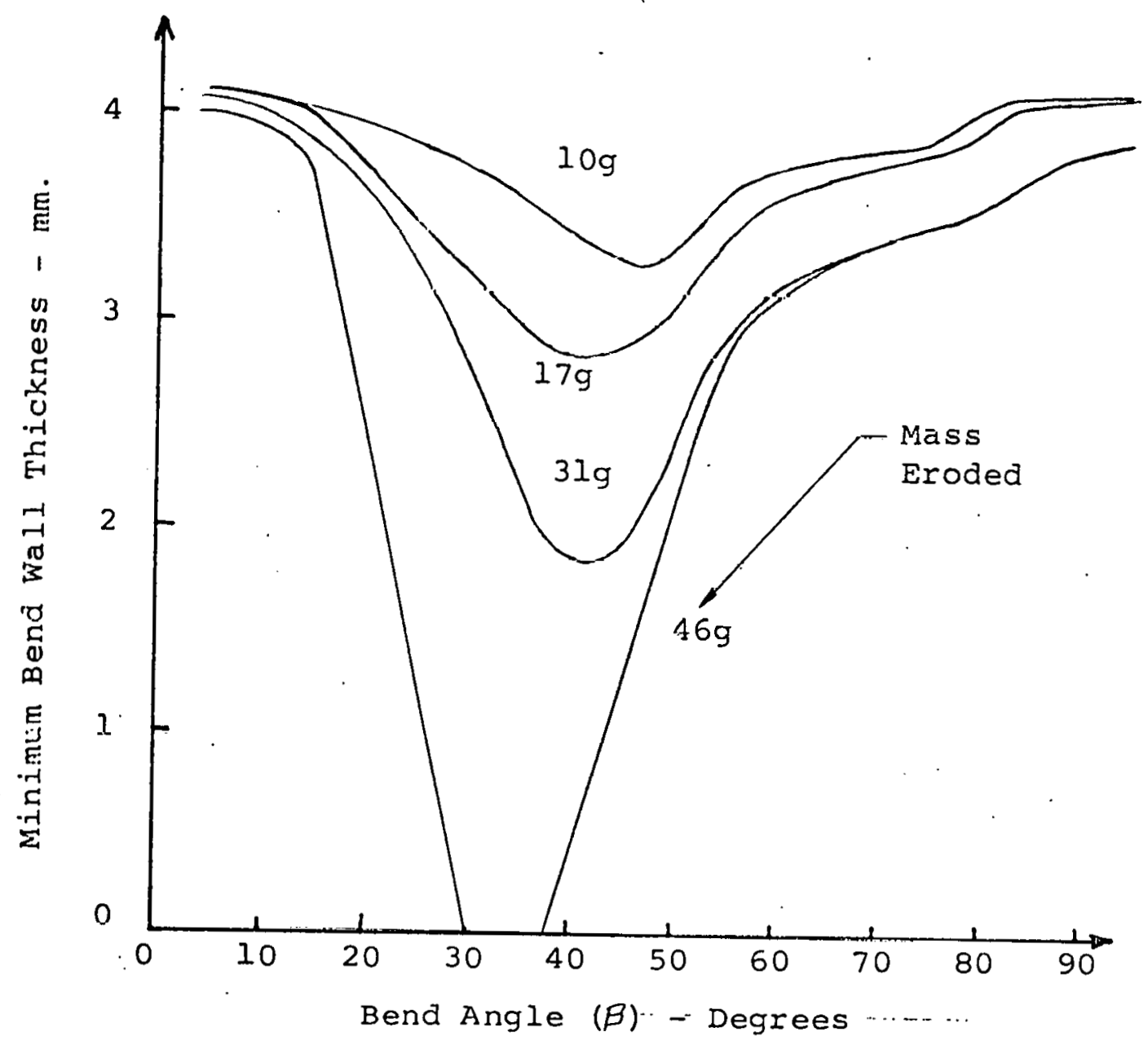

Figure 2.25. Wear Pattern on the Back Arch of the Bend as a Function of Mass Erosion. Phase Density $\phi=3.0$. 


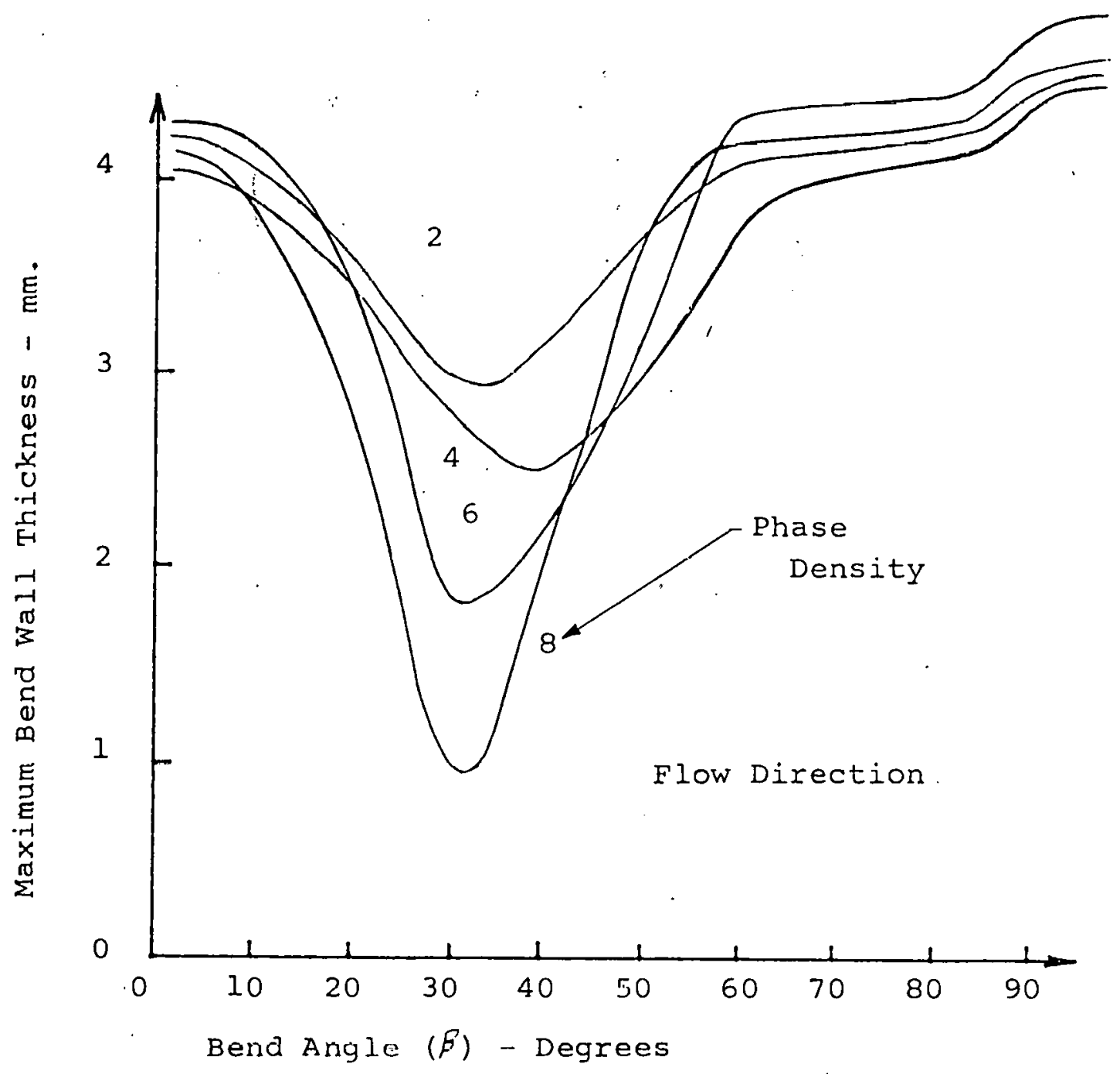

Figure 2.26. Wear Pattern on the Back Arch of the Bend as a Function Phase Density for Constant Mass Erosion of $20 \mathrm{gms}$. 


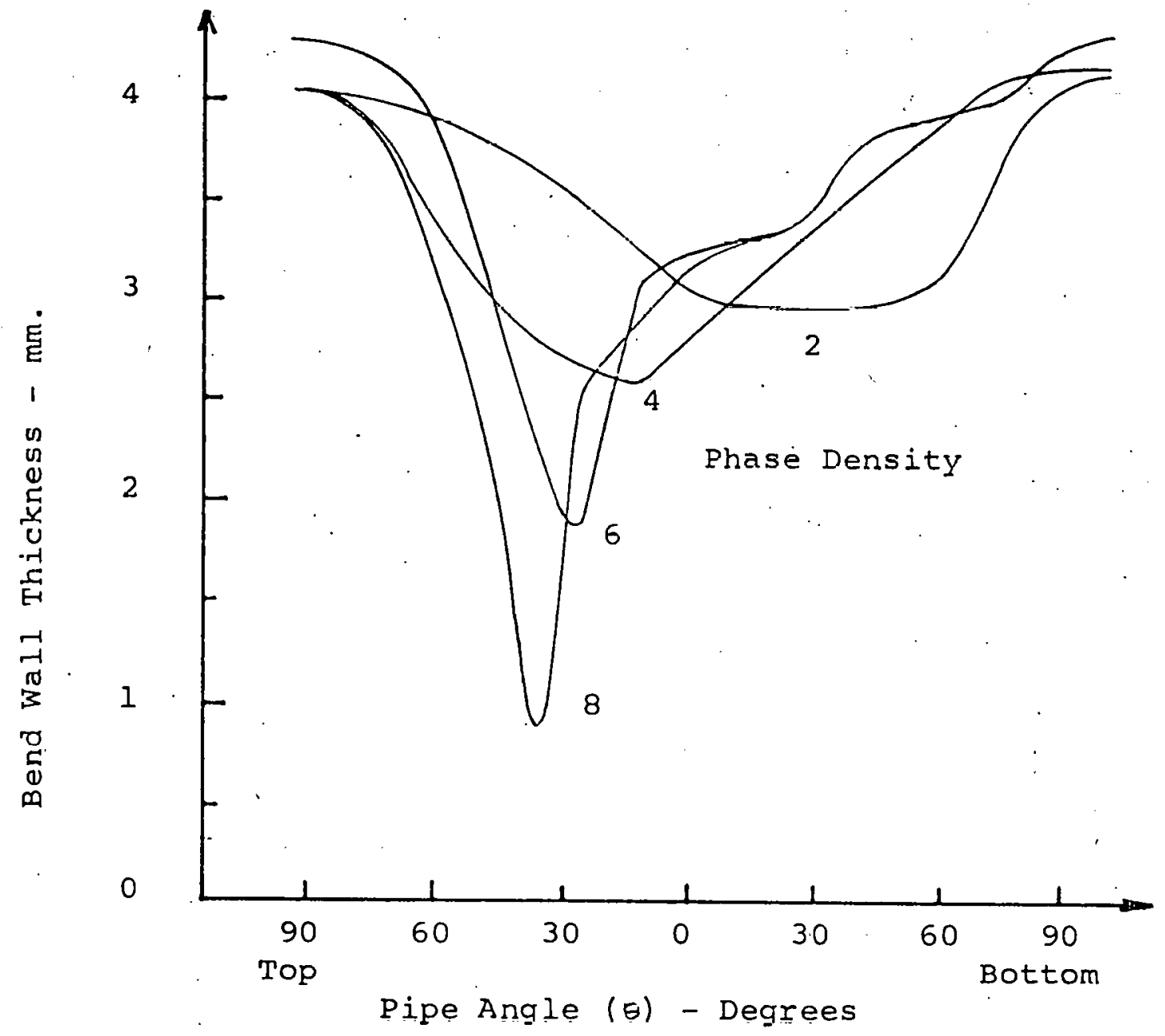

Figure 2.27. Wear Pattern on the Perimeter of $B=33^{\circ}$ as a Function of Phase Density for Constant Mass Erosion of $20 \mathrm{gm}$. 


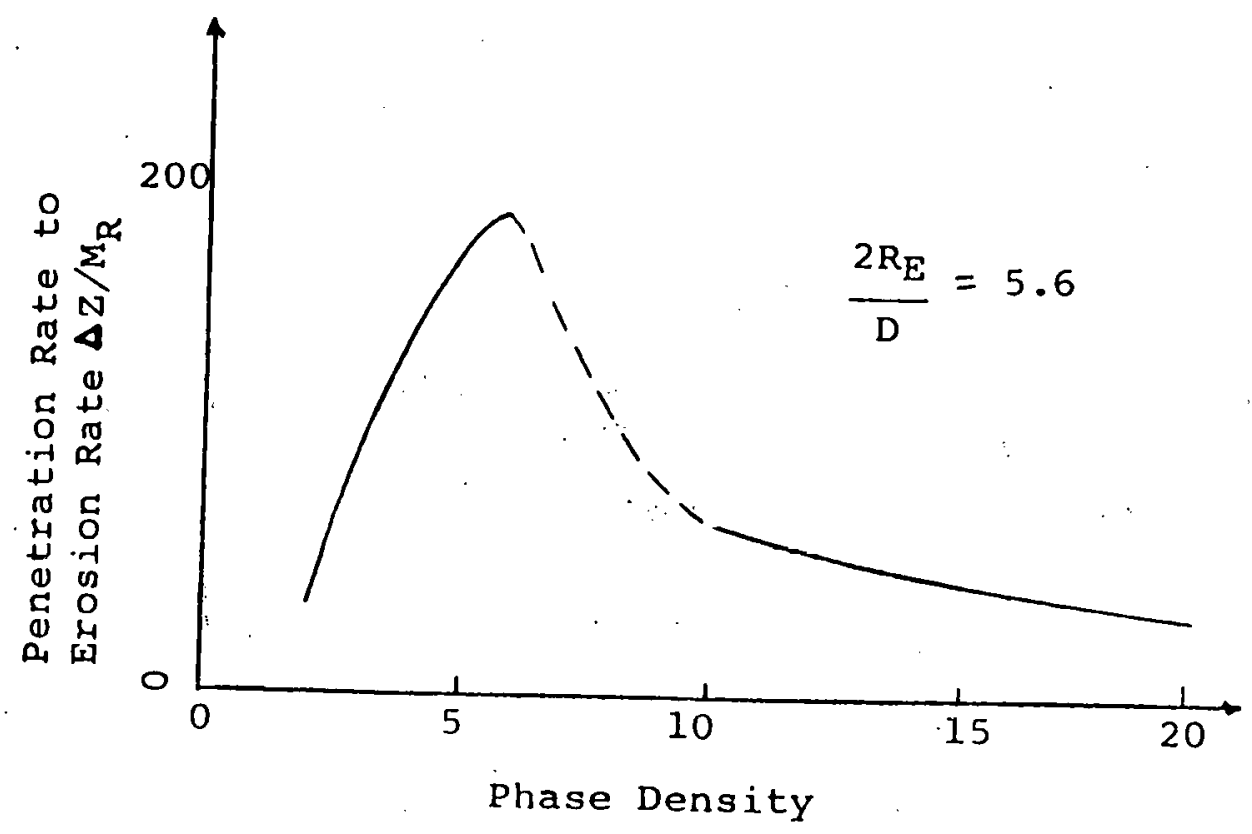

Figure 2.28. Ratio of Penetration to Mass Eroded as a Function of Phase Density.

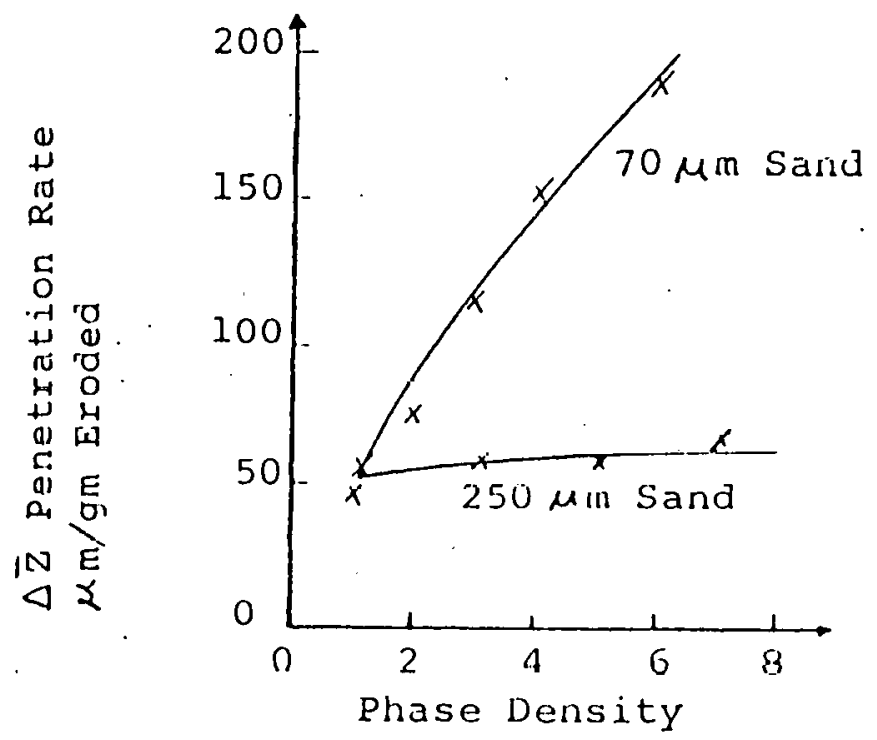

Figure 2.29. Penetration Rate as a Function of Phase Density for Particles at Two Different Sizes. 


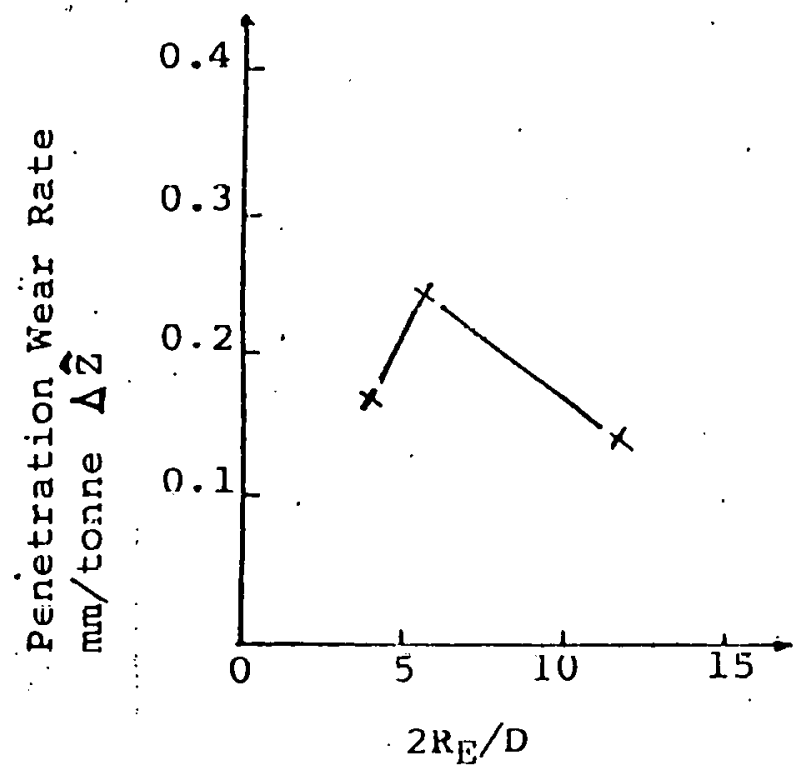

Figure 2.30. Variation of Penetration of Wear as a Function of Elbow Geometry. 


\section{EXPERIMENTAL SYSTEM}

\section{$\underline{3.1 \quad \text { Introduction }}$}

The purpose of the experimental test loop was to evaluate the concept of reducing the erosion rate in bends (elbows) by means of flow-field modification. Thus a test loop was designed in which the bends could be rapidly removed and reinstalled or replaced. In addition, sight glasses were installed upstream and downstream of each bend in order to observe any unexpected flow patterns. As a secondary effort, pressure taps were installed at one-foot intervals downstream of each bend to determine what (if any) effect the flow-field modifications in the bends would have on the overall pressure drop.

The test loop was assembled in the Fluidization Research Center at West Virginia University. The basic test loop is shown in Figure 3.1. Air available for the test loop is 600 SCFM at 15 psig (2 bara). The pipe is 1 \% inch nominal (1.900" O.D. and 1.610" ID) low-carbon steel. The straight sections of pipe before each test bend are 16', 19', 16', and 18' long, corresponding to $\mathrm{L} . \mathrm{D}$ ratios of 128,152 , and 144 . These $\mathrm{L} / \mathrm{D}$ ratios should be sufficient to reestablish the flow field downstream of the feeder and each bend. Provisions were made in the design of the pipe supports to allow for a range of bend radii to be tested. The bend radius selected for Part $I$ was 5 " for a $2 \mathrm{R}_{\mathrm{B}} / \mathrm{D}$ ratio of 6.21 .

A review of the existing pneumatic-transport literature revealed that any attempt to predict the performance of the test loop would be questionable. Consequently, no definite analysis was attempted relating to the pressure drop and the solids flow rate. However, one of the many pressure-drop equations considered suggests that for a superficial air velocity of $80 \mathrm{ft} / \mathrm{sec}$ and a phase density of 10 , the pressure drop in the test loop would be about 12 psi. Thus, it is anticipated that the desired test conditions should be satisfied by this test loop.

\subsection{Test-Loop Design Philosophy}

The test loop contains at least four bends that may be considered acceptable for this erosion study. Initially, the concept of testing four different bend designs in each test run appeared to be feasible. However, upon reviewing the literature, it was found that erosion on several bends in a system was not consistent. To avoid this inconsistency (or scatter of data) only one bend was used in each test run.

Inconsistent rates in bends are apparently caused by the occurrence of ropes in the air-solids flow. These ropes may be either formed or dissipated in bends. To observe these. phenomena and possibly correlate these observations with test data, sight glasses have been installed to observe the flow field upstream and downstream of each test bend. Figure 3.2 illustrates the typical sight-glass installation. If additional flow-field information is required, sight glass sections may be incorporated in the straight pipe sections. 
Pressure taps were placed at one-foot intervals on the straight pipe lengths in order to determine the acceleration length and pressure gradient downstream of each bend. This information is necessary in order to compare the performance of this test loop with those reported in the literature. Data from this test loop has been quite consistent with the data in the literature; thus the test loop was considered capable of testing the new bend designs.

\section{$\underline{3.3 \quad \text { Test-Loop Design }}$}

The basic design of the test loop is shown in Figure 3.1. Solids are loaded into the test loop through the door of the filter assembly. The receiving and feed hoppers have a volume of $15 . \mathrm{ft}^{3}$. The solids in the receiving hopper flow to the feed hopper through the ball valve. Facility air, 600 SCFM at 15 psig, enters the system through the system inlet valve and passes through a flow meter, across a temperature probe and through a pressure regulator. In addition to being the transport medium, the air pressurizes the feed hopper and the solids-feed system.

Solids travel from the feed hopper, down an inclined passage (Figure 3.3), and into the solids feed port assembly, (Figure 3.4.) Air injection is used to move the solids into the primary air flow where the solids are entrained in the flow. The solids-gas mixture then flows through the test loop. The test run completed, the solids are deposited in the receiving hopper, and the transport air, along with the air from the test bend, are passed through an air filter. The clean air is then sent into the atmosphere. The solins that accumulated in the filter were extremely fine and were consequently removed from the test loop.

\section{$\underline{3.4 \quad \text { Instrumentation }}$}

The basic quantities relevant to this project are the erosion rates, both mass loss and penetration depth and the conditions which produced these erosion rates. The conditions producing the erosion in these tests are basically the phase density, gas (air) velocity, test bend design and operation, and the characteristics of the solids.

The erosion rate was primarily determined by the changing mass of the test bend. These measurements were made by an Ohaus 5000 gram scale. Penetration depths were measured, when possible, by employing a specially designed micrometer (see Figure 3.5). Unfortunately, the air jet attachments to the test bends frequently interfered with these measurements. An ultrasonic thickness gage was initially to be employed; however, the surface roughness of the unaltered bends made it difficult to obtain consistent readings. The ultrasonic thickness gage would also have been limited to surfaces that were not modified by attachments to the bend.

To analyze the experimental data, the air-flow rate and velocity measurements taken from just upstream of the solids feeder were used. Normally the necessary information for determining these conditions could be determined by measurements at either the air inlet or downstream of the exhaust filter; however, air was being injected into the test loop through the test bends, so, the exhaust air-flow rates were not the air-flow rates upstream of the solids feeder. Therefore, the air-flow rate into the system 
and the air-flow rate to each test bend was measured, and the sum was compared to the measured exhaust flow rates. The air-flow meter into the system was a vortex flow meter. The flow of air to each bend was measured by a rotameter, and the exhaust air-flow rate was initially checked by a turbine flow meter.

The flow rate of solids was to be measured by two methods: 1) the Micro Motion(R) flow meter, and $a$ load-cell to determine the mass rate of accumulation of solids in the receiving hopper. Although the load-cell method was more accurate, the Micro Motion $(R)$ meter would have been more convenient to use during a test. However, after discussions with Micro Motion(R) meter representatives and engineers at the Pittsburgh Energy Technology Center, it appeared that the present models of the Micro Motion $(\mathrm{R})$ meter were not applicable to the range of conditions to be employed in this project. Thus the load-cell method was the only method used in the initial set of experiments. If needed, a more refined solids flow rate measuring technique would be developed for the final tests.

The load-cell measurement system is shown in Figure 3.6. The receiving hopper, with attached vent/fill pipe, is designed to hang from a center mount support. The flexible inlet-flow line and solids outflow line presented only small, insignificant, forces. The system was calibrated and repeatability of readings was assured.

Pressure taps were installed at one-foot intervals on the straight sections of the test loop. Although many pressure taps would significantly increase the roughness of the pipe, experience has shown that air-solid flows smooth the pipe roughness. A typical pressure tap assembly is shown in Figure 3.7. The steel wool acted as a filter, so a sand trap was not required. The Tygon pressure tubing extended from the pressure tap, to the instrument cubical, down the front of a graph-paper-covered panel, and finally attached to a manometer-fluid manifold. That portion of the tubing used as a manometer is shown in Figure 3.8. The bank of manometer tubes shown in the figure represents a section of the loop. Thus, the total pressure drop for the section of the loop was observed as well as the variation of pressure along that section.

A summary of the instrumentation employed in Part 1 of this project, and its associated accuracy, is listed in Table $3-1$. 
Table 3-1

\section{Instrumentation}

Main air flow:

Omega vortex flow meter (volumetric flow meter)

$1 \%$ accuracy

0.2 repeatability

Fluctuation during steady state operation

\pm 20 counts out of $10,000( \pm 0.12 \mathrm{ft} / \mathrm{sec})$

Solids flow:

Sensotec $1000 \mathrm{lb}$. capacity rod end load cell

$\pm 0.1 \%$ accuracy

0.1 lb. readability

Fluctuation during steady state operation

\pm 0.1 1b. 99 percent of time

$\pm 0.3 \mathrm{lb} .1$ percent of time

Elbow thickness measurement:

Specially made micrometer

\pm 0.001 inch readability

* 0.001 inch repeatability

Elbow marking system

Permanent marker

Marked at $5^{\circ}$ intervals

$\pm 1^{\circ}$ error in marking system

Elbow weight measurement:

Ohaus $5000 \mathrm{gm}$ scale

$0.1 \mathrm{gm}$ readability

$\pm 0.1 \mathrm{gm}$ repeatability

Elbow jet flow measurement:

Various Dwyer rotameters

$0.5 \%$ repeatability

Fluctuation during steady state operation

$\pm 2.5 \%$ of full scale

Main air flow temperature measurement:

Fisher scientific $0-100^{\circ} \mathrm{C}$ thermometer

$0.5^{\circ} \mathrm{C}$ readability

Main air flow inlet pressure measurement:

Ashcroft $0-50 \mathrm{psi}$ test gauge

0.25 psi readability 


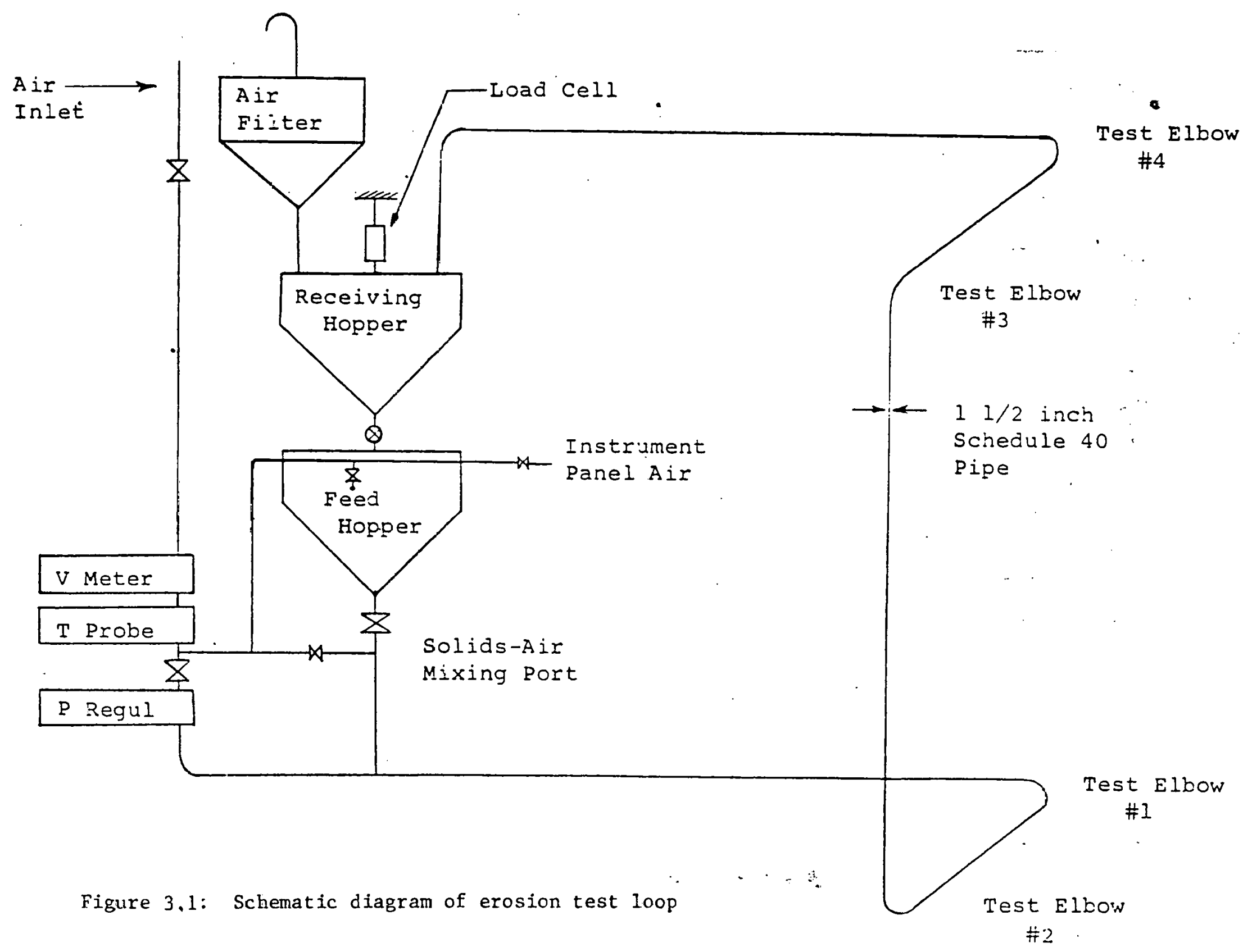

$\because$ 


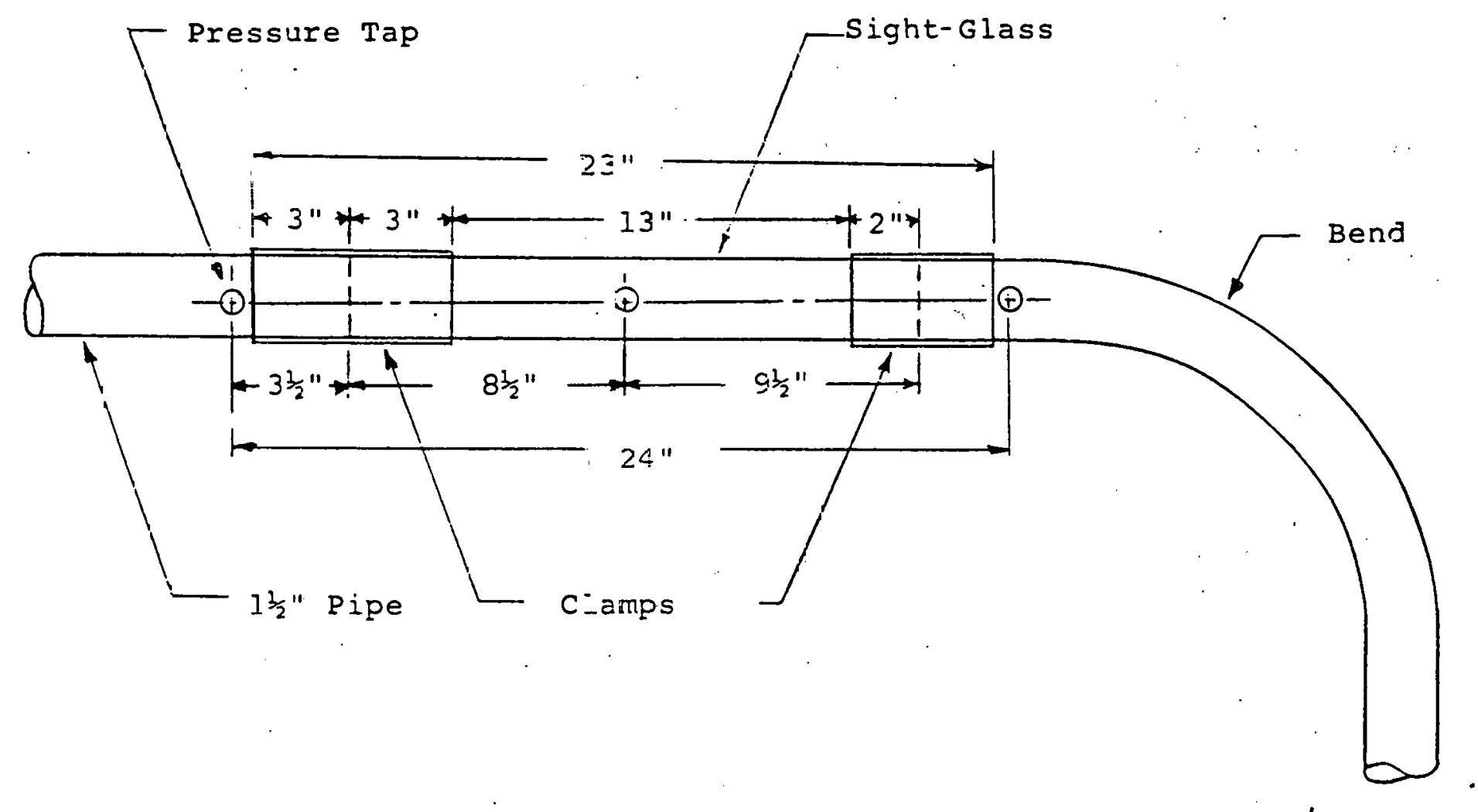

Figure 3.2: Sight-Glass Installation 

2 Inch ball
$\vdots$
Feed Hopper
Presgurizing Port

Feed Hopper
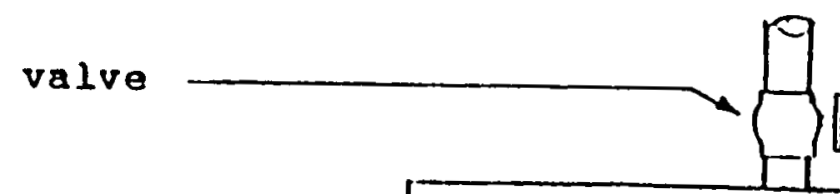

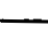

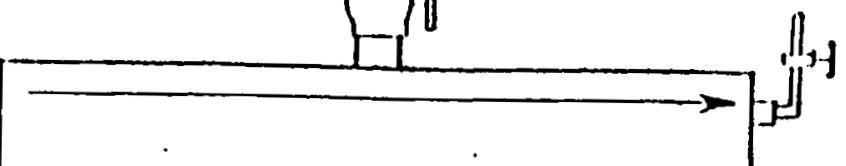

6 inch by 4 inch reducer

4 inch by 2 inch reducer

2 inch 45 elbow

If Inch oight glaso

Pipe support

Pipe clamp

1' fnch gate valve

1 Inch copper tube

solids feed port
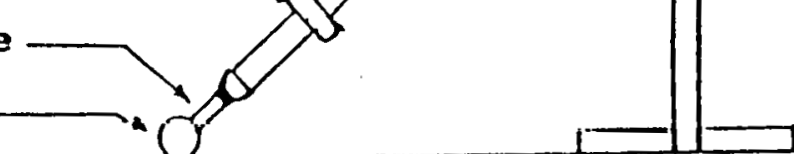

Figure 3.3: Solids feed assremb]y 


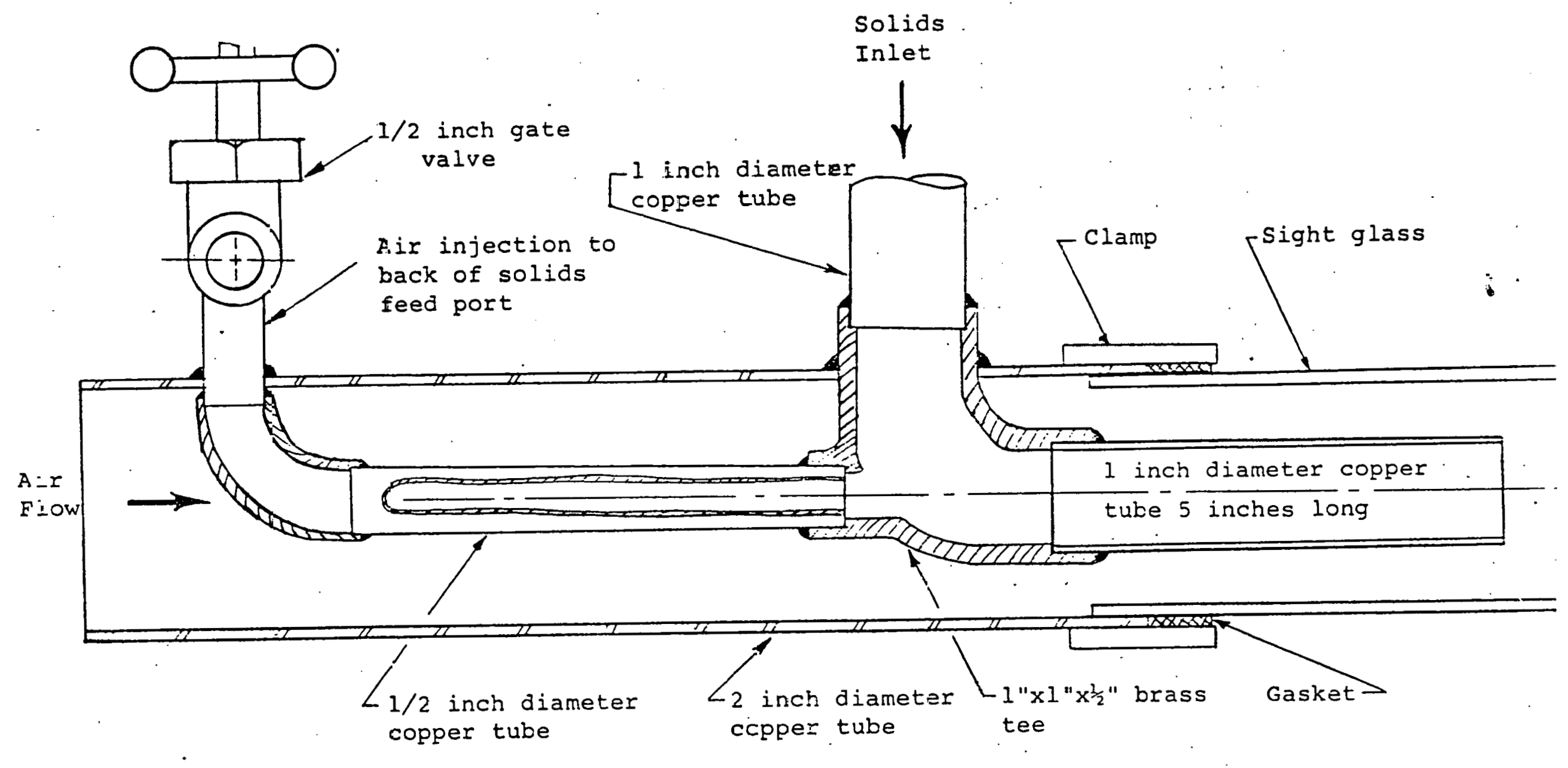

Figure 3.4: Solids feed port assembly 


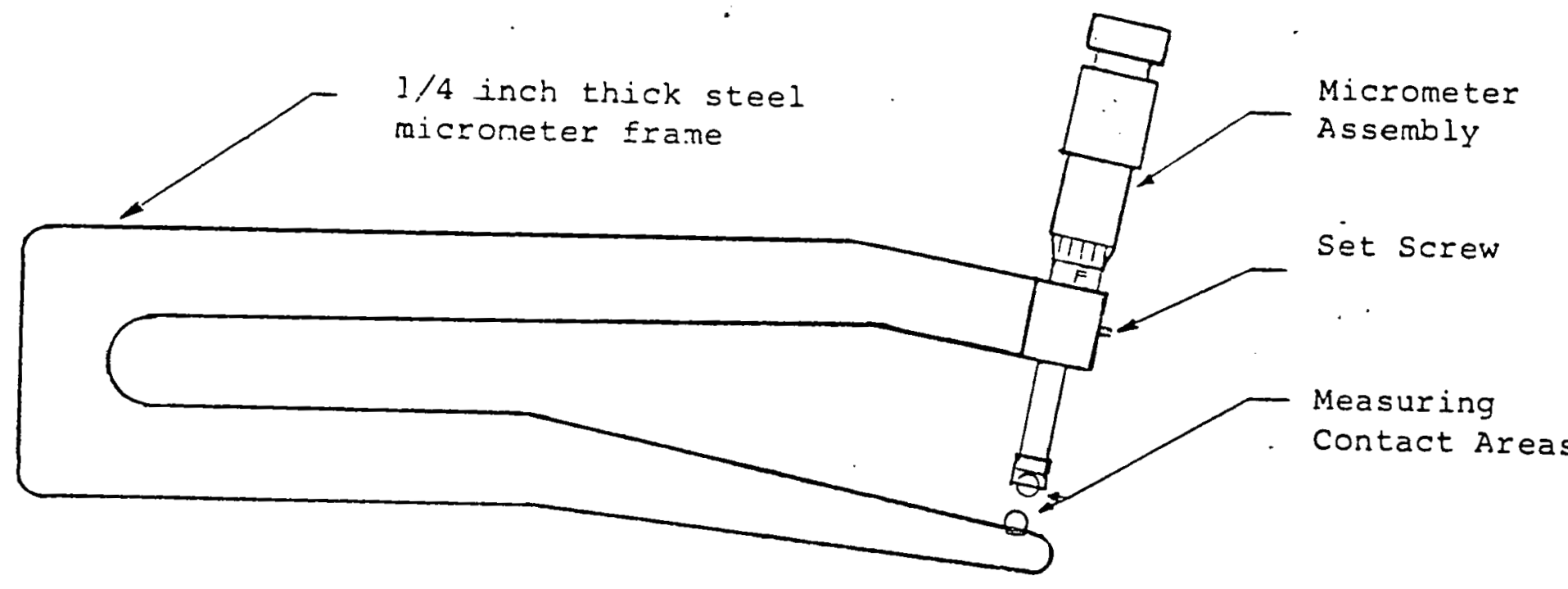

Figure 3.5: Micrometer for Measuring Elbow Wall Thickness 


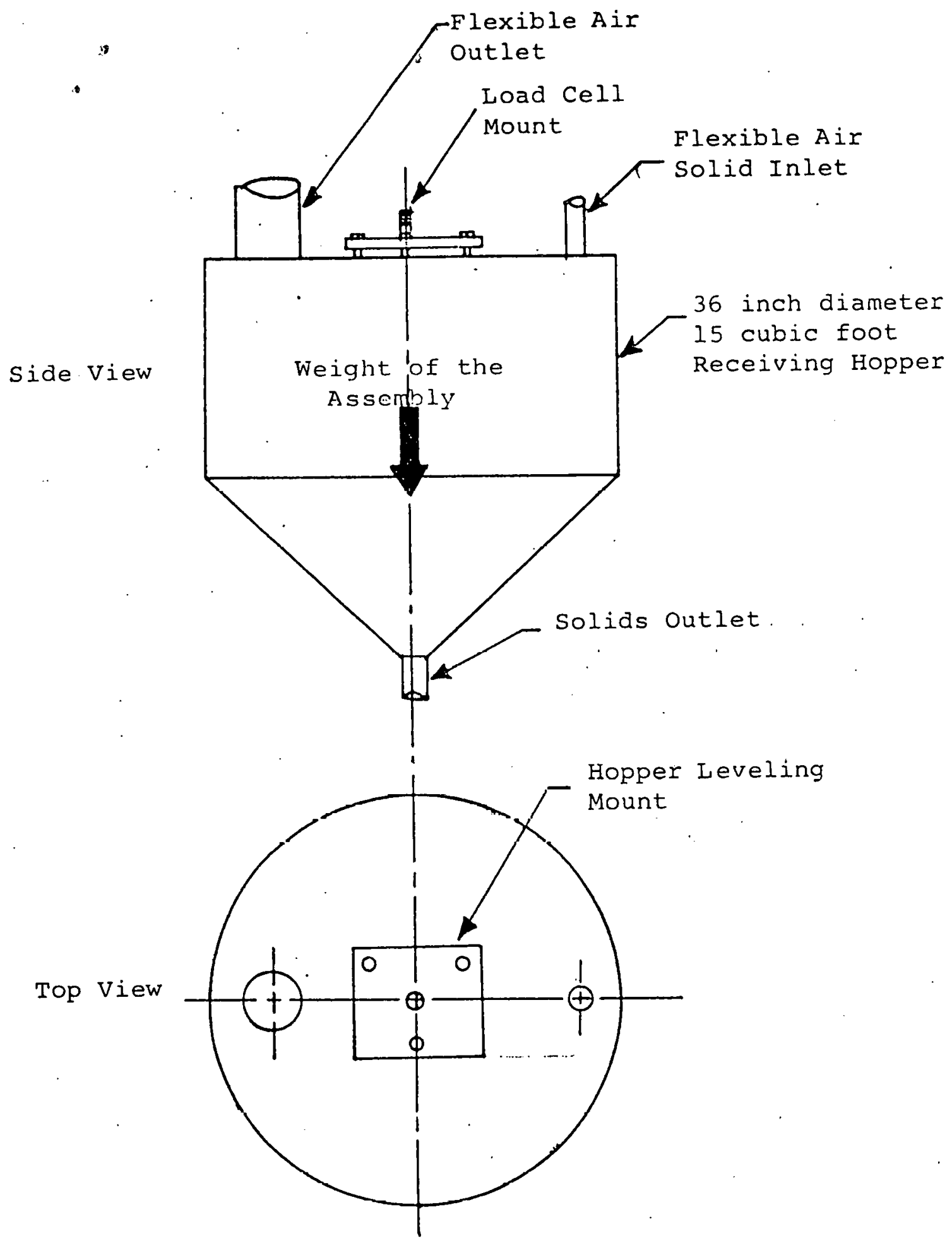

Figure 3.6: Receiving hopper with load cell mount, 


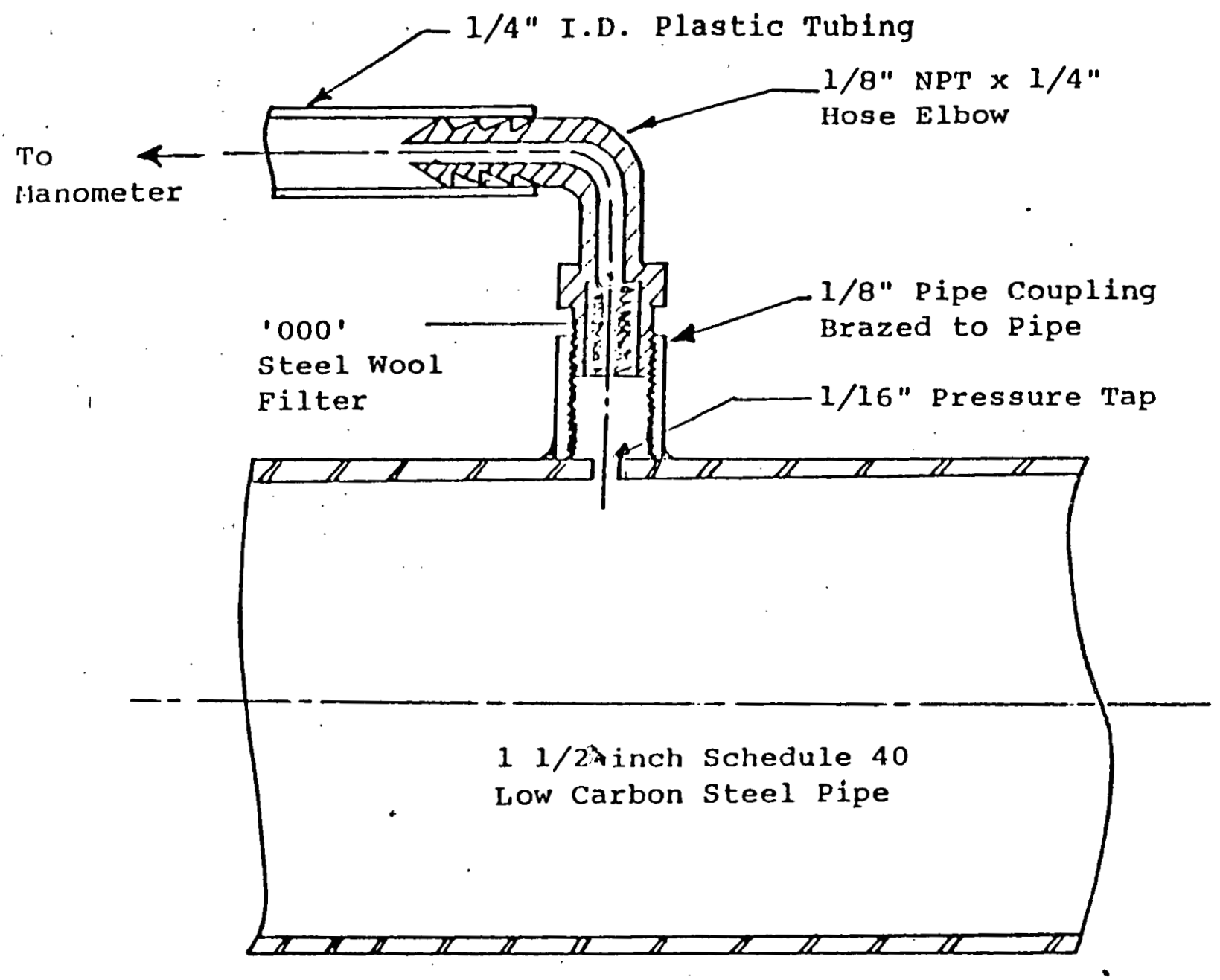

Figure 3.7: Pressure Tap Assembly 
TO PIPE PRESSURE TAPS

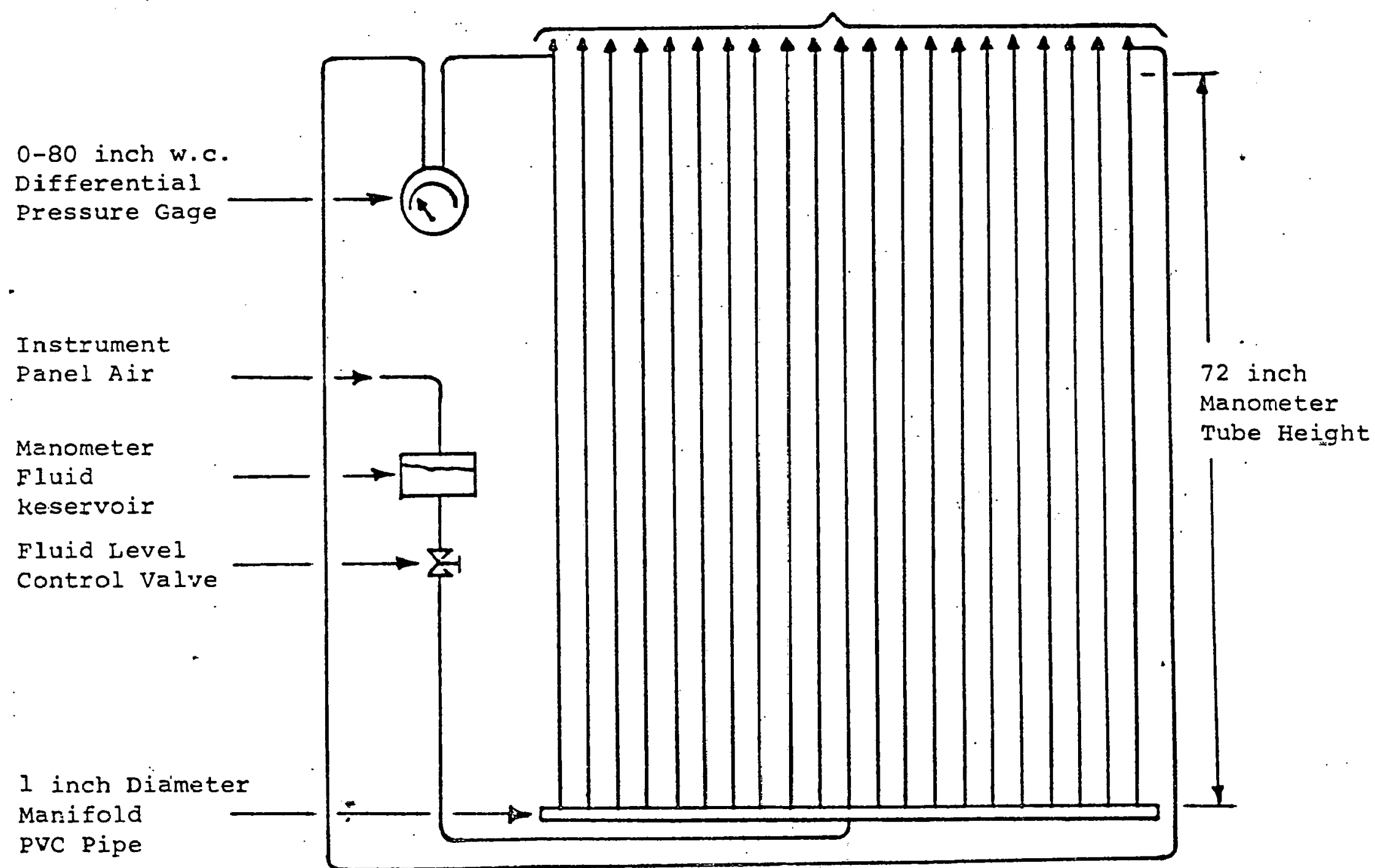

Figure 3.8: Differential Pressure Marometer with Adjustable Fluid Level 


\section{PROCEDURE AND DATA REDUCTION}

\section{$\underline{4.1 \text { Introduction }}$}

The objective of this experimental study was to determine the feasibility of modifying the flow field in bends in order to reduce the erosion rate due to gas-solid flow. Part I of this project was to show the feasibility of modifying the flow field in bends to reduce the erosion rate. The flow field in bends was modified by the use of one or more air jets. Part II of this project is to include further experimentation and analysis, leading to a design methodology for incorporating. this concept into pneumatic transport systems. This final report is for Part $I$ of this project.

Part I of this project may be considered an exploratory study. Other than in the work of F. Schmidt $[2-30]$, the subject of flow field modification in bends is an unexplored concept. Since F. Schmidt appeared to be more interested in avoiding plugging problems than erosion, his work only indicates that the concept should be feasible.

The independent variables for this exploratory study were initially selected to be:

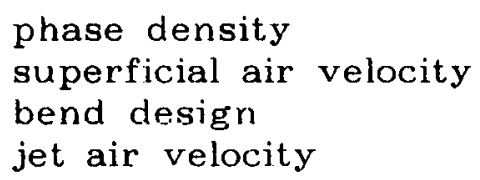

The dependent variable was the erosion rate, both in terms of mass loss and penetration depth (when possible). Also, the flow regime into and out of the bends was observed and was utilized in the discussion of the experimental results. The literature survey indicated that these variables would be sufficient for evaluating the concept.

The literature relating to erosion in bends (elbows) appeared to show several inconsistencies; and indeed, studies of the pressure drop due to bends have also shown inconsistencies. Inconsistencies are frequently the result of an incomplete understanding of the phenomena(on) being investigated. Thus, it appears that the flow of gas-solid mixtures in bends has not been adequately understood or described. This situation creates a degree of uncertainty in establishing the test conditions for comparing the performance of the various bend designs investigated in this study.

The three most important inconsistencies appearing in the literature relating to gas-solid flows are: 1) the pressure gradient downstream of the bend (and acceleration length) may be different than the pressure gradient Cupstream of the bend; 2) the erosion rate may vary significantly from bend to bend in a loop; and 3) the erosion data for a single bend may be scattered. Experimental data [4-1] has shown that in some situations, every other bend will experience a high erosion rate. These three inconsistencies may be reconciled by assuming that a change in flow regime may occur in a bend, and that the flow regime established in one bend may be destroyed in the next bend. Thus, this projcct attompted to establish the flow regime into and out of each bend for that test. This was accomplished by observing the flow 
through the sight glasses upstream and downstream of each bend.

\subsection{Test Matrix}

In this section, the independent variables usually associated with pneumatic transport plus the additional variables due to the jet-protected bends are listed. A rationale for selecting the experimental variables and their associated range of values is then described. Finally, the selected test matrix for this project is presented. This matrix involved at least one hundred tests.

The independent variables which appear in the literature relating to erosion in bends are:

$$
\begin{aligned}
\Phi & =\text { phase density } \\
\mathbf{v}_{\mathbf{O}}= & \text { transport air veloeity (upstream of the solids } \\
& \text { injection port) } \\
\left\langle\mathrm{d}_{\mathbf{p}}\right\rangle= & \text { average particle size } \\
\mathbf{R}_{\mathrm{B}}= & \text { radius of the bend } \\
D= & \text { inside diameter of pipe } \\
= & \text { angularity of the particles } \\
E & =\text { modulus of elasticity, bend or particle material } \\
\nu & =\text { Poisson's ratio, bend or particle } \\
P & =\text { density, gas (air) or particle } \\
& =\text { flow regime }
\end{aligned}
$$

In addition, the independent variables introduced by the test bends are:

$$
\left.\begin{array}{l}
\boldsymbol{B}_{. j}=\text { location of the jets } \\
\mathrm{d}_{j}=\text { jet port diameter }
\end{array}\right\} \text { bend design }
$$

Because the quantities of angularity and flow regime are difficult to quantify, there are no symbols for them. Normally, the gas employed for the protective jets would be the same as the transport media; thus the jet gas would nut introduce a new variable.

As the objective of this exploratory research was to determine the feasibility of the jet protection concept, the experiments involved some of the most severe erosion conditions encountered in the pneumatic transport process. Small sand particles, $\left\langle d_{p}\right\rangle \leqslant 100 \mu m$ were transported through 
low-carbon steel bends. Fresh sand was charged into the test loop at regular intervals to insure the presence of sharp, angular solid particles. Experimental data suggested that the selected basic bend, with a $2 R_{B} / D^{\circ}$ of $6-2 / 3$, suffered a relatively high erosion rate. Thus, with the above conditions, it was anticipated that the standard bend would fail after transporting five to ten tons of sand [4-1].

The remaining independent variables were: 1) the phase density; 2) transport air velocity; 3) jet-protected bend design; 4) jet-air velocity; and 5) jet-port diameter. A phase density of $\Phi=0.5$ corresponds to typical pulverizer flow in a pulverized-coal-fired boiler. Thus, this value of phase density served as a lower limit, and an upper limit for phase density in this study was arbitrary. A minimum gas (air) velocity was required to transport the solids; and for sand, the literature reported. values of about $15 \mathrm{~m} / \mathrm{sec}$. A maximum gas velocity for pneumatic transport is usually based on erosion. Consequently, it is not significantly greater than the minimum transport velocity. The design and operation of jet-protected bends were the unknowns to be investigated. Thus, the design and operation of these bends changed as more information was developed during the tests.

The test matrix initially selected for this project was as follows:

five phase densities: $\Phi=0.5,1,2,4$, and 8

two transport gas velocities: $v_{0}=18$ and $25 \mathrm{~m} / \mathrm{sec}$

fiṿe bend designs

two jet-air velocities: $v_{p}=60$ and $90 \mathrm{~m} / \mathrm{sec}$

The variations in jet-port diameters were included in the different jet-protected bend designs. This matrix represented one hundred tests.

The bends to be tested included a standard bend which served as the reference condition in evaluating the jet-protected bend designs. For each bend design, a control bend was first employed to obtain a reference erosion value. The test bend was then tested under the same conditions. Another control bend was then employed as a check on the first control bend. Consistent agreement between the two control bends led to the decision to eliminate the second control bend test. Figure 4.1 illustrates the tentative design of the jet protected bends. The first jet port was located at $\beta=20^{\circ}$, and the second jet port is at $\beta=45^{\circ}$. The jets were directed at a $45^{\circ}$ angle relative to the surface. One jet-protected bend design involved only a jet from the first jet port. Thus, one actual jet-protected bend served as two designs. One bend had 1/8" jet-port diameters, and the other bend had $3 / 16^{\prime \prime}$ diameter jet-ports.

As the testing program progressed, several problems became apparent. First, the initial bend designs selected air jet velocities for the low phase-density tests produced increased erosion rates. In addition, for some test bends, the erosion rates were so great it was apparent that the test bends would not survive the sequence of tests. As a result of these early runs with their unexpected results, the initial test matrix was abandoned, and 
a new set of test bends were designed. Because the number of test bends had been increased, it was decided to limit the test conditions to one phase density ( $\Phi=0.75)$, one, gas (air) velocity ( $80 \mathrm{ft} / \mathrm{sec}$ at the test bend), and two air jet velocities. The results from the new set of test bends.did not show a significant decrease in erosion.

It was noted that the elbow used in the solds feed port assembly, with its air jet, did not show any signs of wear. The early work of F. Schmidt was again reviewed. The common factor in these two cases was that the phase-density with high, and the air injection velocity was low. Thus, one test bend design was tested at a phase-density of seven and a low air jet velocity. After a series of tests at $\dot{a}$ high phase density and a low air injection velocity into an elbow with a series of slots a reduction of erosion of at least $10 \%$ was achieved. This last series of tests brought an end to Part I of the project.

\subsection{Accuracy and Uncertainty Analysis}

The factors that affect the accuracy of the results are the mass flow rates of solids (particles) $\left(m_{p}\right)$ and air $\left(m_{a}\right)$. These factors are proportional to the mass lost from the elbow $\left(M_{r}\right)$ and the loss of wall thickness $\left(\Delta Z_{r}\right)$.

Here, the phase density $\left(\phi=\mathrm{m}_{\mathrm{p}} / \mathrm{m}_{\mathrm{c}}\right)$ is a function of both $\mathrm{m}_{\mathrm{p}}$ and $\mathrm{m}_{\mathrm{a}}$. The solids mass flow rate is adjusted every minute to a calculated flow rate. The maximum and approximate average control errors are $\pm 5 \%$ and $\pm 2 \%$ of reading, respectively. The percent errors held for experimental runs with phase density values between 4 and 6 . The load cell has an accuracy of .1 lbm full scale. The control error is much larger than the instrument accuracy and will be used. Three measurements were collected to determine the mass flow rate of air. First, the temperature gauge at the flow meter has a readability of $0.5^{\circ} \mathrm{C}$. Secondly, the pressure gauge at the flow meter has a readability of 0.125 psig. Last, the volumetric flow rate of air (v) is measured by a vortex flowmeter that has an accuracy of $1 \%$ of the reading.

\section{Typical Uncertainty Calculations}

$$
\begin{array}{cc}
\Phi=\frac{\dot{m}_{p}}{\dot{m}_{a}} & R=\frac{R}{M} \\
P V=\dot{m}_{a} R T & \dot{m}=\frac{P \dot{p}}{R T} \\
\Phi=\left[\frac{\dot{m}_{p}}{R T}\right] &
\end{array}
$$




$$
\begin{aligned}
\Phi & =\frac{\dot{m}_{p} R T}{P \dot{V}} \\
\Delta \Phi & =\left[\left|\frac{R T}{p \dot{V}} \Delta \dot{m} p\right|+\left|\frac{\dot{m}_{p}^{R}}{p \dot{V}} \Delta T\right|+\left|\frac{-\dot{m}_{p}^{R T}}{p \dot{V}}\right|+\left|\frac{-\dot{m}_{p}^{R T}}{\dot{P V}^{2}} \Delta \dot{V}\right|\right] \\
\% E & =\frac{\Delta \Phi}{\phi}(100)
\end{aligned}
$$

For the phase density of 6

$$
\begin{aligned}
\dot{\mathrm{m}}_{\mathrm{p}} & =41 \mathrm{lbm} / \mathrm{min} \pm 5 \% \text { of rearding } \\
\mathrm{T} & =106^{\circ} \mathrm{F} \text { or } 566^{\circ} \mathrm{R} \pm .9^{\circ} \mathrm{R} \\
\mathrm{R} & =7 \mathrm{psig} \text { or } 3124 \mathrm{PSFA} \pm 18 \mathrm{PSFA} \\
\dot{\mathrm{V}} & =67.1 \mathrm{CFM} \pm 1 \% \text { of reading } \\
\mathrm{E} \theta & =[(0.295)+(0.00939)+(0.0340)+(0.0590)] \\
\mathrm{E} \theta & =0.3977 \\
\% \mathrm{E} & =\frac{0.3977}{6}(100) \\
& =6.6 \%
\end{aligned}
$$

Calculate at the same phase density and with approximate average error $2 \%$

$$
\% \mathrm{E}=3.7 \%
$$

Elbow erosion - mass loss

$$
m_{R}=m-m_{F}
$$

The scale has a digital readout that is accurate to .05 gram

$$
E m_{\dot{R}}=2(0.05)=.1 \text { gram }
$$

For a 5 grann hass loss

$$
\begin{aligned}
\% E & =\frac{0.1}{5} \\
& =2.0 \%
\end{aligned}
$$


Elbow erosion - penetration depth

$$
\Delta Z_{R}=Z_{i}-Z_{F}
$$

The modified micrometer has an accuracy of 0.001 inch. The penetration depth varied from .001 inch to the wall thickness.

$$
E \Delta Z_{R}=2(0.001)=0.002 \text { inch }
$$

For a 0.015 inch $\Delta z_{R}$ :

$$
\begin{aligned}
E \Delta Z_{R} & =\frac{0.002}{0.015} \\
& =13.3 \%
\end{aligned}
$$




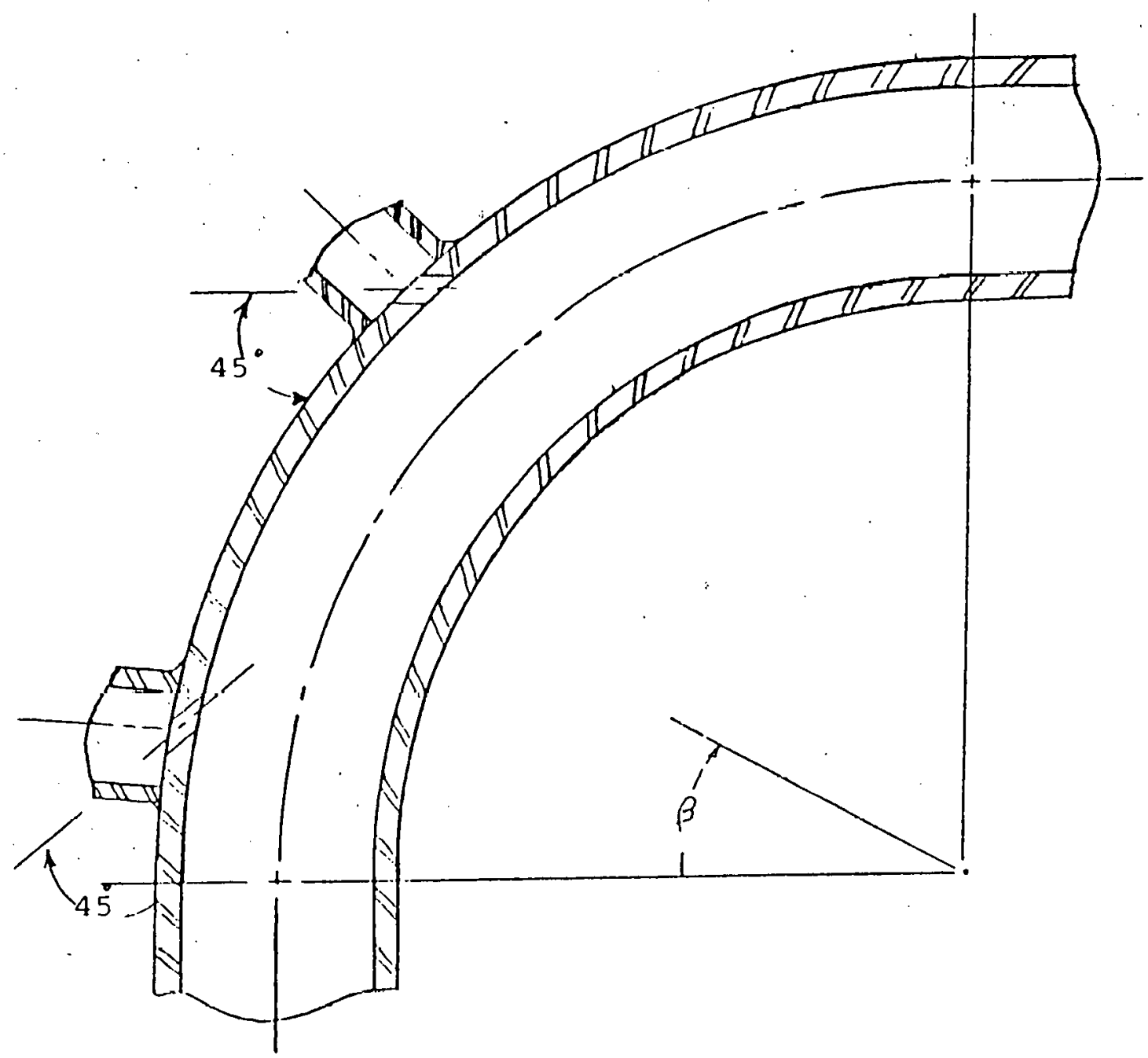

Figure 4.1: Basic Jet Protection Bend 


\section{6}

\section{RESULTS}

\section{$\underline{5.1}$ Introduction}

In an exploratory study, one usually encounters results that were difficult, if not impossible, to anticipate. Thus this effort has consisted of three stages. The first stage involved an optimistic matrix in which the test bends would survive a series of test conditions. Because a significant increase in the erosion rate was noted in early test bend designs, it was decided to modify the test matrix. Several new bend designs were selected and tested at one phase-density and one gas velocity. The phase density selected was 0.43 , and the gas velocity at the test bend was $102 \mathrm{ft} / \mathrm{sec}$. Two air jet velocities were employed. Again the results were disappointing. After (1) evaluating the erosion patterns on the bends' surface, (2) noting that the elbow used in the solids feeder showed no signs of wear, and (3) noting that the work of F. Schmidt [2-30] was at high phase-densities, a high phase-density test was conducted with a slotted test bend design. This test represented the third stage of the experimental effort, and an average $10 \%$ reduction in the erosion rate was observed relative to the control bends.

This chapter will present each test bend employed in this study and describe the erosion results along with the conditions which produced the results. A summary section will then present a discussion of a tentative model based on the observations in this study.

\subsection{Discussion of Each Bend Design}

\subsubsection{Test Bend Design Data}

Figures 5.1 through 5.12 show the twelve bend configurations tested in this exploratory study. Each figure also states the test conditions experienced by the design. The amount of erosion that uccurred, in terms of mass lost, is also stated. The erosion of an unaitered bend (control bend) that experiences the same conditions as the test bend is also stated for comparison with the test bend results. It should be noted that test bend design 9-T (Figure 5.12) reduced erosion for a relatively high phase density.

\subsubsection{Erosion Patterns}

Photographs were taken of the erosion patterns exposed by cutting several bends apart. The erosion patterns in the unaltered (control) bends were compatible with the erosion patterns described in the literature. Thus the maximum erosion occurs between $30^{\circ}<\beta<40^{\circ}$ on the back arch. Figure 5.13 shows the variation in bend wall thickness for a control bend with a smooth surface. However, the turbulent effects of the two-phase, gas-solid. mixture going through a bend are clearly shown in Figure 5.14. This figure also shows the thinning of the bend wall. If the erosion process is allowed to continue, the result will be similar to that shown in Figures 5.15 and 5.16. These photographs show an actual hold through a bend. The hole occurs at about $\beta=40^{\circ}$, where the turbulent erosion pattern begins. Thus it appears that the erosion process results obtained from the test loop are in agreement with published results from other test loops. 
In this exploratory study, the flow field modification in bends was achieved by air jets. A method for creating the jets is to attach a nozzle to the bend, as shown in Figure 5.1. Figure 5.17 is a photograph of test bend design 8-T with four injection nozzles aligned with the tangent of the centerline of the bend. Two important factors were observed from this design. First, any portion of the nozzle protruding into the flow field is quickly eroded away. Second, if the nozzle is recessed from the inner bend surface, a relatively large crater will quickly form about the recess. For the case of a nozzle exit flush with the bend wall, a deep rut (trench) is formed during dilute phase flow. Figure 5.18 shows the rut starting at the nozzle exit and almost extending to the next nozzle exit. The bend wall has been penetrated just upstream of the second nozzle. The air jet appears to be accelerating the erosion process.

Another air injection arrangement was developed by cutting slots at shallow angles into the bends, as shown in Figure 5.19. These slots provide a means of injecting air over a broader area of the inside surface of the bend. This design (9-T) was tested for a relatively high phase-density, and the erosion rate was reduced. The erosion was concentrated on the lip of the injection ports, as shown in Figure 5.20.

\subsubsection{Penetration Depth}

The measurement of the penetration depth, as a means of describing the erosion process, is complicated by the fact that the test bends have attachments in regions of interest. However, the control bends and test bend design 9-T do not have any attachments. Thus the penetration depth pattern was obtained for the 9-T bend after its two test runs. Also, the penetration depth pattern was obtained for the control bend used for the $9-\mathrm{T}$ bend test. Figure 5.21 illustrates the accumulated penetration depth for the two test runs for the 9-T test bend. The difference between the penetration depth for the 9-T test bend and the control bend after one test run is shown in Figure 5.22. A study of the photograph Figure 5-20, as well as Figures 5.21 and 5.22 will provide the data required for improved designs to minimize the erosion process in bends.

\section{$\underline{5.3 \quad \text { Summary }}$}

In organizing the results of this exploratory experimental study, two tentative models have emerged. The first model is for dilute flow, and the second model is for the flow conditions in which a rope flows through the bend. Dilute phase flow implies that there is very little interaction between the particles and that the particle motion is controlled by the fluid flow field and the bounding surfaces. The placement of a high velocity jet in a dilute-phase flow field will create a secondary flow field with locally high velocities near the jet port. Figure 5.23 illustrates this process for a jet in coaxial flow. Extending this concept to a bend with an air jet (Figure 5.24), it appears that the jet will both concentrate and accelerate the particles striking the bend surface about the jet port. Inspection of Figure 5.18 shows excess erosion near the jet port and in the wake region of the jet.

The second model involves a rope of particles flowing along a surface in the bend. It appears that the injection of low velocity air tends to enhance 
the fluidization of the rope and lift the rope off of the bend surface. This model then assumes that the injected air acts in a manner. similar to that of air assisted gravity conveyors. Because the interaction between the solids (rope) and the surface has not been minimized, the erosion rate must be significantly reduced. In reviewing the work of $F$. Schmidt, for a phase density of about seven and approximated seven percent air injection through several ports, only a trace of erosion was noted. The bend in the solids-feed-port of the test loop did not show any signs of erosion. Finally, test bend 9-T showed improved erosion resistance when the phase density was seven, and a small amount of air was injected through a series of slots. Thus it appears that an erosion resistant bend, employing flow field modification may require that the solids for a rope as it flows through a bend.

The models presented in this section are based on a limited amount of information and experimental data. Therefore, these models can only be considered tentative until more information becomes available. 
Test Conditions

Flow velocity: $102 \mathrm{ft} / \mathrm{sec}$

Flow temperature: $100 \mathrm{~F}$

Phase density: 0.43

Solids Flow rate: $5 \mathrm{lb} / \mathrm{min}$

Jet flow conditions: $145 \mathrm{scfh}$ per jet at $25 \mathrm{psig}$

Test Results

Erosion rate of control elbow: $5.5 \mathrm{gm}$

Erosion rate of test elbow: $6.2 \mathrm{gm}$

$2,1 / 8$ inch diameter, jets mounted as shown with $\theta_{j}$ equal to $35^{\circ}$

$$
1 \text { to }
$$




\title{
Test Conditions
}

Flow velocity: $102 \mathrm{ft} / \mathrm{sec}$

Flow Temperature: $100^{\circ} \mathrm{F}$

Phase density: 0.43

Solids flow rate: $5 \mathrm{lb} / \mathrm{min}$

Jet flow conditions: $145 \mathrm{scfh}$ per jet at 9 psig

Test Results

Erosion rate of control elbow: $5.5 \mathrm{gm}$

Erosion rate of test elbow: $5,8 \mathrm{gm}$

$2,1 / 8$ inch

diameter, jets

mounted as.

shown with

$\theta_{j}$ equal to $35^{\circ}$

\author{
(n)
}


Test Conditions,

Flow velocity: $102 \mathrm{ft} / \mathrm{sec}$

Flow temperature: $100^{\circ} \mathrm{F}$

Phase density: 0.43

Solids flow rate: $5 \mathrm{lb} / \mathrm{min}$

Jet flow conditions: $145 \mathrm{scfh}$ per slot at 25 psig

Test Results

Erosion rate of control elbow: $5.5 \mathrm{gm}$

Erosion rate of test elbow: $6.3 \mathrm{gm}$

Maximum

Wear region

$21 / 16$ inch wide slots cut to encompass the maximum wear region as shown with equal to $30^{\circ}$.

e
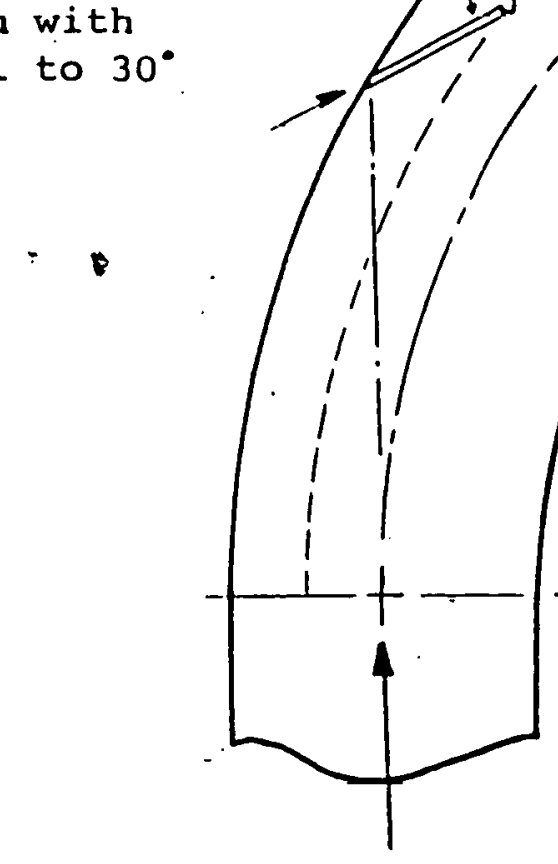

Flow

5 inch center-line radius schedule $401 \frac{1}{2}$ inch diameter low carbon steel 90 degree clbow 


\section{Test conditions}

Flow velocity: $102 \mathrm{ft} / \mathrm{sec}$

Flow temperature: $100^{\circ} \mathrm{F}$

Phase density: 0.43

Solids flow rate: $5 \mathrm{lb} / \mathrm{min}$

Jet flow conditions: $145 \mathrm{scfh}$ per slot at $25 \mathrm{psig}$

Test Results

Erosion rate of control elbow: $5.5 \mathrm{gm}$

Erosion rate of test elbow: $5.2 \mathrm{gm}$

Maximum

Wear region

$21 / 16$ inch wide slots cut to encompass the maximum wear region as shown

.

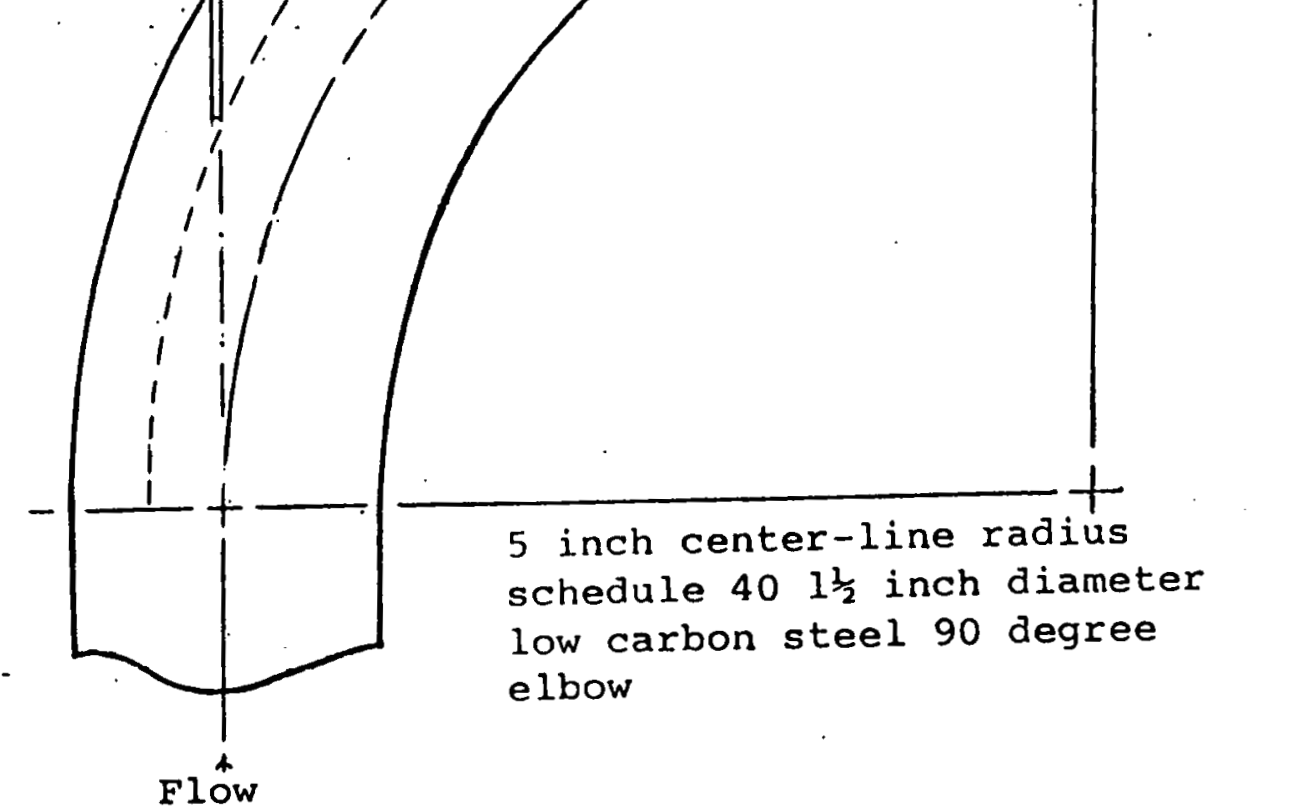

Figure 5.4: Flow modification elbow design 2-T-R 


\section{Test Conditions}

Flow velocity: $102 \mathrm{ft} / \mathrm{sec}$

Flow temperature: $100^{\circ} \mathrm{F}$

Phase density: 0.43

Solids flow rate: $5 \mathrm{lb} / \mathrm{min}$

Jet flow conditions: $180 \mathrm{scfh}$ at 9 psig into 2 . jets ..

Test Results

Erosion rate of control elbow: $5.5 \mathrm{gm}$

Erosion rate of test elbow: $5.7 \mathrm{gm}$

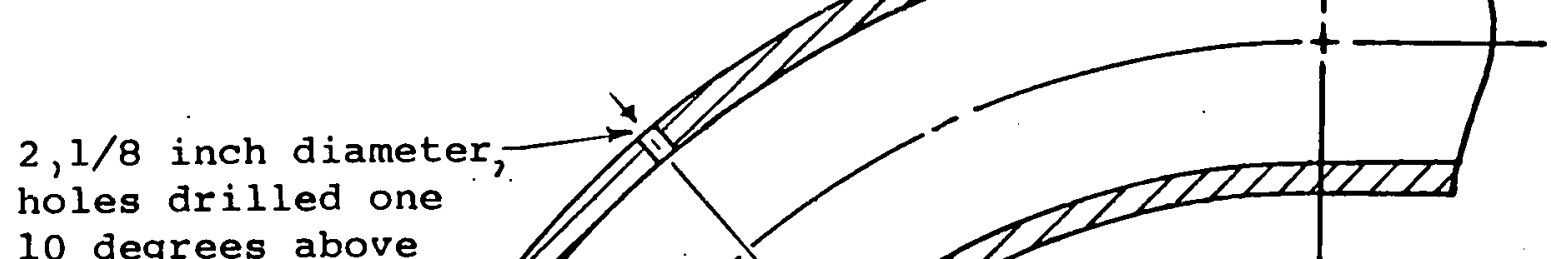
10 degrees above the back centerline and one 10 degrees below the back centerline 
Test Conditions

Flow velocity: $102 \mathrm{ft} / \mathrm{sec}$.

Flow temperature: $100 \mathrm{~F}$

Phase density: 0.43

Solids flow rate: $5 \mathrm{lbm} / \mathrm{min}$.

Jet flow conditions: 320 scfh at 9 psig

Test Results

Erosion rate of control elbow: $5.5 \mathrm{gms}$.

Erosion rate of test elbow: $5.6 \mathrm{gms}$.

$1 / 4$ inch diameter drilled normal to the bend wall

\author{
wall.
}

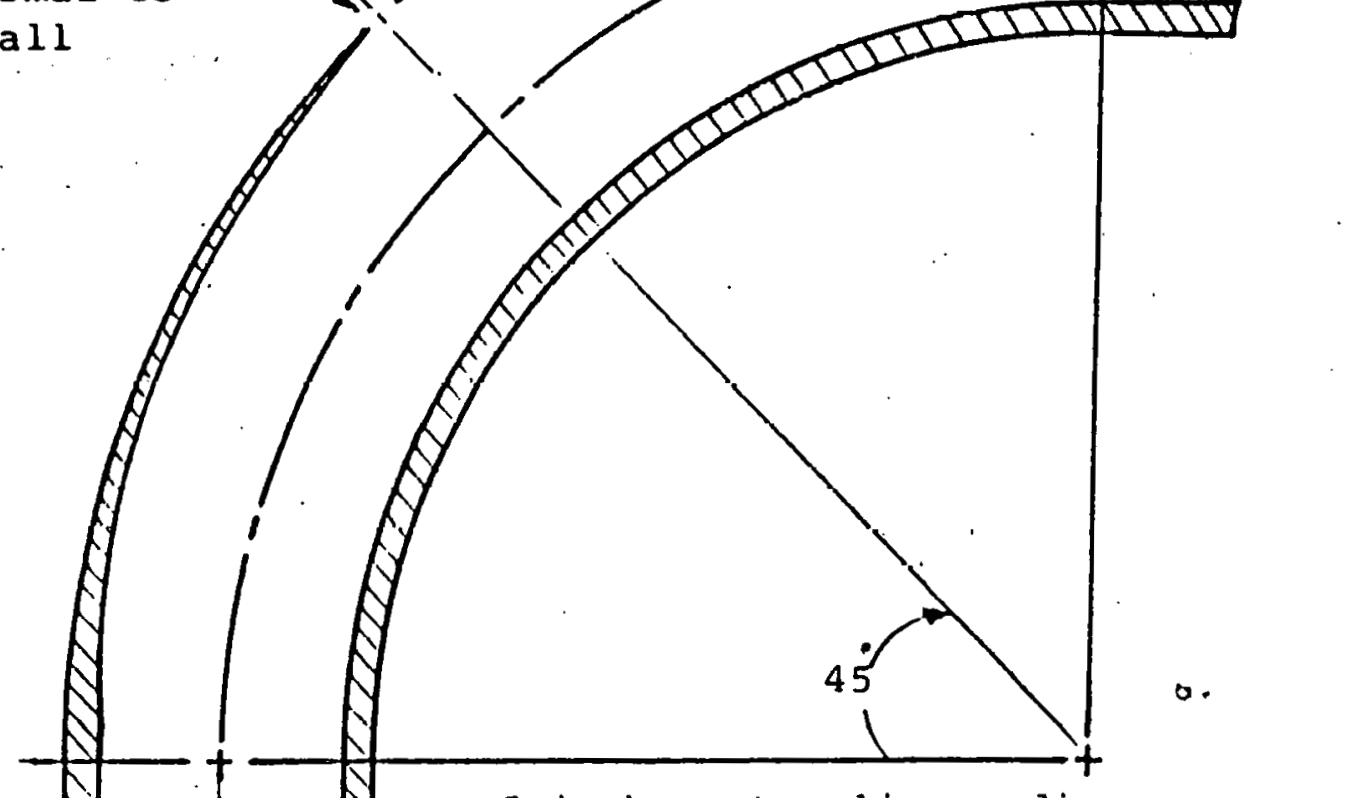

5 inch center-line radius

schedule $401 \frac{1}{2}$ inch diameter

low carbon steel 90 degree

elbow

F'igure 5.6: Flow moditication design elbow 4-T 
Test Conditions

Flow velocity: $102 \mathrm{ft} / \mathrm{sec}$

Flow temperature: $100^{\circ} \mathrm{F}$

Phase density: 0.43

Solids flow rate: $5 \mathrm{lb} / \mathrm{min}$

Jet flow conditions: 18 scfm at 35 psig

Test Results

Erosion rate of control elbow: $5.5 \mathrm{gm}$

Erosion rate of test elbow: $10.2 \mathrm{gm}$

$\frac{1}{4}$ inch diameter

hole drilled normal to elbow

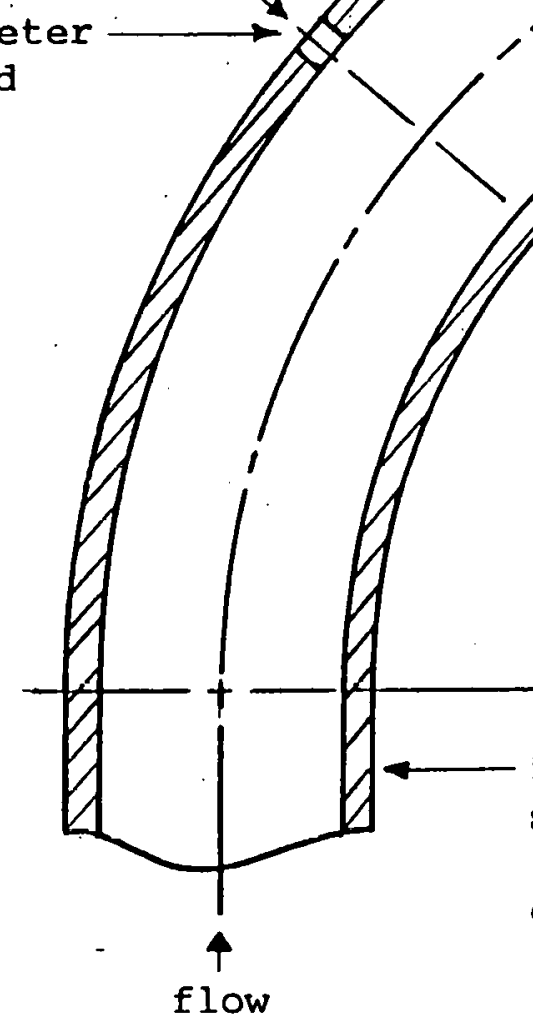

5 inch center-line radius schedule $40 \quad 1 \frac{1}{2}$ inch diameter low carbon steel 90 degree elbow

flow

Figure 5.7: Flow modification elbow design 5-T 
Test Conditions

Flow velocity: $102 \mathrm{ft} / \mathrm{sec}$

Flow temperature: $100^{\circ} \mathrm{F}$

Phase density: 0.43

Solids flow rate: $5 \mathrm{lb} / \mathrm{min}$

Jet flow conditions: Sonic flow at 35 psig

Test Results

Erosion rate of control elbow: $5.5 \mathrm{gm}$

Erosion rate of test elbow: $30.7 \mathrm{gm}$

$33 / 32$ inch diameter jets mounted as shown with $\theta$,

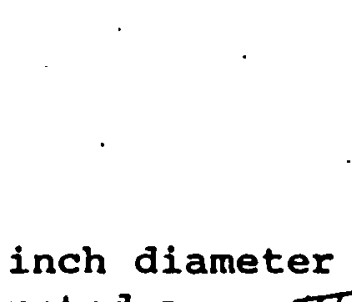
equal to $30^{\circ}$
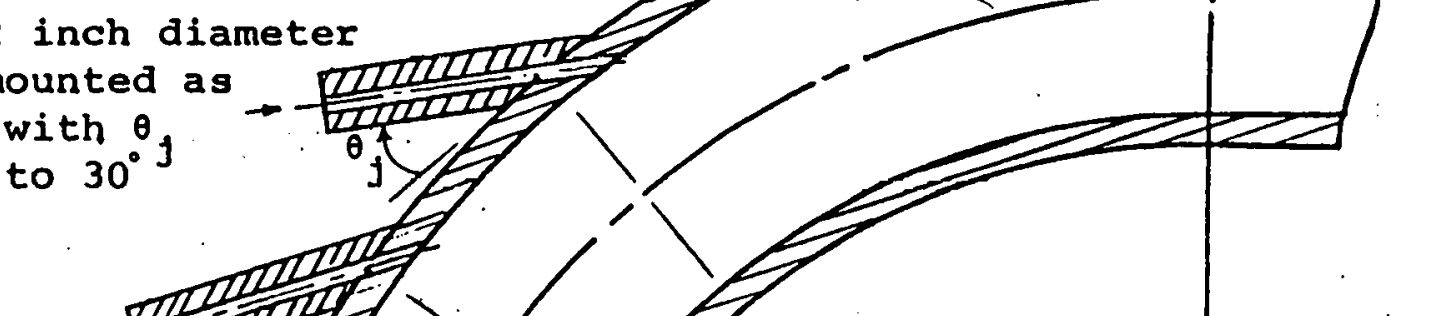

(

$\mathrm{j}$

Flow

Figure 5.8: Flow modification elbow design 6-T 
Test Conditions

Flow velocity: $102 \mathrm{ft} / \mathrm{sec}$

Flow temperature: $100^{\circ} \mathrm{F}$

$\phi$

Phase density: 0.43

Solids flow rate: $5 \mathrm{lb} / \mathrm{min}$

Jet flow conditions: Sonic at $35^{\circ} \mathrm{psig}$

\section{Test Regultg}

Erosion rate of control elbow: $5.5 \mathrm{gm}$ Erosion rate of test elbow: $13.0 \mathrm{gm}$

$3,3 / 32$ inch diameter, jets mounted as shown with $\theta$
equal to $30^{\circ} \mathrm{j}$

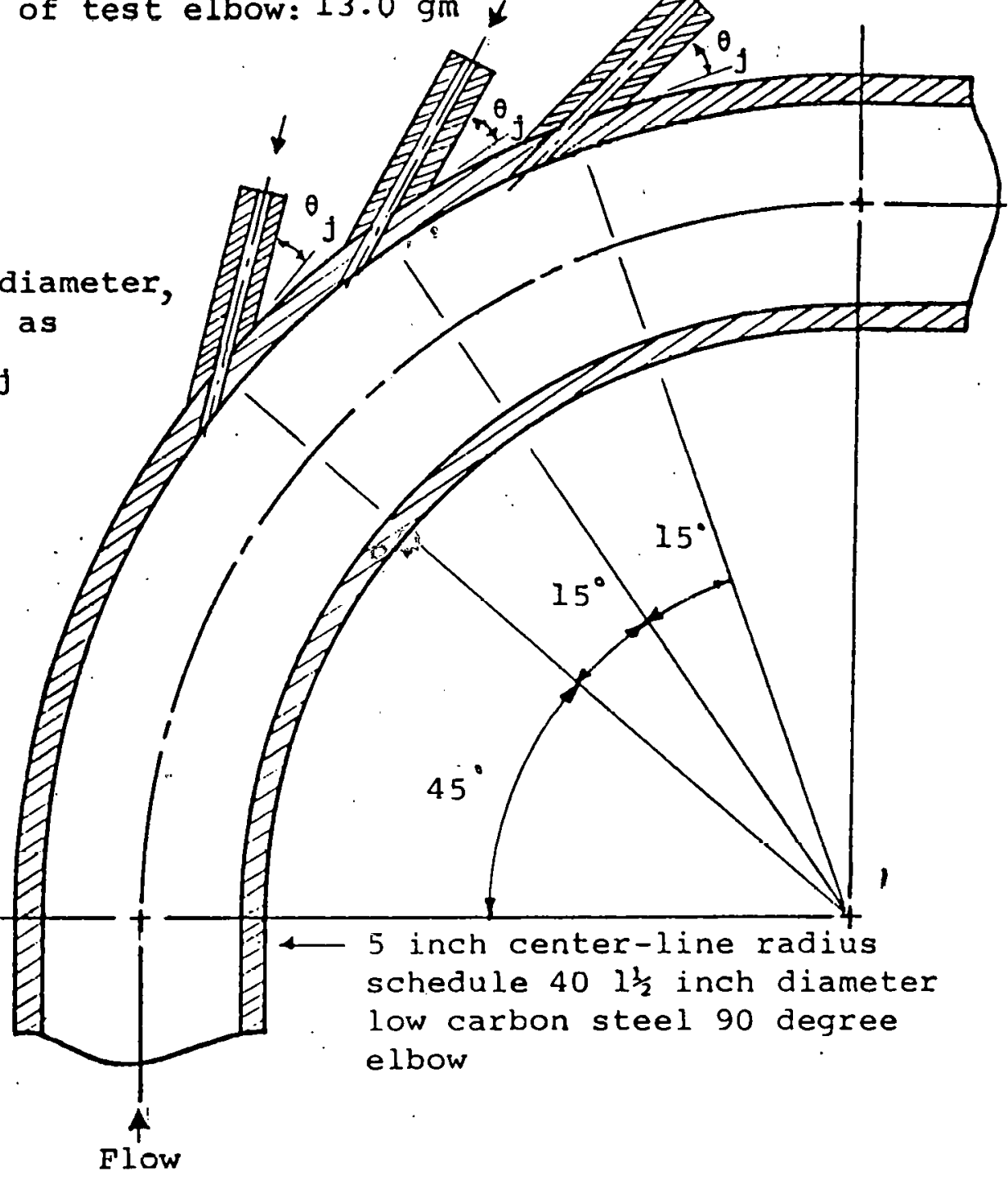

Figure 5.9: Flow modification elbow design 6-T-R 
Test Conditions

Flow velocity: $102 \mathrm{ft} / \mathrm{sec}$

Flow temperature: $100^{\circ} \mathrm{F}$

Phase density: 0.43

Solids flow rate: $5 \mathrm{lb} / \mathrm{min}$

Jet flow conditions: Sonic flow at 35 psig

\section{Test Results}

Erosion rate of control elbow: $5.5 \mathrm{gm}$

Erosion rate of test elbow: $8.4 \mathrm{gm}$

$3,1 / 16$ inch diameter, holes drilled on the inside center-line of the pipe normal to the pipe wall at that point

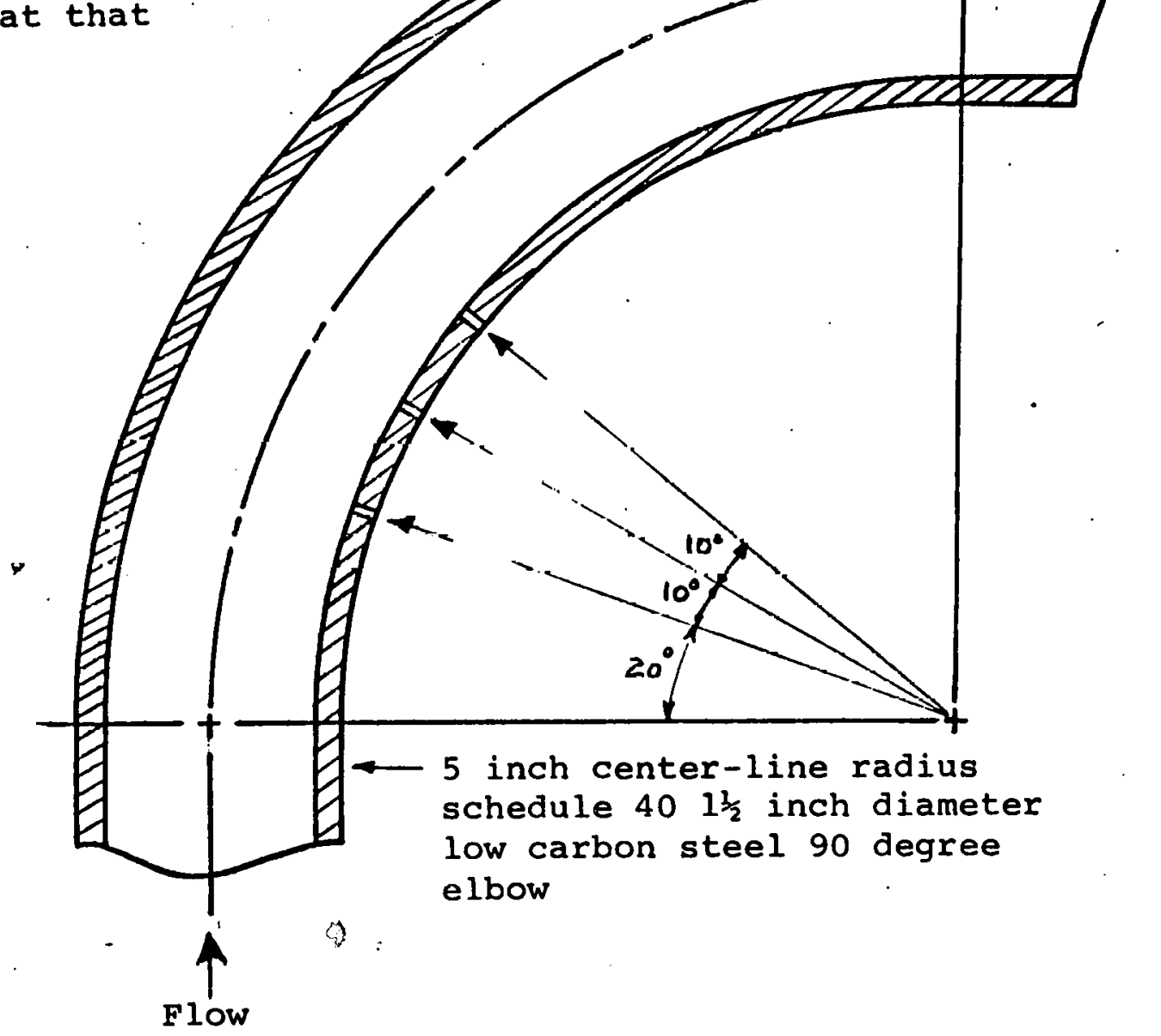

Figure 5.10: Flow modification elbow design 7-T 
Flow velocity: $102 \mathrm{ft} / \mathrm{sec}$

Flow temperature: $100^{\circ} \mathrm{F}$

Phase density: 0.43

Solids flow rate: $5 \mathrm{lb} / \mathrm{min}$

Jet flow conditions: Sonic flow at 35 psig.

\section{Test Results}

Erosion rate of control elbow: $5.5 \mathrm{gm}$

Erosion rate of test elbow: $26.8 \mathrm{gm}$

$4,3 / 32$ inch diameter, jets mounted on the back center-line in.the positions shown with $\theta$;

being $20^{\circ}$

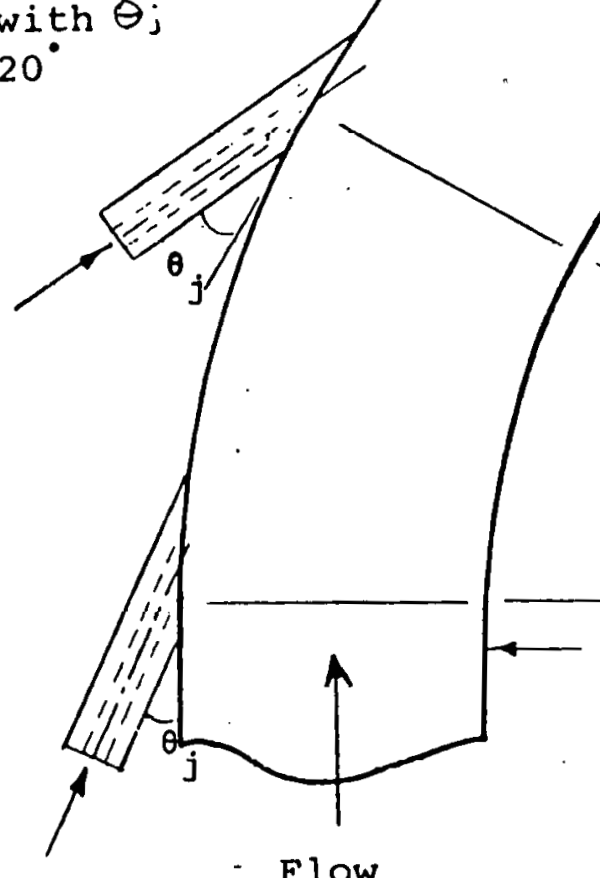

- Flow
$+$ 
Test Conditions

Flow Velocity: $102 \mathrm{ft} / \mathrm{sec}$

Flow Temperature: $100 \mathrm{~F}$.

Phase Density: 4.2

Solids Flow Rate: $49 \mathrm{lbm} / \mathrm{min}$.

Jet Flow Conditions: $\Delta P$ of $3 " h_{2} O$ across the slots

\section{Test Results}

Erosion Rate of Control Elbow: $10.8 \mathrm{gms}$.

Erosion Rate of Test Elbow: $9.6 \mathrm{gms}$.

All'slots cut at a 25 elbow

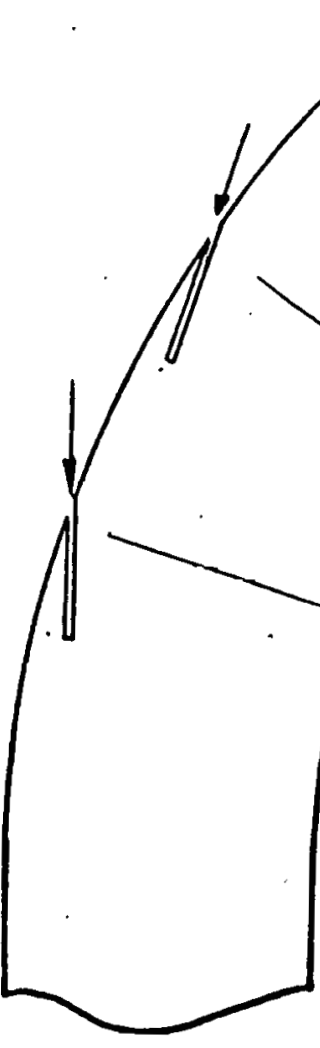

5 inch centerline radius schedule $401 \frac{1}{2}$ inch diameter low carbon steel $90^{\circ}$ degree elbow

Figure 5.12: Flow Modification elbow design 9-T 


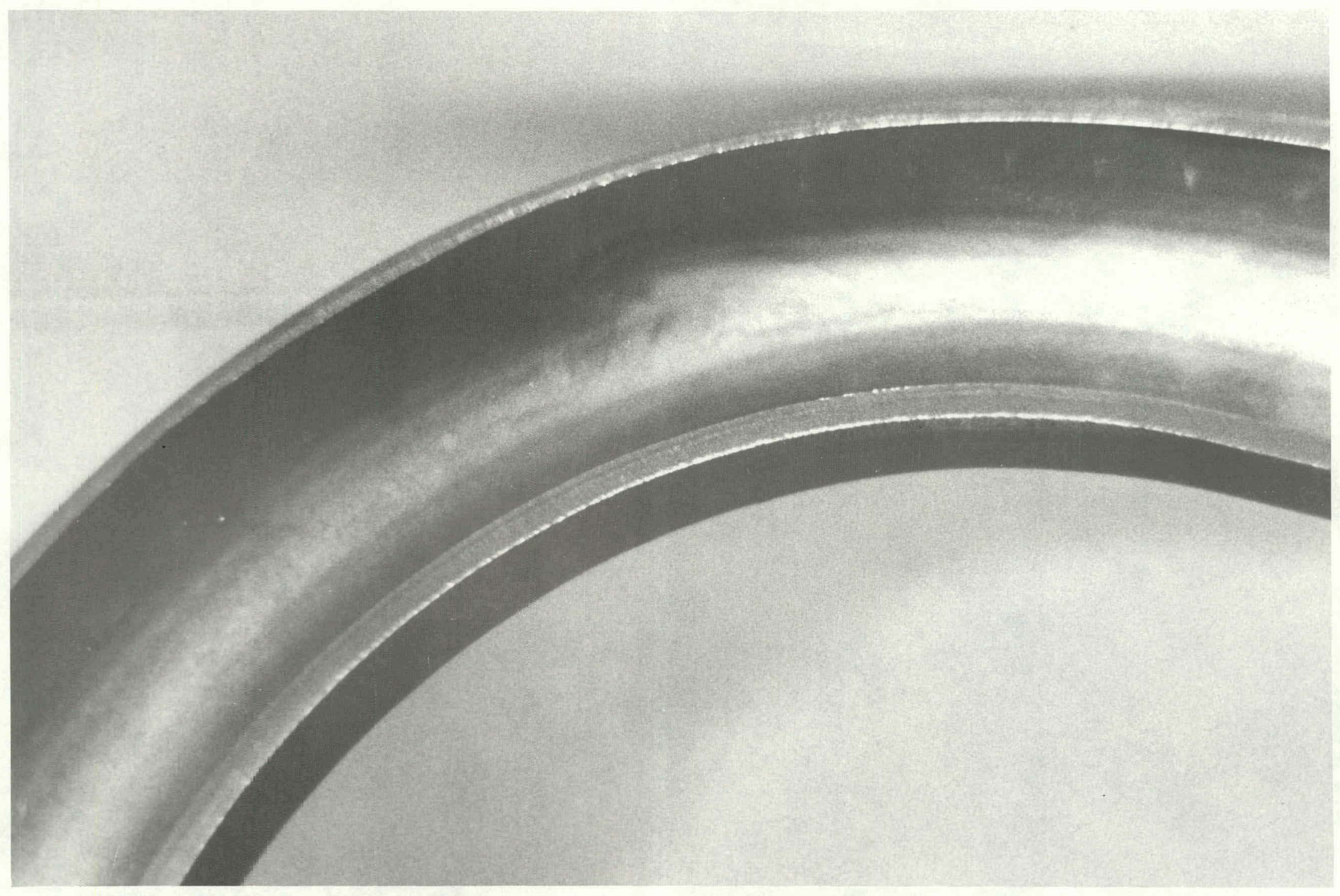

Figure 5-13. Erosion Pattern. Back Wall Thinning in Elbow 3-C3. 



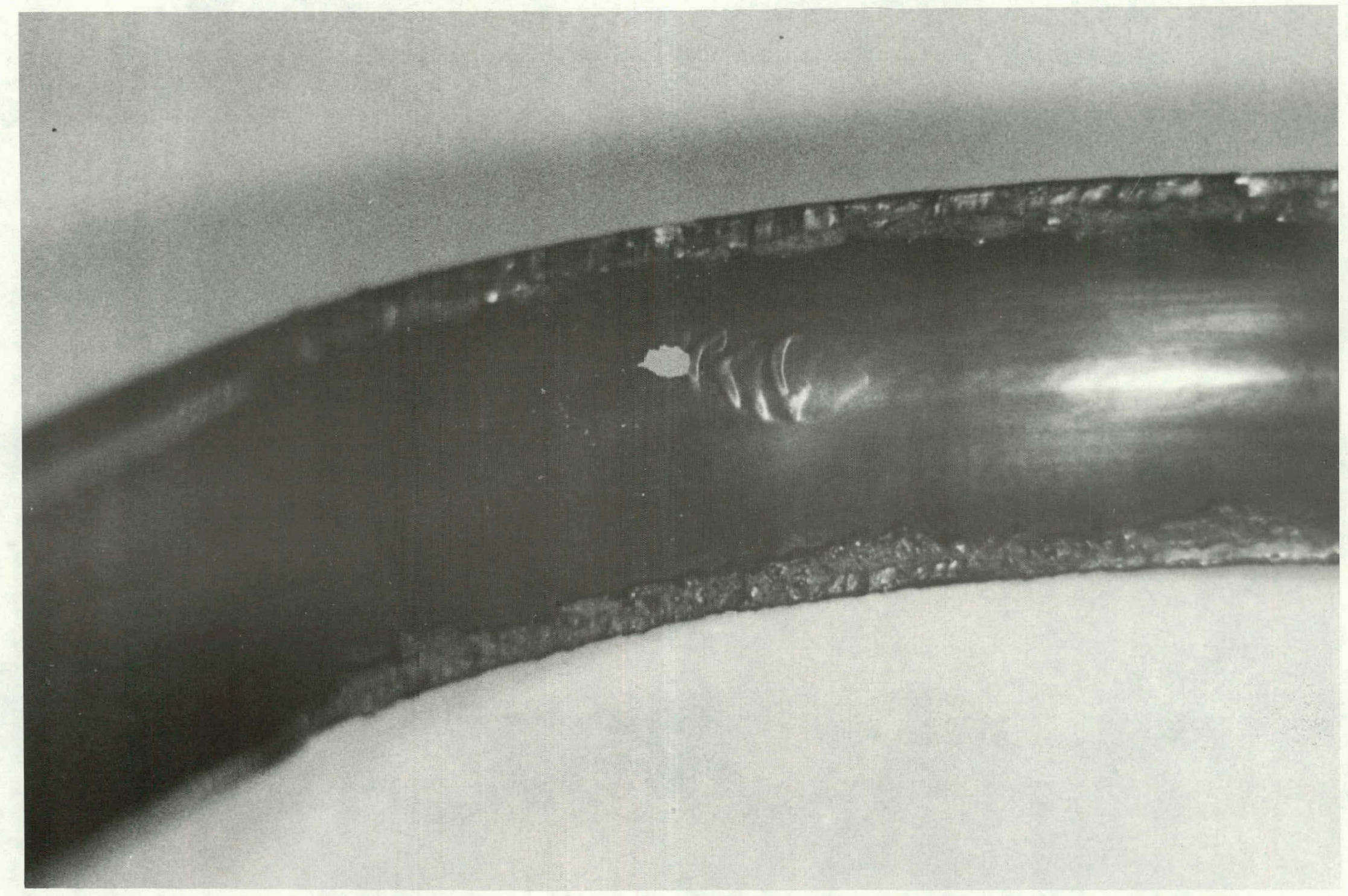

Figure 5-15. Erosion Pattern. Complete Penetration in Back Wall - Inside View. 


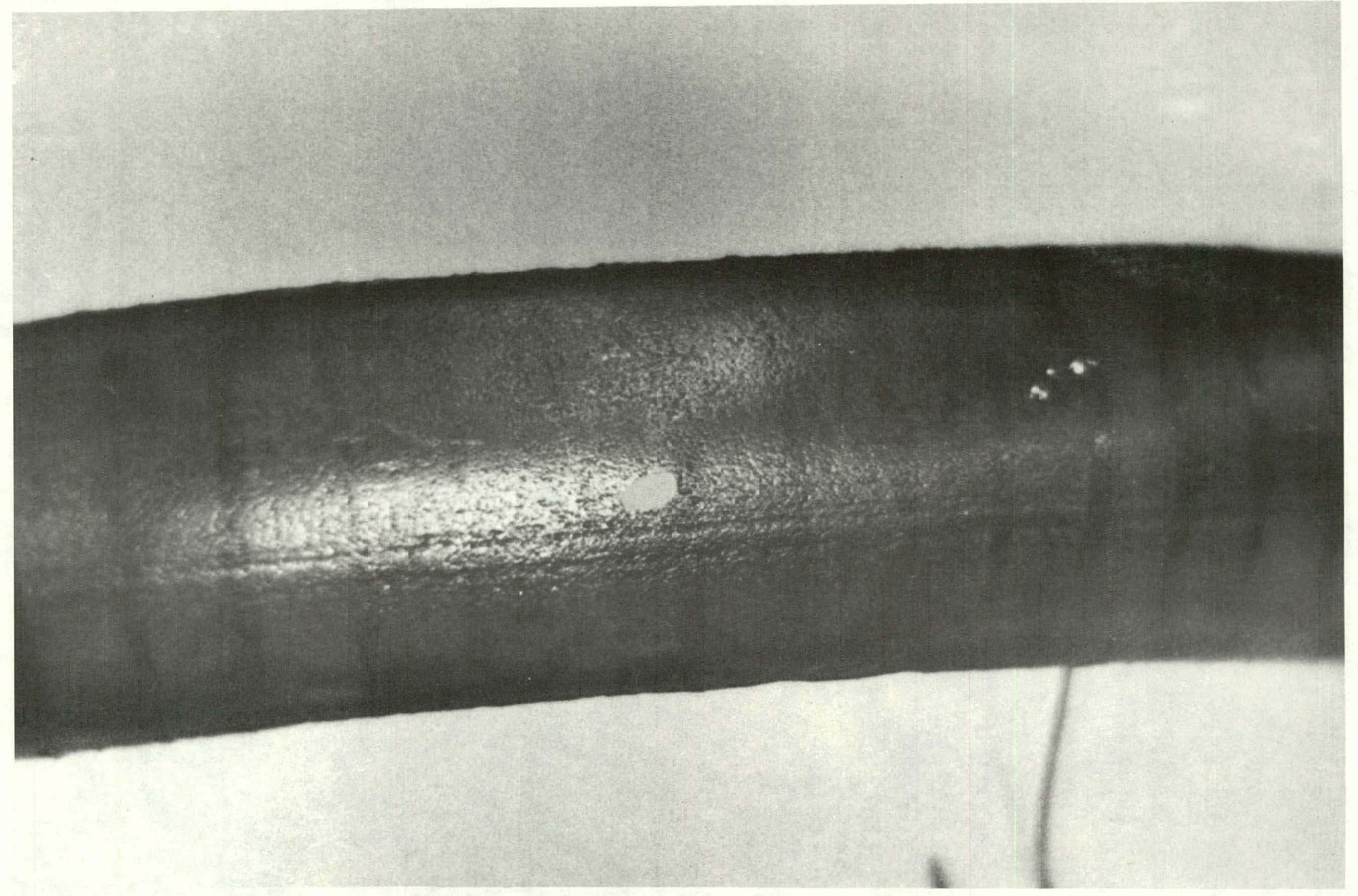

Figure 5-16. Erosion Pattern. Complete Penerration in Back Wall - Outside View. 


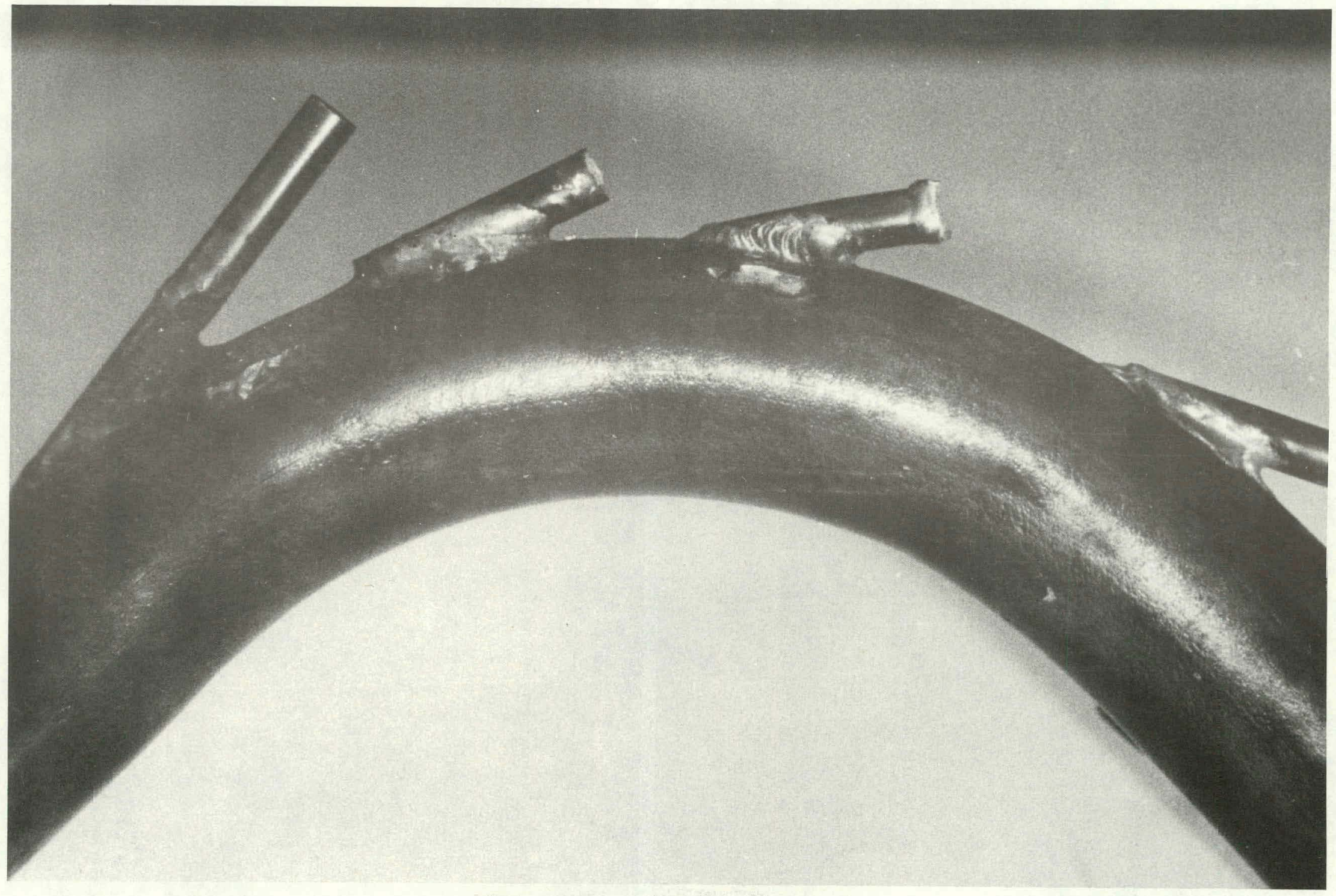

Figure 5-17. Nozzle Arrangement. Four Part Injection Arrangement. 


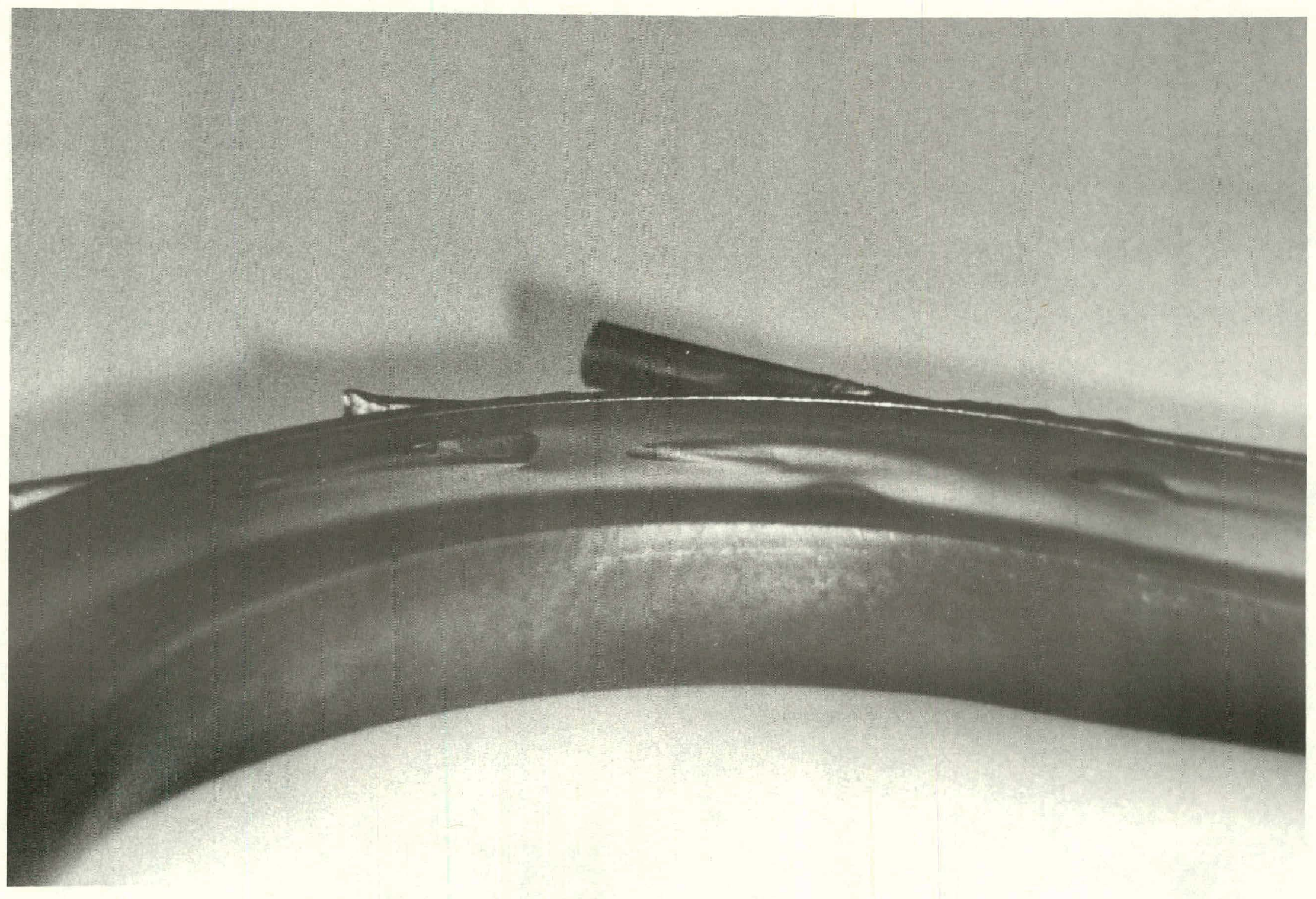

Figure 5-18. Erosion Pa:tern. Four Nozz_e Arrangement - Inside View. 


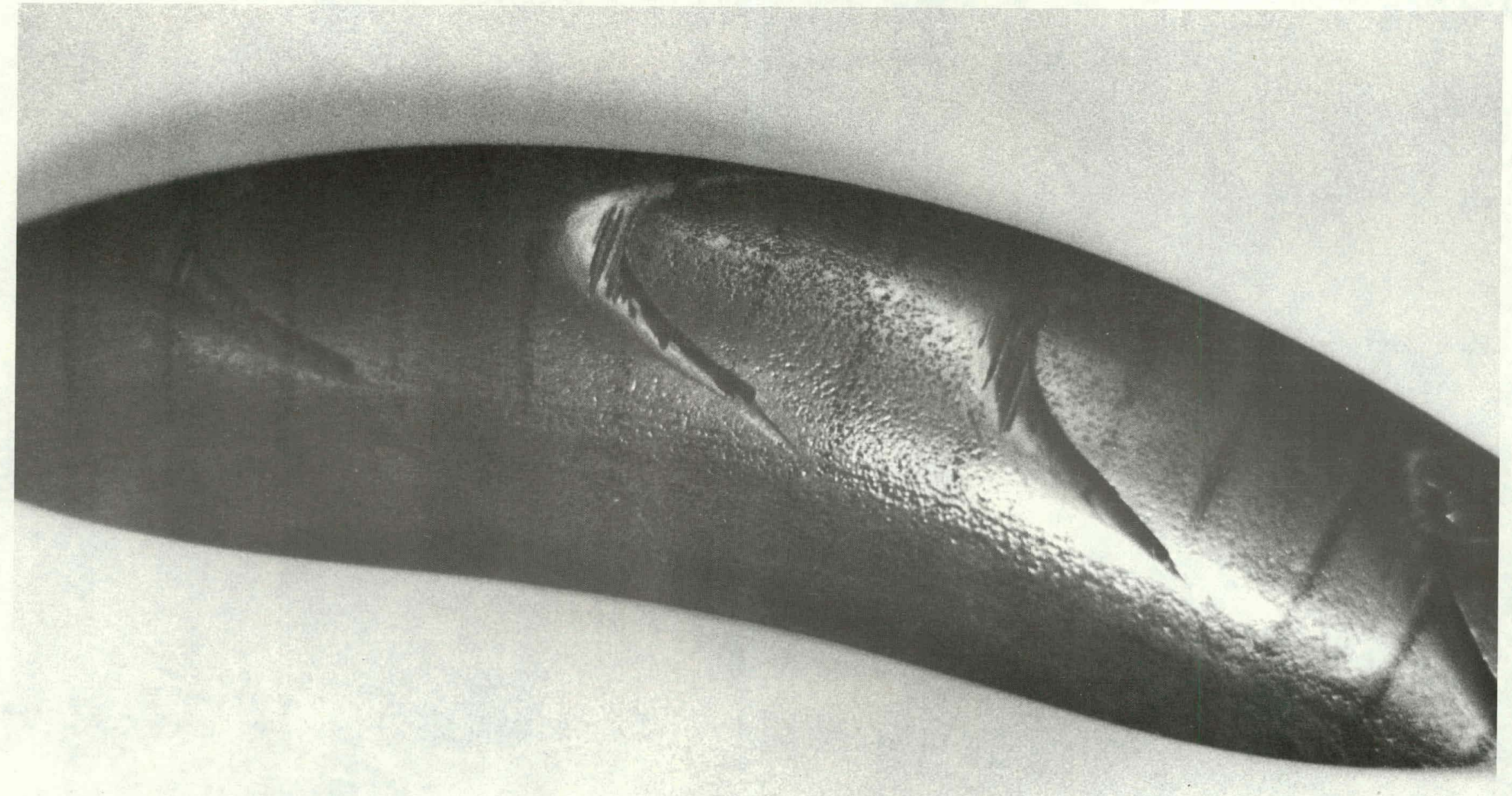

Figure 5-19. Nozzle Arrangement. Four Slot Injection Arrangement. 


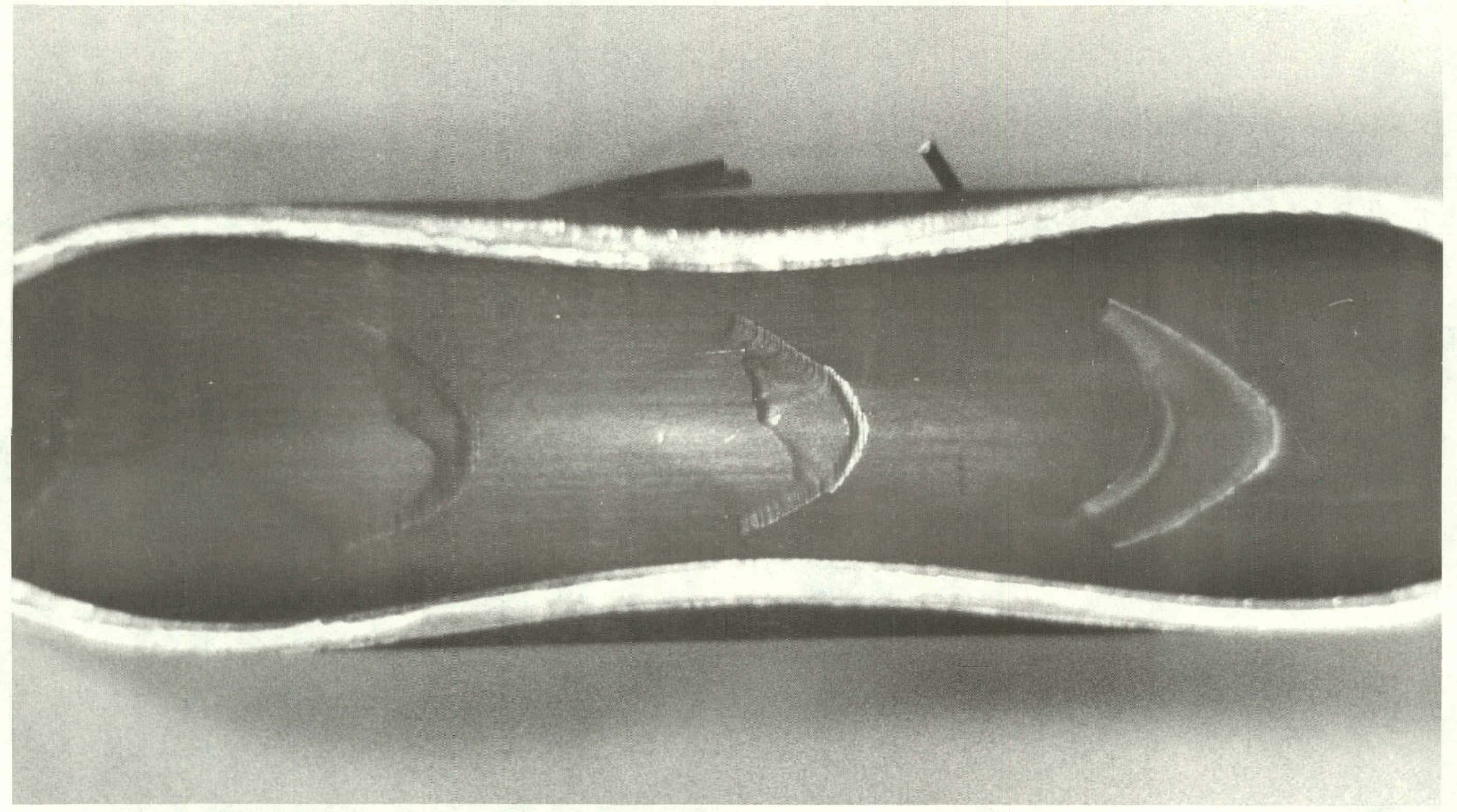

Figure 5-2C. Erosion Pattern. Four S-ot Arrangement - Inside View. 


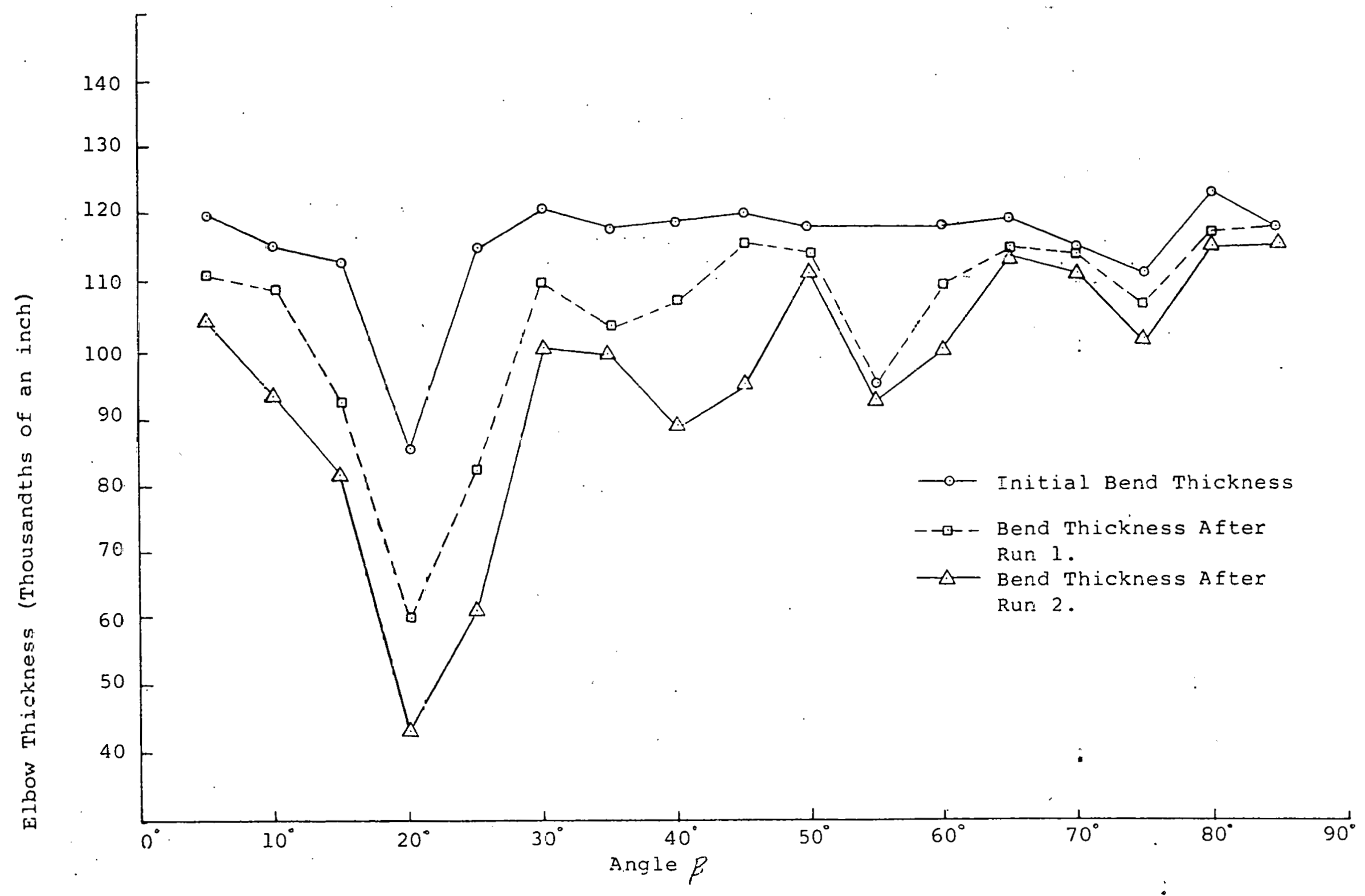

Figure 5.21: Comparison of Depth of Wear for Run 1 and Run 2 for Elbow 9-T 


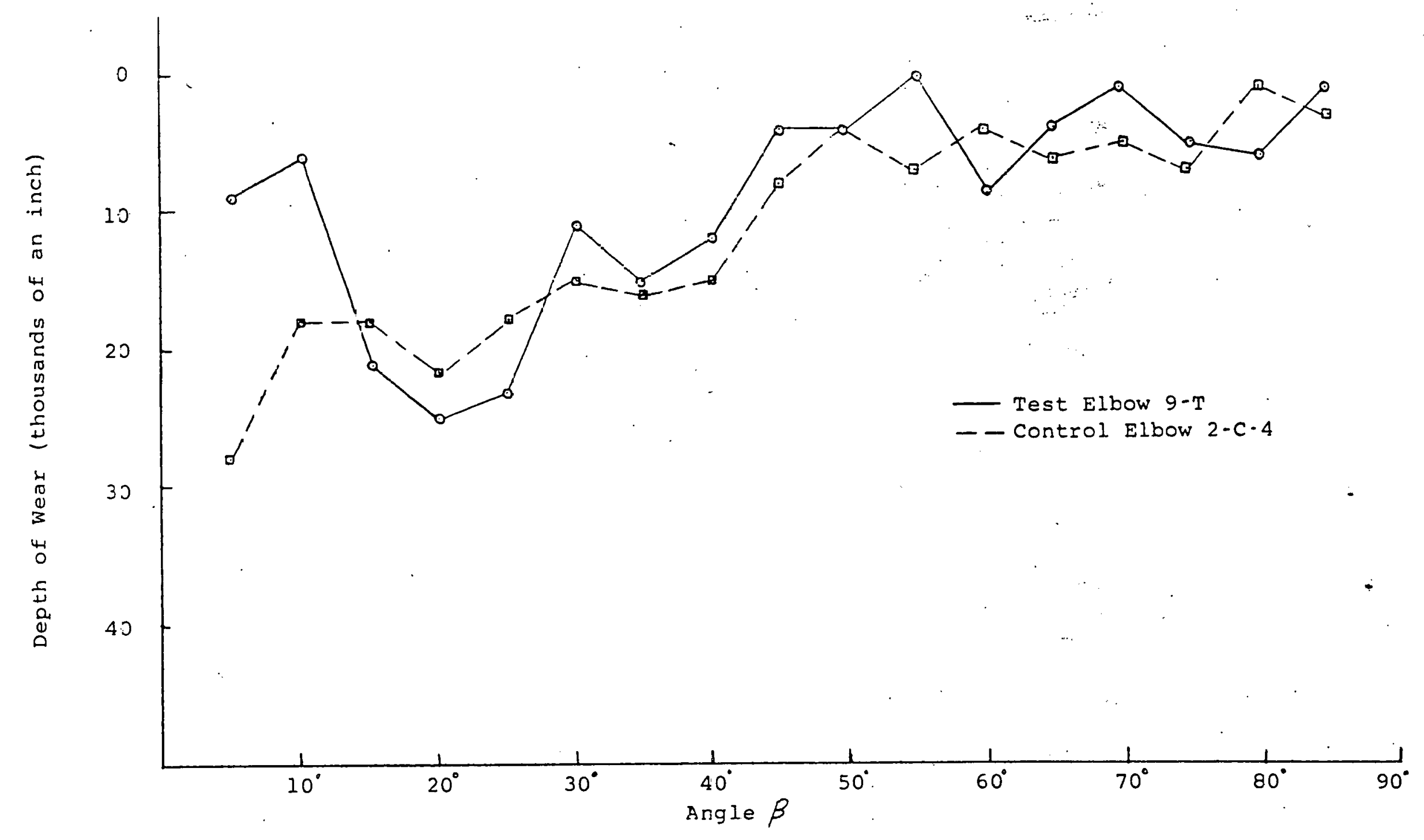

Figure 5.22: Comparison of Depth of wear fcr eltows $9-T$ and control elbow $2-\Xi-4$ 
$\div$

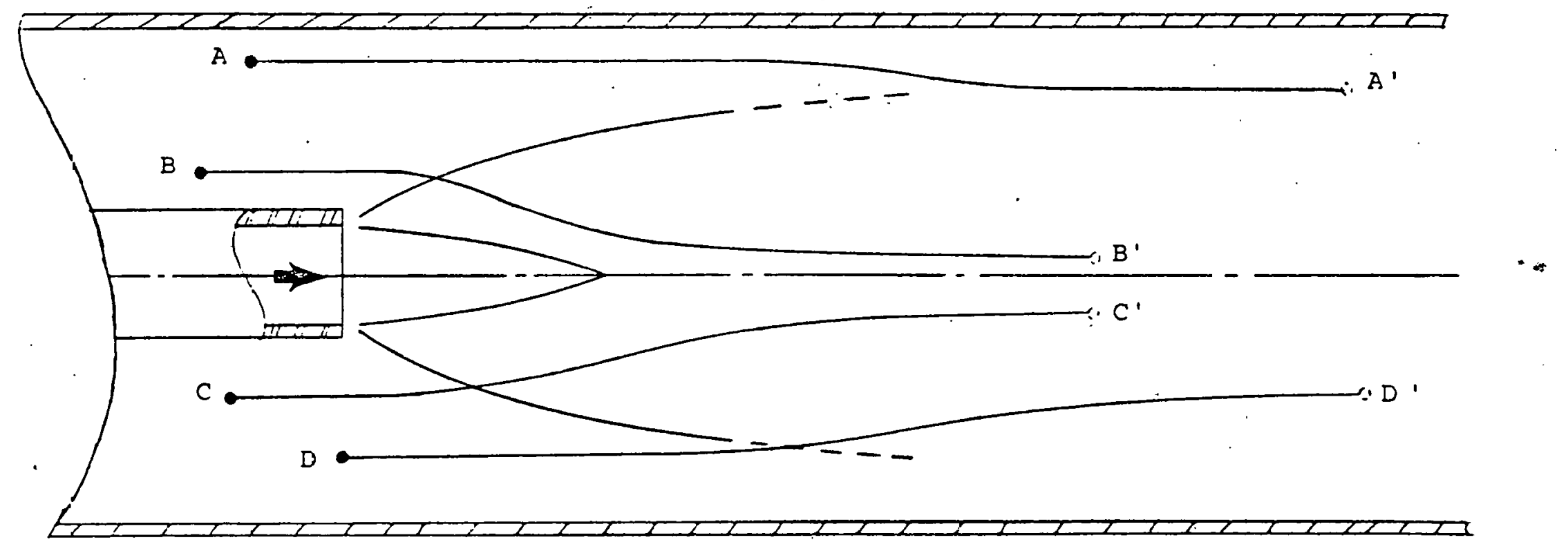

Figure 5,23 Diagram showing the concentration of particles from the secondary stream into the primary jet flow. 


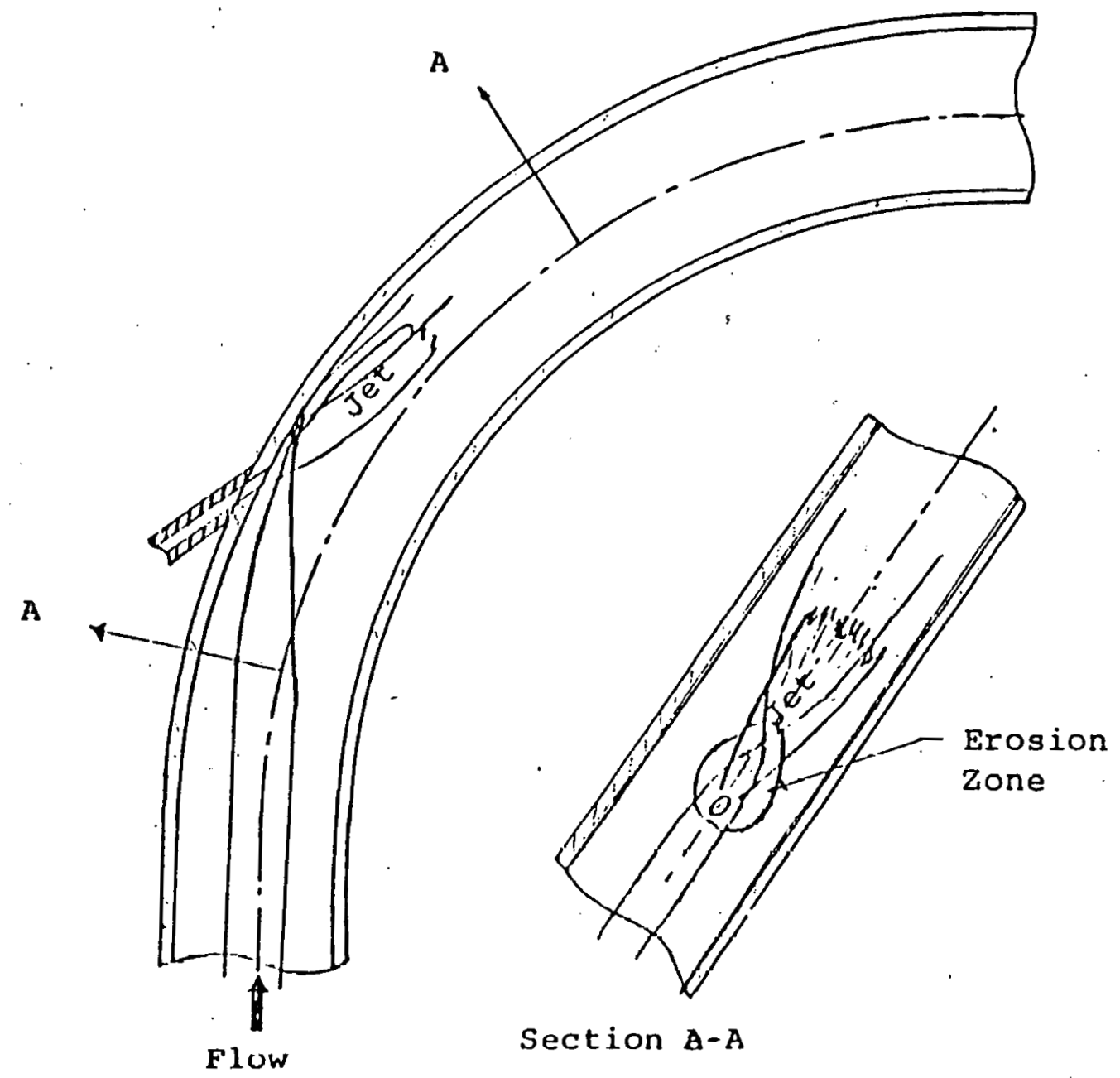

Figure 5.24: Bend flow due to a jet injection port . along the back arch of the bend. 


\section{CONCLUSIONS AND RECOMMENDATIONS}

\section{$\underline{6.1}$ Conclusions}

The exploratory effort of this project, Part I, has been completed. The flow field modifications in a bend, created by air jets, have been shown to have a significant effect on erosion in the bends. These effects include 1) reduced erosion rates, 2) a modified erosion pattern without significantly changing the erosion rate, and 3) a significantly accelerated erosion rate. A primitive understanding of the effect of flow-field modification on erosion rates in bends has now been established.

The concept of reducing erosion in bends by modifying the flow field appears feasible for high phase density flow and low air velocity jets. The critical condition for reducing erosion appears to be the formation of a rope in the flow. Erosion in bends is accelerated by jets during dilute phase flow. Thus, other approaches to the reduction of erosion must be developed for dilute phase.

A pneumatic transport test loop has been developed as part of this project. This test loop is ideally suited for a more detailed investigation of gas-solid flows in bends and the associated erosion problems. The performance of this test loop is comparable to those described in the literature and may operate over a wide range of conditions.

\subsection{Recommendations}

It is recommended that Part II of this project be initiated. With the primitive understanding of the erosion process in a bend and with a modified flow field, future test bend designs should show the full potential of this concept for reducing erosion. A pneumatic transport test loop has been developed which is capable of supporting the tests of the new test bend designs. In addition, further testing and analysis will contribute to the models suggested for this study and will consistute a contribution to the general body of knowledge of the flow of gas-solid mixtures.

A preliminary proposal [6-1] has been written for Part II of this project. 
LIST OF SYMBOLS

$\left\langle d_{p}\right\rangle=$ diameter of particle

$\mathrm{D}=$ inside diameter of pipe (duct)

$\dot{\mathrm{m}}_{\mathbf{a}}=$ mass flow rate of air (gas)

$\dot{\mathrm{m}}_{\mathrm{p}}=$ mass flow rate of solids (particles)

$m_{\mathrm{R}}=$ mass eroded

$\stackrel{\Lambda}{\mathrm{m}}_{\mathrm{R}}=$ mass eroded per mass of particles

$R_{E}=$ radius of the elbow .

$\mathrm{V}=$ velocity of the air (gas)

$v_{p}=$ velocity of the particle(s)

$v_{R}=$ volume of surface eroded

$\hat{v}_{\mathrm{R}}=$ volume eroded per mass of particles

$v_{R}=$ volume eroded per volume of particles

$v_{\mathrm{R}} \quad=$ volume eroded per unit surface area

$\Delta \mathrm{Z}=$ penetration depth into eroded surface

$\Delta \dot{Z}=$ time rate of change of penetration depth

$\Delta \hat{\Delta}$ = penctration depth per mass of particless

$\tilde{\Delta}=$ penetration depth per unit mass eroded

$a=$ angle of attack (figure 2.1.1)

$\beta=$ turning angle (figure 2.5.1)

$\Phi=$ phase density $\left(m_{p} / m_{a}\right)$.

$\dot{V}=$ volumetric flow of air

$R_{u}=$ universal gas constant

$M=$ molecular weight

$P_{L}=$ pressuere at flowmeter

$T_{L}=$ temperature at flowmeter

$\Phi \quad=$ phase density

$E_{\Phi}=$ absolute error of phase density 
$\mathrm{E}_{\mathrm{m}_{\mathrm{r}}}=$ absolute error of mass loss

$E_{\Delta z_{R}}=$ absolute error of penetration depth

$\% \mathrm{E}_{\Phi}=$ percent absolute error of phase density

$\% E_{\mathrm{In}_{\mathrm{r}}}=$ percent absolute error of mass loss

$\mathrm{E} \Delta \mathrm{Z}_{\mathrm{R}}=$ percent absolute error of penetration depth 


\section{REFERENCES}

2-1 Lehrke, W.D., and Nonnen, F.A., "Internal Protection of Pipes Against Abrasion and Corrosion by Abresist Fused-Cast-Basalt", Sept. (1975).

2-2 Wah1, H. and Hartstein, F., Strahlverschleiss, Franckh'sche Verlagshandlung Stuttgart, (1946).

2-3 Siebel, E. and Brockstedt, H.C., "Verschleissminderung", Maschinenbau, Vol. 20 , p. $457,(1941)$.

2-4 Wellinger, K. and Brockstedt, H.C., "Versuche zur Ermittlung des Verschleisswiderstandes von Werkstoffen fur Blasversatzsohr sowie des Einflusses der Rohrverlegung bei Blasversatzanlagen," Gluckaut, Vol. 78, p. 130, (1942).

2-5 Wellinger', K. and Brockstedt, H.C., "ERmittlung des. Verschleiss widerstandes von Werkstoffen fur Blasversatzrohre", Stahl und Eisen, Vol. 62, p. 635, (1942).

2-6 Wellinger, K., "Sandstrahlverschleiss an Metallen", Z. Metallkunde, Vol. 40, p. 361, (1949).

2-7 Wellinger, K., and Vetz, H., "Verschleissuntersuchungen an Gummi", Z. Ver. deut. Ingr, Vol. 96, p. 43, (1954).

2-8 Wellinger, K. and Vetz, H., "Gleitverschleiss, Spulverschleiss, Strahlverschleiss unter der Wirking von kornigen Stotfen", VDI Forschungsheft, p. 449̈, 1955, and Wear Vol. 1, p. 2'25, (1957, 1958).

2-9 Holtey, H., "Uber den Abnutzungsvargang in Blasversatzrohren und die Frage der Bekampfung des Verschleisses", Geologie und Mignbouw, Vol. 1, p. 208, (1838).

2-10 Kashcheev, V.N., "Destruction of a Metal Surface as a Function of the Angle of Impact of Abrasive Particles" (in Russian). Zhur, Tekh. Fiz, Vol. 25, p. 2365, (1955).

2-11 Finnie, I., "An Experimental Study of Erosion", Proceedings of the Soc. Exp. Stress Analysis, Vol. 17, no. 2, (1960).

2-12 Finnie, I., "The Mechanism of Erosion of Ductile Metals", Proc. 3rd, U.S. Natn's congr. Apple. Mech.

2-13 Finnie, I., "Erosion of Surfaces by Solid Particles", Wear Vol. 3, pp. $87-103$.

2-14 Bitter, J.G.A., "A Study of the Erosion Phenomena-Part I", Wear Vol. 6, pp. 5-21, (1963).

2-15 Bitter, J.G.A., "A Study of the Erosion Phenomena-Part II", Wear Vol. 6, pp. 169-190, (1963). 
2-16 Neilson, J.H., and Gilehrist, A., "Erosion by a Stream of Solid Particles", Wear Vol. II, pp. 111-122, (1968).

2-17 Brauer, H. and E. Kriegel, "Untersuchungen uber der Verschleiss von Kunststoffen und Metallen", Chem. Ing. Tech., Vol. 35, pp. 697-706, (1963).

2-18 Tilly, G.P., "Erosion Caused by Airborne Particles", Wear Vol. 14, pp. 63-79, (1969).

2-19 Tilly, G.P., "A Two-Stage Mechanism of Ductile Erosion", Wear Vol. 23, pp. 87-96, (1973).

2-20 Tilly, G.P., and Sage, W., "The Interaction of Particle and Material Behavior in Erọsion Processes", Wear Vol. 16, pp. 447-465, (1970).

2-21 Sheldon, G.L., and Finnie, I, , "One the Ductile Behavior of Normally Brittle Malerials During Erosive Cutling", ASME Jour. of Engr. for Industry, Vol. 88, pp. 387-392, (1966).

2-22 Arundel, P.A., I.A. Taylor, W.Dean, J.S. Mason, and T.E. Doran, "The Erosion of Various Pipe Wall Materials by a Stream of Abrasive Alumina Particles", proceedings Pneumotransport 2, Sept. (1973).

2-23 Bartenev, G.M. and Penkin, N.S., "Relaxiation and Wear of Rubber in Abrasive Particle Stream", Soviet Journal of Friction and Wear Vol. 1, No. 4, pp. 10-18. (1980).

2-24 Rao, P.V., and D.H. Buckley, "Solid Impingement Erosion Mechanism and characterization of Erosion Resistance of Ductile Materials", Liquid-Solid Flows and Erosion Wear of Industrial Equipment. ASME FED. Vol. 13, (1984).

2-25 Mason, J. S. and Mills, D., "The Influence of Bend Geometry on Pressure Drop in Pneumatic Conveying System Pipelines," Proceedings of the 10th Ann. Powder \& Bulk Solids Conf., Chicago, IL, May 1985.

2-26 Mnlerus, 0., "Prediction of Pressure Drop With Steady State Pneumatic Conveying of Solids in Horizontal Pipes," Chem. Engr. Sci., Vol. 12, No. 12,1981 .

2-27 Ito, H. "Pressure Losses in Smooth Pipe Bends", ASME Jour. of Basic Engr., Vol. 82, pp. 131-143, (1960).

2-28 Schuchart,, P.. Pressure Losses in Gas-Solid Flow in Bends and Curves," Chem-Ing-Tech. $40(21 / 22): 1060$, (1968).

2-29 Morikawa, Y., Y. Tsuji, K. Matsui, and Y. Jittani, Pressure Drops Due to Pipe Bends in Air-Solids Two Phase Flows: Circular and Elliptic Bends, Int. Jour. of Multiphase Flow, Vol. 4, pp. 575-583, (1978).

2-30 Schmidt, F., "Betriebserfahrung mit einem verschleißsichern Rohrkrumer," Gluckauf, Nr. 25, 1937. 
2-31 Crowe, C.T., "Cas-Particle Flow," in Pulverized-Coal Combustion and Gasification, Eds. L.D.S. Smoot and D.T. Pratt, Plenum Press N.Y., N.Y., (1979).

2-32 Adam, O., "Feststof fbeladena Luftstromung hoher Geschwindigkeit," Chem. Engr. Tech., Vol. 29, pp. 151-159, (1957).

2-33 Goto, K. and Iinoya, K., "Flow Characteristics of Solid-Gas Mixture in a Horizontal Pipeline", Kagaku Kogaku (Chem. Engr. Japan), Vol. 28, p. 73, (1964).

2-34 Brauer, H. and E. Kriegel, Verschleiss an Rohrleitungen bei Hydraulischur Forderung von Feststoffen, Stahl Eisen, Vol. 84, p. 1313, (1964).

2-35 H. Brauer und E. Kriegel, "Verschleiss" von Rohrkrumern beim Pneumatischen und Hydraulischen Feststofftransport," Chem. Ing. Tech. Vol. 37, P. 265-276, (1965).

2-36 Brauer, H. und E. Kriegel, "Die Problems des Verschleisses von Rohrlwitungen beim Pneumatischen und Hydraulischen Feststofftransport," Maschinenmarkt, Vol. 71, p. 20, (1965).

2-37 Bikbaev, F.A. et.al., "Wear on Branches in Pneumatic Conveying Ducting", Chem. Pet. Eng., Vol. 8, p. 465-466, (1972).

2-38 Bakbaev, F.A. et.al., "Main Factors Affecting Gas Abrasive Wear of Elbows in Pneumatic Conveying Pipes", Chem. Pet. Eng., Vol. 9, p. $73-75,(1973)$.

2-39 Krasnov, V.I. and I.B. Zhilinskii, "Investigations of Material Reliabilities Under Gaseous Abrasive Wearing Conditions", Chem. Pet. Engr., Vol. 9, p. 1029-1032, (1973).

2-40 Mason, J.S. and B. V. Smith, "The Erosion of Bends by Pneumatically Conveyed Suspensions of Abrasive Particles," Powder Technology, Vol. 6, pp. 323-335, (1972).

2-41 Mills, D. and J.S. Mason, "Particle Concentration Effects in Bend Erosion," Powder Technology, Vol. 17, pp. 37-53, (1977).

2-42 Mills, D. and Mason, J.S., "Particle Size Effects in Bend Erosion" Wear Vol. 44, pp. 311-328, (1977).

2-43 Mills, D, Mason, J.S., and Tong, K.N., "The Role of Penetrative Wear in the Erosion of Pipe Bends", Proc. 6TH Int. Conf. on Erosion by Liquid and Solid Impact, Sept. (1983).

2-44 Agarwal, V.K., Mills, D., and Mason, J.S., "A Comparison of the Erosive Wear of Steel and Rubber Bends in Pneumatic Conveying System Pipelines", Proc. 6th Int. Conf. on Erosion by Liquid and Solid Impact, Sept. (1983). 
2-45 Mason, J. S., Mills, D., and Agarwal, V. K.

4-1 Mills, D. and Mason, S., "Erosive Wear Problems in Industry with Particular Reference to Power Plant, Power Stations, and Bulk Solids Handling Systems," Unpublished notes presented at the 10th Anniversary Powder and Bulk Solids Conference and Exhibit, Chicago, IL, 1985.

6-1 Johnson, E. K. and Means, K. H., "Preliminary Proposal for Part II Reduction of Erosion in Elbows Due to Flow Field Modifications," Submitted to DOE/METC, May 1986. 
